\title{
WestVirginiaUniversity
}

THE RESEARCH REPOSITORY @ WVU

Graduate Theses, Dissertations, and Problem Reports

1999

\section{Investigation of hot gas desulfurization utilizing a transport reactor}

David A. Berry

West Virginia University

Follow this and additional works at: https://researchrepository.wvu.edu/etd

\section{Recommended Citation}

Berry, David A., "Investigation of hot gas desulfurization utilizing a transport reactor" (1999). Graduate Theses, Dissertations, and Problem Reports. 944.

https://researchrepository.wvu.edu/etd/944

This Thesis is protected by copyright and/or related rights. It has been brought to you by the The Research Repository @ WVU with permission from the rights-holder(s). You are free to use this Thesis in any way that is permitted by the copyright and related rights legislation that applies to your use. For other uses you must obtain permission from the rights-holder(s) directly, unless additional rights are indicated by a Creative Commons license in the record and/ or on the work itself. This Thesis has been accepted for inclusion in WVU Graduate Theses, Dissertations, and Problem Reports collection by an authorized administrator of The Research Repository @ WVU. For more information, please contact researchrepository@mail.wvu.edu. 


\title{
INVESTIGATION OF HOT GAS DESULFURIZATION UTILIZING A TRANSPORT REACTOR
}

\author{
By \\ David A. Berry \\ Thesis submitted to the College of Engineering \\ at West Virginia University \\ in partial fulfillment of the requirements \\ for the degree of \\ Master of Science \\ in \\ Chemical Engineering \\ John W. Zondlo, Ph.D., Chair \\ Eric K. Johnson, Ph.D. \\ Alfred H. Stiller, Ph.D. \\ Department of Chemical Engineering \\ Morgantown, West Virginia \\ 1999
}




\section{ABSTRACT \\ Investigation of Hot Gas Desulfurization Utilizing a Transport Reactor \\ by}

\section{David A. Berry}

This thesis investigated the use of transport reactor technology to conduct hot gas desulfurization (HGD). The need or market drivers for this technology were assessed to identify the demand and opportunity. A literature review was conducted to assess the status of HGD and the issues involved with its development.

Design requirements were identified for integrated gasification combined cycle (IGCC) power plants that would utilize transport HGD reactors to baseline the design for the technology. A target of 1/10 of the New Source Performance (NSPS) for the emission of sulfur dioxide was chosen as the sulfur removal requirement for the system. Process design activities were then undertaken to design the experimental unit. Maintaining the reactor gas flowrate above the choking velocity and removal of excessive heat caused by the chemical reaction were the two principle operating parameters of concern.

Finally, the experimental reactor was built and underwent successful shakedown testing. In addition, a preliminary desulfurization test was successfully conducted with the unit. It was shown that a hydrogen sulfide-containing fuel gas could be cleaned from an initial hydrogen sulfide concentration of 1000 ppmv to under 250 ppmv (below NSPS levels). The test was conducted with real coal-gas making it the first and only known test of its kind in the world. 


\section{ACKNOWLEDGMENT}

This author would like to express his sincere gratitude to his advisor, Dr. John W. Zondlo, for his ideas, advice, and continued guidance throughout this investigation. Also acknowledged are the contributions made by the members of his academic examining committee: Dr. Alfred H. Stiller and Dr. Eric K. Johnson.

Appreciation is expressed to Mr. Larry W. Kisner and Ms. Susan R. Shoemaker for their invaluable help and assistance during the construction of the experimental riser reactor designed and built as part of this thesis research.

This thesis is dedicated to the author's daughter, Samantha Marie Berry. Grateful appreciation and gratitude is also expressed to the author's family and friends for their encouragement and support. 


\section{TABLE OF CONTENTS}

$1.0 \quad$ Introduction................................................................................ 1

2.0 Background and Literature Review

2.1 Market Opportunity - Technology Drivers.............................. 2

2.1.1 Power Generation Demand......................................... 2

2.1.2 Environmental Standards........................................... 3

2.1.2.1 New Source Performance Standards.................. 4

2.1.2.2 Title IV Acid Deposition Control........................ 4

2.1.2.3 State Implementation Plans (SIPs)................... 9

2.2 Integrated Gasification Combined Cycle (IGCC) Concept.......... 10

2.3 Hot Gas Desulfurization (HGD) History................................. 12

$2.4 \quad$ HGD Sorbents............................................................... 15

2.5 HGD Processes............................................................... 18

2.5.1 Fixed-Bed Reactors ............................................... 21

2.5.2 Fluid-Bed Reactors...................................................... 25

2.5.3 Transport Reactors.................................................. 29

3.0 Experimental Approach - Design and Construction

3.1 Design Requirements..................................................... 35

3.1.1 IGCC System Requirements................................... 35

3.1.2 HGD Subsystem Requirements.................................. 48

3.2 Transport Reactor Process Design....................................... 51

3.2.1 Design Basis............................................................... 51

3.2.2 Reactor Hydrodynamics............................................. 53

3.2.3 Reaction Thermodynamics........................................ 64

3.2.4 Reaction Kinetics................................................ 69

4.0 Results

4.1 Design Results....................................................................... 72 
4.2 Test Results............................................................... 74

5.0 Conclusions......................................................................... 78

$6.0 \quad$ Recommendations................................................................ 79

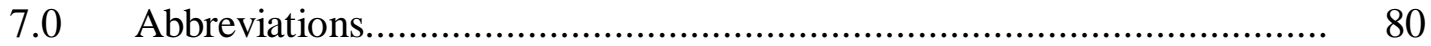

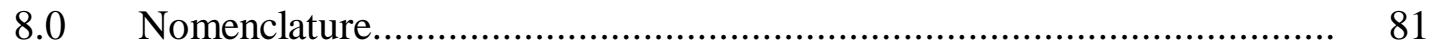

9.0 Literature Sited..................................................................... 82

10.0 Appendix

10.1 Excel Spreadsheet for Hydrodynamic Calculations................... 86

10.2 Computer Programs for Thermodynamic Calculations................ 93 


\section{LIST OF FIGURES}

FIGURE $\quad \underline{\text { TITLE }}$

Figure 2.1 Integrated Gasification Combined Cycle................................. 11

Figure 2.2 Contacting Modes for Gas / Solid Systems.............................. 20

Figure 2.3 Fixed-bed HGD Subsystem................................................... 23

Figure 2.4 Moving-bed HGD Subsystem................................................ 24

Figure 2.5 Two-Vessel Fluid-bed HGD Concept..................................... 27

Figure 2.6 Single-Vessel Fluid-bed HGD with Riser.............................. 30

Figure 2.7 Circulating Transport Reactor HGD Subsystem....................... 31

Figure $3.1 \quad$ NSPS Sulfur Removal Requirements................................... 37

Figure 3.2 Gasifier and HGD Block Flow Diagram................................ 39

Figure 3.3 HGD Subsystem Block Flow Diagram................................... 46

Figure $3.4 \quad$ Conceptual HGD Riser Reactor.......................................... 50

Figure 3.5 Pressure Drop Across a Dilute Pneumatic Conveying Line.......... 55

Figure 3.6 Riser Pressure Drop versus Superficial Gas Velocity.................. 65

Figure 3.7 Particle Diameter versus Superficial Choking Velocity............... 66

Figure 3.8 Relationship Between Sulfide Conversion and Reactor.............. 68 Temperature

Figure 4.1 PFD of the Experimental Riser Reactor................................. 73

Figure 4.2 Transport HGD Performance Curve on Real Coal-gas............... 77

\section{LIST OF TABLES}

$\underline{\text { TABLE }} \quad \underline{\text { TITLE }}$

Table 3.1 Stream Summary Table for Gasifier and HGD Block Diagram..... 40 


\subsection{Introduction}

The U.S. Department of Energy (DOE) is developing advanced coal-conversion power generation systems to meet expected rising electrical power generation needs and replace/repower older existing power plants nearing retirement. One of the most promising of these advanced conversion systems is Integrated Gasification Combined Cycle (IGCC). In this concept, coal is gasified and the resultant fuel gas is later combusted downstream in an advanced gas turbine. Energy from the gas turbine exhaust is typically recouped by a heat recovery steam generator and hence, the term combined cycle. But before the sulfur-laden coal gas is combusted, it must be cleaned of sulfur and particulates. The hot gas desulfurization (HGD) subsystem is a key developmental item in reducing the cost and increasing the efficiency of the IGCC concept. Early efforts to utilize fixed-bed reactors of metal oxide sorbents for the HGD subsystem identified significant shortcomings due to inherent temperature control limitations. However, the favorable temperature control characteristics of transport reactors has led to their proposed use for HGD. In addition, higher throughput and continuous operation of transport reactors provide opportunity for cost savings when compared to fixed-bed and fluid-bed systems. The primary objectives of this thesis were to investigate the use of transport reactors for hot gas desulfurization by: 1.) Examining the need and requirements for IGCC HGD systems; 2.) Conducting the design and construction of an experimental unit; and 3.) Conducting a preliminary test to evaluate the feasibility of the technology. A secondary objective is to construct a flexible experimental system to allow the conduct of future research and development. 


\subsection{Background and Literature Review}

\subsection{Market Opportunity - Technology Drivers}

Hot gas desulfurization is a key and integral part of the IGCC concept. IGCC technology is expected to play a significant role in demand for repowered or increased electrical generation capacity in the near future. Increasing environmental regulations are also dictating that high efficiency, low $\mathrm{SO}_{2}$ emission power generation technologies like IGCC (with HGD) be employed.

\subsubsection{Power Generation Demand}

Historically, the demand for electricity has been tied closely to economic growth. In the United States, moderate economic growth will result in an estimated need for 150,000 to 200,000 megawatts of new electrical capacity by the year 2010 [1]. Total sales of electricity are expected to rise from 2.7 trillion kilowatt-hours in 1990 to 3.5 trillion in 2010 , and to 4.5 trillion in 2030. In addition to this new capacity, a significant portion of our current capacity will need to be replaced or repowered as existing plants are retired. Worldwide, as developing countries aim at higher gross domestic product, the demand for electric power is expected to double by 2010. A significant percentage of this demand (currently $56 \%$ the U.S. and $40 \%$ worldwide) is expected to be met by coal [1].

The majority of current electrical power generation from coal is provided by conventional pulverized coal (PC) boiler systems. In PC plants, steam is generated by combusting pulverized coal in a boiler in which high pressure boiler tubes are located. The production 
of this steam and subsequent expansion through a steam turbine, which turns an electrical generator, is approximately $32 \%-35 \%$ efficient [2]. With the advent of tougher clean air requirements (1990 Clean Air Act Amendments), these plants are incorporating flue gas scrubbers to minimize emission of sulfur oxides that lead to acid rain [3]. In addition to more stringent emission requirements, increasing fossil fuel costs are dictating the development of advanced coal conversion systems. Many of these higher-efficiency systems will incorporate advanced coal combustion technology or gasification.

\subsubsection{Environmental Standards}

Federal environmental standards are another significant driver of advanced coal conversion systems. Determination of allowable emission rates/limits for various pollutents identified in these standards are not however, straightforward. Since this thesis deals primarily with HGD for IGCC power plants, requirements that pertain directly to $\mathrm{SO}_{2}$ emissions will be considered.

The Clean Air Act (CAA) is the primary standard in defining the emission of pollutents. In order to operate a power plant, various permits regarding emission limits are required. Title $\mathrm{V}$ of the CAA provides a permitting program to cover all CAA requirements. For this example, there are three primary requirements that factor into Title V. They are:

1. New Source Performance Standards (NSPS)

2. Title IV Acid Deposition Control 
3. State Implementation Plans (SIP)

\subsubsection{New Source Performance Standards}

In 1970, the Clean Air Act formalized the governmental regulation of acid-rain forming precursor gases which include sulfur dioxide $\left(\mathrm{SO}_{2}\right)$ and nitrogen oxides (NOx). It also introduced the concept of New Source Performance Standards to regulate the utility industry. The NSPS were ammended in 1978 to place more stringent emission standards for utility boilers constructed after 1978. No longer were emissions based in terms of absolute tonnages of emitted pollutents, but rather by the amount of heat released by the fuel consumed in the plant - the greater the heat generated in the boiler, the greater the allowable emission. The current NSPS limit for $\mathrm{SO}_{2}$ emission is $1.2 \mathrm{lbs} \mathrm{SO}_{2}$ output per million Btu of fuel input. And, depending on plant size, a second criteria of a $90 \%$ reduction in potential emissions must also be met. Each plant or source must comply with the lesser of these two criteria. This requirement, in essence, defined a concentration for $\mathrm{SO}_{2}$ emissions.

\subsubsection{Title IV Acid Deposition Control}

The Clean Air Act Amendments (CAAA) of 1990 are the latest revisions to the Clean Air Act. Among the numerous provisions of the CAAA of 1990 is Title IV, which requires the Environmental Protection Agency (EPA) to establish the Acid Rain Program to reduce the adverse effects of acidic deposition (acid rain). The CAAA was passed on November 15, 1990 and resulted in over 700 pages of legislation including mandates for 175 regulations. 
The revised CAA focuses on several air pollution issues and is divided into specific titles to address various pollution and implementation problems. These include:

Title I "Provisions for Attainment and Maintenance of National Ambient Air Quality Standards"

Title II "Provisions Relating to Mobile Sources"

Title III "Hazardous Air Pollutants"

Title IV "Acid Deposition Control"

Title V "Permits"

Title VI "Stratospheric Ozone Protection"

Title VII "Provisions Relating to Enforcement"

Title VIII "Miscellaneous Provisions"

Title IX "Disadvantaged Business Concerns"

Title X "Clean Air Employment Transition Assistance"

Title IV was structured to place a cap on annual $\mathrm{SO}_{2}$ emissions and allow for a unique emissions trading system based on $\mathrm{SO}_{2}$ allowances. The goal of the acid rain control program is to reduce $\mathrm{SO}_{2}$ emissions by 10 million tons $(\mathrm{Mt})$ per year nationwide, about a $50 \%$ reduction from 1980 levels. This reduction is to take place over two phases with a 3 Mt per year reduction targeted by January 1, 1995 (Phase I) and another 7 Mt per year by January 1, 2000 (Phase II). To accomplish the $\mathrm{SO}_{2}$ reductions, Phase I specifically targets 110 highly polluting power plants and imposes an average emission level of $2.5 \mathrm{lb}$ of $\mathrm{SO}_{2}$ per million Btu of energy input. Phase II applies to all coal and oil powered plants over 25 megawatts (MW) 
and imposes an average emission level of $1.2 \mathrm{lb}$ of $\mathrm{SO}_{2}$ per million Btu of energy input after January 1, 2000. In addition, there will be an overall cap of 8.9 million tons of $\mathrm{SO}_{2}$ per year on total nationwide emissions after January 1, 2000 [4].

By virtue of the CAAA, the EPA is enforcing this overall cap through a unique market-based emission reduction program of $\mathrm{SO}_{2}$ allowances for all major emission sources. An allowance is the authorization to emit one ton of $\mathrm{SO}_{2}$ and the total number of allowances will be limited to 8.9 million each year after 2000 . The idea of the allowances is not only to cap the total $\mathrm{SO}_{2}$ emissions, but also permit the owners of units required to make reductions to utilize excess $\mathrm{SO}_{2}$ allowances as one method of achieving the required reductions in the most cost effective manner. Thus, the traditional "command-and-control" method of regulation is replaced by market-based incentives to achieve the same goal [5]. Regardless of the number of allowances a source holds, however, it may not emit at levels that would violate Federal or State limits set under Title I or other provisions of the act and its previous amendments to protect public health.

The $\mathrm{SO}_{2}$ allowances are allocated annually to the participating utilities. These allowances can be used in the year they are issued, held (or banked) for use in later years, or sold if the plant emits less than its allotment. Each plant is given an allowance based on its historical (19851987) energy production levels and will be required to match each ton of $\mathrm{SO}_{2}$ emitted during the year with one allowance. None of the plants are issued enough allowances to cover current emissions, so they will have to reduce their emissions, obtain more permits, or shut 
down. Electrical generating units that began operation after November 15, 1990, did not receive any allowances. Instead, they will have to purchase allowances that were initially allocated to other units, which will limit per plant emissions even more as new fossil-fueled plants are built [6]. Any source whose emissions exceed allowances held will be required to pay $\$ 2,000$ per excess ton of $\mathrm{SO}_{2}$, and will be required to offset excess emissions with allowances the following year.

In addition to the initial allocation, allowances are available in three different reserves. The EPA has created a reserve of 3.5 million allowances as an incentive given to units which install a qualifying Phase I technology (a technology that can be demonstrated to remove at least 90 percent of the unit's $\mathrm{SO}_{2}$ emissions). A second reserve provides allowances as incentives for units achieving reductions through customer-oriented conservation measures or renewable energy generation. The third reserve is set aside for auctions and direct sales. The auctions are designed to send the market an allowance price signal. The direct sales allow generators to purchase allowances at a fixed price of $\$ 1500$ each [7].

Utilities today are actually overcomplying with the requirements of the CAAA of 1990. For example, the owner of a fossil-fueled power generating unit is issued a specific number of allowances annually. The number of allowances granted to each facility is a product of an emission rate $\left(2.5 \mathrm{lbs}\right.$. of $\mathrm{SO}_{2} / \mathrm{mmBtu}$ of fuel input in Phase I and $1.2 \mathrm{lbs}$. of $\mathrm{SO}_{2} / \mathrm{mmBtu}$ of fuel input in Phase II) and the average fuel consumed during 1985 through 1987. An example of the allowances required for a typical $250 \mathrm{MW}(\mathrm{e})$ unit is shown below: 
Assuming a heat rate of $9,800 \mathrm{Btu} / \mathrm{Kwh}$ and a capacity factor of 65 percent:

Average heat input $=9,800 \mathrm{Btu} / \mathrm{Kwh} \times 1,000 \mathrm{Kw} / \mathrm{MW}$ x $250 \mathrm{MW}$ x mmBtu/10 ${ }^{6} \mathrm{Btu}$ $=2,450 \mathrm{mmBtu} / \mathrm{hr}$.

Phase II allowances $=2,450 \mathrm{mmBtu} / \mathrm{hr} \times 1.2 \mathrm{lbs} \mathrm{SO}_{2} / \mathrm{mmBtu} \times 8,760 \mathrm{hrs} / \mathrm{yr} \times$ ton/2,000 lbs. x $0.65=8,370$ allowances or tons of $\mathrm{SO}_{2} / \mathrm{yr}$.

Based on the calculations shown above, a $250 \mathrm{MW}(\mathrm{e})$ unit burning 2.0 percent sulfur coal would only need 66 percent $\mathrm{SO}_{2}$ removal to comply with Phase II requirements. Today's scrubber units remove 90 percent or more of $\mathrm{SO}_{2}$ from the flue gas. Therefore, the result of forced scrubbing puts more allowances on the market than are necessary, resulting in an oversupply and downward pressure on the price.

A variety of compliance options are available for the owners of these plants including: 1) hold or purchase allowances (as long as New Source Performance Standards (NSPS) and Prevention of Significant Deterioration (PSD) requirements are met) [8]; 2) use a substitution plan (power purchases or changes in unit utilization) to meet electric demand; 3) fuel switching and/or blending (such as switching to a low sulfur coal or co-firing with natural gas); 4) install desulfurization equipment (such as scrubbers or in-duct lime injection systems); 5) retire an existing "dirty" unit and replace the generating capacity with a new lean technology or power purchases; 6) repower with a clean coal technology (such as fluidized bed combustion or integrated gasification combined cycle). 


\subsubsection{State Implementation Plans (SIPs)}

It may be possible for a generating source to comply with NSPS and Title IV requirements and still not be permitted. In conjunction with the EPA, each state prepares a state implementation plan (SIP) to regulate emissions within their jurisdiction. This plan examines more site-specific considerations than contained in the nation-wide provisions of Title IV and NSPS.

The first provision which a generator must meet is the prevention of significant deterioriation (PSD) review. This review examines PSD emissions in a local region. If it is determined that additional emissions from the generating source do not exceed set local limits, a PSD permit is granted.

The second provision that must be met in the SIP is the national ambient air quality standard (NAAQS). The NAAQS looks at emissions in a broader region (usually called basins) than the PSD. So, even if a source generator is granted a PSD, it may fail to comply with the NAAQS. If a region is found to be not in attainment, the SIP will require a generator utilize lowest achievable emission rate (LAER) cleanup technology. And even if an area is found to be in attainment, the SIP could still require the use of best attainment control technology (BACT) which, could be above and beyond Title IV or NSPS requirements.

One can see from the previous discussion that defining allowable emission limits is a complex subject. It will have to be defined on a case-by-case basis and is definitely site specific. Most 
states end up adopting the national standards, but some exceptions do exist (California is a noted example). In terms of defining sulfur control targets for this investigation, the Department of Energy's Office of Fossil Energy goals will be adopted. A Clean Coal Technologies Program Plan published in 1993 defined a target for $\mathrm{SO}_{2}$ emissions at 1/10 NSPS by the year 2010 [9]. This translates into $0.12 \mathrm{lb} \mathrm{SO}_{2}$ per million Btu fuel input with $90 \%$ reduction in potential emissions. This limit will be factored into the reactor design later in this report.

\subsection{Integrated Gasification Combined Cycle (IGCC) Concept}

Many advanced coal conversion systems are based on gasification. Coal gasification is a process in which coal is partially combusted in the presence of air, oxygen, and/or steam to produce a low to medium Btu fuel gas. This gas consists primarily of $\mathrm{H}_{2}, \mathrm{CO}, \mathrm{N}_{2}, \mathrm{CH}_{4}, \mathrm{CO}_{2}$, and $\mathrm{H}_{2} \mathrm{O}$ [10]. One of the most promising and highly developed concepts utilizing this technology is the Integrated Gasification Combined Cycle (IGCC) system (Figure 2.1) [11]. IGCC developers tout system efficiencies in the $40 \%-50 \%$ range which translates into lower fuel costs and decreased emissions per unit of power produced. In the IGCC concept, fuel gas from a coal gasifier passes through a hot gas cleanup subsystem. It is then fed to a high efficiency advanced gas turbine which provides the mechanical power for the electrical generators. Exhaust from the gas turbine is coupled to a heat recovery steam turbine/generator where additional power is extracted and hence the term combined cycle. One of the most critical features of this system is the ability to clean the fuel gas as close to the gasifier outlet temperature (typically $1800^{\circ} \mathrm{F}$ ) as possible. Prior to entering the 


\section{Integration Gasification Combined Cycle (IGCC)}

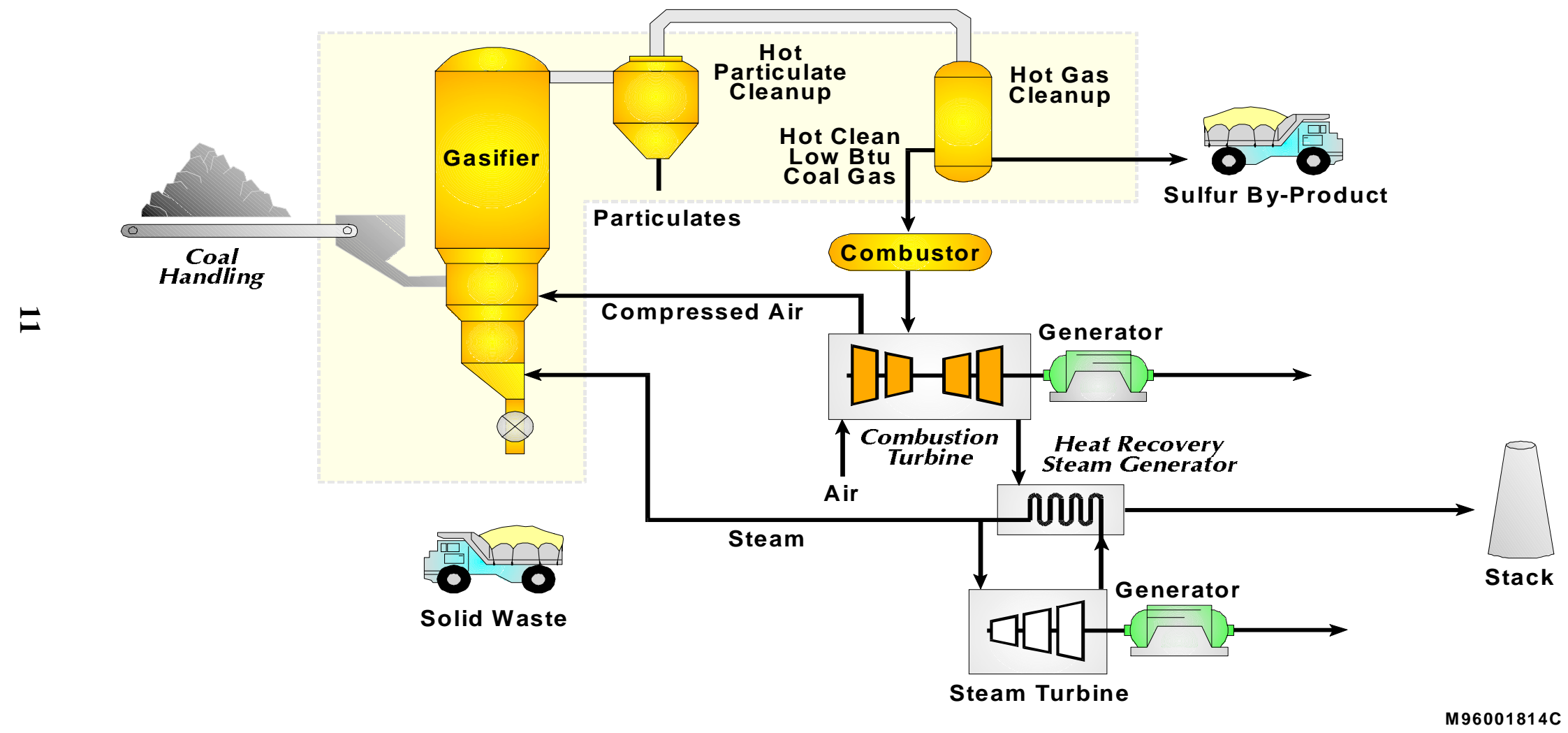

Figure 2.1 Integrated Gasification Combined Cycle 
combustor, product fuel gas from the gasifier is usually expanded to a lower pressure and cooled to approximately $1000^{\circ} \mathrm{F}$ because of valve and piping constraints/costs and to a lesser degree, cleanup technology limitations. Sulfur, which is usually found as a minor constituent in coal-gas, is removed at this point (as opposed to removal from the flue gas as in a conventional PC plant) to help protect expensive turbo machinery and the heat recovery subsystem components downstream. This desired ability to conduct hot gas desulfurization (HGD) minimizes the efficiency loss associated with currently available cold gas cleanup technologies which require cooling of the fuel gas before treatment. It is both difficult and expensive to recover the extracted "heat" energy removed in cold gas cleanup.

\subsection{Hot Gas Desulfurization for IGCC Systems}

As mentioned previously, the HGD subsystem is a key component in the IGCC concept. The ability to control and remove sulfur species will determine the success of IGCC and other high efficiency advanced coal conversion systems. Therefore, the success of the HGD subsystem will largely determine the fate of these power plants.

In order to investigate HGD with a transport riser reactor, it is important to understand general sulfur removal and disposal options/issues for IGCC systems. Figure 2.1 depicted a schematic of a generic IGCC system. What is not clearly depicted is the potential to remove sulfur along with the ash in the gasifier. This approach, called "in-bed" sulfur capture, requires that limestone or dolomite be injected along with the coal feed into the gasifier. As coal is gasified and hydrogen sulfide released, the limestone reacts to form calcium sulfide. 
The calcium sulfide must then be oxidized in an external sulfator. This is done to form calcium sulfate (gypsum), which is a stable compound suitable for landfilling. The governing reactions are as follows:

$$
\begin{array}{ll}
\text { In the Gasifier } & \mathrm{CaCO}_{3}+\mathrm{H}_{2} \mathrm{~S}=\mathrm{CaS}+\mathrm{CO}_{2}+\mathrm{H}_{2} \mathrm{O} \\
\text { In the Sulfator } & \mathrm{CaS}+2 \mathrm{O}_{2}=\mathrm{CaSO}_{4}
\end{array}
$$

There are few potential problems with this approach. Although 70\% - 95\% sulfur capture has been demonstrated, in-bed capture may only be viable in fixed-bed gasifier systems [12]. This potentially limits other commercial gasifier types such as fluid- and entrained-bed units from using this option. Also, an external sulfator is required to oxidize the $\mathrm{CaS}$ to the more stable sulfate form, which increases capital cost for the plant. More importantly, it is not known how viable landfilling will actually be given today's everchanging environmental regulations. The variable composition of ash that is removed with the calcium sulfate makes this senerio difficult to predict. It is this same ash (impurities) that limits the sale and use of the gypsum for certain sulfur markets such as fertilizer manufacturers. Gypsum can be considered a sulfur supply feedstock when disposed of naturally as a mixed fertilizer. In the agriculture industry, gypsum performs as a soil conditioner, provides a source of calcium and sulfur, and helps retain organic nitrogen in the soil. As a natural component in fertilizer, the sulfur in gypsum is returned to the earth in a useful manner without incurring a disposal cost penalty. 
Most IGCC systems involve the use of a hot gas desulfurization (HGD) subsystem immediately downstream of the gasifier. The HGD subsystem typically relies on absorption of the sulfur from the $\mathrm{H}_{2} \mathrm{~S}$ onto a solid metal oxide particle (commonly referred to as a sorbent) [13]. The metal oxides are rather expensive and cannot be disposed. Therefore, they need to be "regenerated" so that they can be used again. Regeneration is accomplished by reacting the metal sulfide with air. This produces a renewed metal oxide sorbent and byproduct sulfur dioxide and nitrogen gas. Handling of the effluent $\mathrm{SO}_{2}$ gas is required and defines how the regenerator portion of the HGD subsystem is operated. Prior schemes involved sending the $\mathrm{SO}_{2}$ back to the gasifier to react with the in-bed limestone, but this approach raises questions previously discussed. It is important to note that HGD regeneration schemes are closely tied to sulfur recovery options. Several sulfur recovery options are available for treatment of the $\mathrm{SO}_{2}$ depending on the final form of sulfur required.

An evaluation of the U.S. sulfur market was conducted to identify the most common sulfur feedstock forms [14]. While elemental sulfur constituted $86 \%$ of the sulfur supply market, $83 \%$ of that is consumed to form sulfuric acid. The average stockpile time for elemental sulfur (in 1988) was only 1.2 months [14]. The majority of the market demand for sulfur is the phosphate fertilizer industry. Given these facts, the decision to make elemental sulfur or sulfuric acid is purely site-specific, and at the discretion of the owner.

There are various sulfur recovery processes available. The DOE has recently been developing a Direct Sulfur Recovery Process (DSRP) with the Research Triangle Institute (RTI) to 
produce elemental sulfur. This concept involves reacting the $\mathrm{SO}_{2}$ laden off-gas with a reducing gas $\left(\mathrm{H}_{2}, \mathrm{CO}, \mathrm{H}_{2} \mathrm{~S}\right.$, etc. $)$ in the presence of a catalyst to produce elemental sulfur directly. The reducing gas can be conveinently obtained from the gasifier in an IGCC system. Sulfur recovery efficiencies approaching 99\% have been demonstrated [15]. There are also various commercial sulfuric acid processes available such as the Monsanto Enviro-Chem System and the Haldor-Topsoe Wet Sulfuric Acid Process. These processes essentially involve the oxidation of sulfur dioxide to sulfur trioxide and subsequent hydrolysis to produce sulfuric acid. Conversion efficiencies greater than $98 \%$ can be expected. Whether selecting DSRP to produce elemental sulfur or utilizing one of the sulfuric acid processes, the one common requirement to make these processes economically viable is availibility of a concentrated $\mathrm{SO}_{2}$ reactant feed stream. If stoichiometric air regeneration is conducted, the theoretical maximum $\mathrm{SO}_{2}$ concentration that can be obtained is $15 \%$. This is more than adequate to meet the requirements of these processes.

In summarizing this section, HGD is a key component of the IGCC system. High $\mathrm{H}_{2} \mathrm{~S}$ removal by the HGD absorber and production of a concentrated $\mathrm{SO}_{2}$ off-gas in the HGD regenerator are critical factors for system viability.

\subsection{Hot Gas Desulfurization (HGD) Chemistry}

Hot gas desulfurization (HGD) involves reacting a sulfur-laden fuel (coal) gas with a desulfurization sorbent which "cleans" the fuel gas of sulfur (usually in the form of $\mathrm{H}_{2} \mathrm{~S}$ when generated by a gasifier). These HGD sorbents are typically various combinations of metal 
oxides (MeO) which react with the $\mathrm{H}_{2} \mathrm{~S}$ to form a metal sulfide and water. The current focus is on zinc-based sorbents. This reaction is usually called sulfidation or sulfur adsorption. A typical sulfidation reaction looks like:

$$
\mathrm{MeO}+\mathrm{H}_{2} \mathrm{~S}=\mathrm{MeS}+\mathrm{H}_{2} \mathrm{O}
$$

For Zinc:

$$
\mathrm{ZnO}+\mathrm{H}_{2} \mathrm{~S}=\mathrm{ZnS}+\mathrm{H}_{2} \mathrm{O} \quad \mathrm{H}_{\mathrm{rxn}}=-31,930 \mathrm{Btu} / \mathrm{lb}-\mathrm{mole}
$$

Most metal oxides are too "valuable" simply to dispose of after sulfidation, so they must be regenerated back to their original oxide state and reused in the absorption (sulfidation) stage. In many cases this is done with an oxygen-containing gas such as air and (ignoring $\mathrm{N}_{2}$ ) the general reaction can be expressed as:

$$
\mathrm{MeS}+3 / 2 \mathrm{O}_{2}=\mathrm{MeO}+\mathrm{SO}_{2}
$$

For Zinc:

$$
\mathrm{ZnS}+3 / 2 \mathrm{O}_{2}=\mathrm{ZnO}+\mathrm{SO}_{2} \quad \mathrm{H}_{\mathrm{rxn}}=-191,581 \mathrm{Btu} / \mathrm{lb} \text {-mole }
$$

Both the sulfidation and regeneration reactions are highly exothermic and therefore, heat management becomes extremely important. The initial feed temperature of the reactants must be high enough to initiate reaction at a sufficient kinetic rate, but must not be so high that the additional heat of reaction causes an adverse effect on the sorbent (such as sintering). This is not so much of a problem in the absorber because the concentration of hydrogen sulfide in 
the fuel gas available for reaction is only in the range of hundreds of parts per million volume (ppmv) and the heat generated is easily absorbed by the other gases. In the regenerator however, the effect is much more serious because of the higher heat of reaction and the higher concentration of reactant gas (usually air with $21 \%$ oxygen). It is for this reason that fixedbed reactors regenerate with a very dilute-oxygen containing reactant gas. This however, results in increased size and cost of both the regenerator and downstream sulfur recovery process equipment due to the excessive diluent gas needed.

Another important consideration when examining HGD chemistry is sulfate formation. Normally, the sulfided sorbent is oxidized to a metal oxide in the regenerator. Under certain conditions however, the sorbent can be further oxidized to a metal sulfate. The primary concern associated with $\mathrm{MeSO}_{4}$ formation is expansion of the solid lattice which is believed to cause excessive stresses within the sorbent particle [16]. The molar volume of $\mathrm{ZnSO}_{4}$, for example, is approximately three times the molar volume of $\mathrm{ZnO}$ and twice that of $\mathrm{ZnS}$. This could lead to increased sorbent attrition, especially in fixed-bed HGD reactors which use larger sorbent pellets that rely more on intraparticle reactions than the surface reactions of the smaller particle systems such as fluid-bed and transport HGD. Another general disadvantage to the formation of sulfates is increased oxygen requirements for regeneration. For example, compare the following reactions involving a zinc-based sorbent:

For Regeneration

$$
\mathrm{ZnS}+3 / 2 \mathrm{O}_{2}=\mathrm{ZnO}+\mathrm{SO}_{2}
$$


For Sulfate Formation:

$$
\mathrm{ZnS}+2 \mathrm{O}_{2}=\mathrm{ZnSO}_{4}
$$

Sulfate formation requires $33 \%$ more oxygen than the oxidation of zinc and increases the air/oxygen requirements for the regenerator. This could lead to increased air compressor costs.

The exact reaction mechanism for sulfate formation is not clearly known, but appears to require the simultaneous presence of $\mathrm{ZnS}, \mathrm{O}_{2}$ and $\mathrm{SO}_{2}$ [17]. The reaction also seems to favor low temperatures (below $1400^{\circ} \mathrm{F}$ ) and high partial pressures of oxygen [18]. However, higher operating tempertures as a means of sulfate control can lead to accelerated particle sintering. Minimization of $\mathrm{O}_{2}$ and $\mathrm{SO}_{2}$ partial pressures as a control strategy requires the use of a diluent gas which increases reactor volume, decreases regeneration kinetics, and complicates downstream sulfur recovery process options. It becomes clear that sulfate formation should be avoided if at all possible. The low residence times and stoichmetric operation of a transport regenerator could act to minimize this reaction.

\subsection{Hot Gas Desulfurization (HGD) Processes}

Gas/solid reaction systems, like those encountered in IGCC HGD, can be accomplished in a variety of reactors. Figure 2.2 depicts various forms of possible contacting modes for these systems. At very low gas velocities, gas passes through the interstitial spaces in a fixed bed 
of particles (a). As the gas velocity increases, the particles "unlock" and the bed becomes fluidized (b). A gradual increase in gas velocity results in a slight increase in bed expansion with smooth fluidization until a point is reached where gas bubbles form. This point is known as bubbling (d). A point can sometimes be reached, especially in long narrow fluidized beds, where slugging can occur (e \& f). When the gas velocity is further increased, entrainment of the upper portion of the bed can be appreciable and turbulent motion of particle clusters and voids of gas can be observed (g). Above this point, gas velocity is increased sufficiently high enough to transport all of the particles out of the vessel (h). The type of gas/solid contacting is very important when designing a reactor for HGD. Some of the advantages and disadvantages for fixed, fluid, and transport reactors will be discussed in the following sections. 

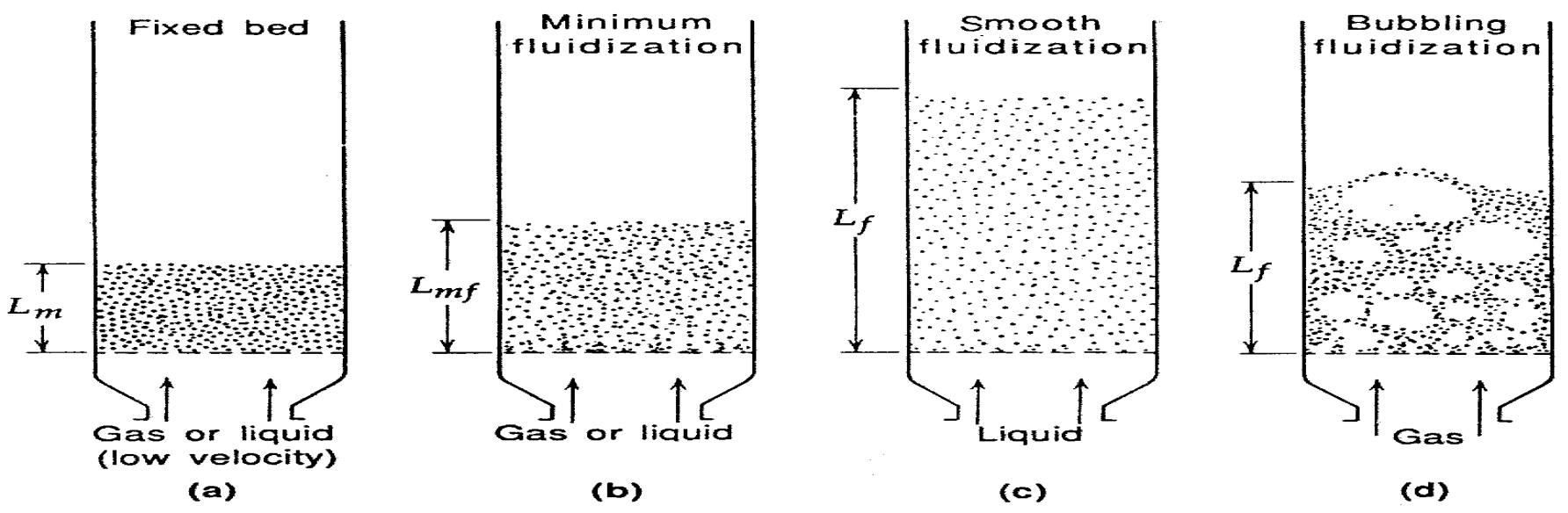

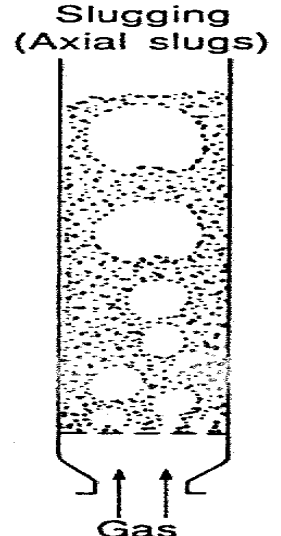

(e)

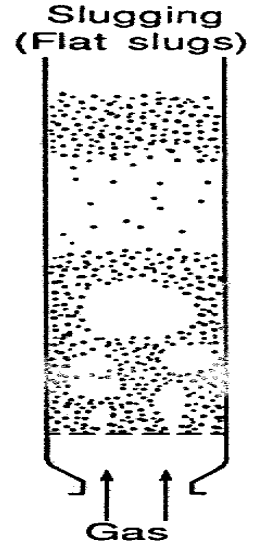

(f) (c)

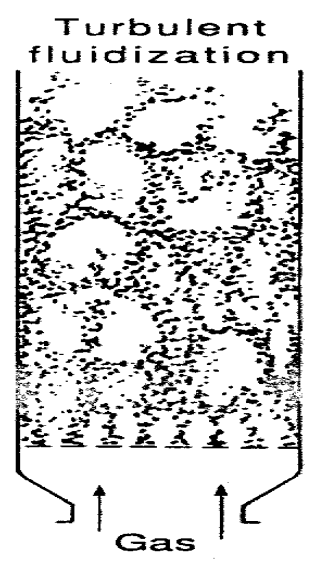

(g) (d)

Lean phase fluidization

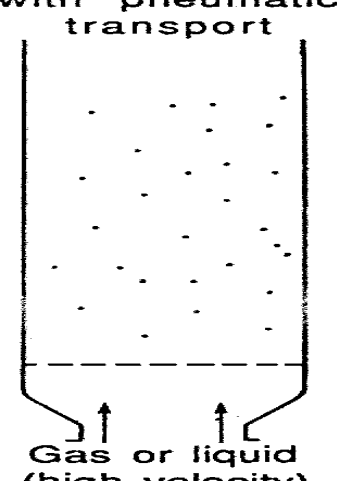

(high velocity)

(h)

Figure 2.2 Gas and Solids Contacting Modes 


\subsubsection{Fixed-Bed Reactors}

Prior hot gas desulfurization research and development (and current bench-scale experimental work) were based on fixed-bed reactors. Simplicity of design and high reactant conversion rates (due to plug flow of gas) are two of the principle advantages associated with these type of reactors. Figure 2.3 depicts a possible configuration of an IGCC HGD subsystem involving three fixed-bed reactors. In this concept, sulfur-laden (usually in the form of $\mathrm{H}_{2} \mathrm{~S}$ ) coal gas from the gasifier flows into an absorption reactor containing fresh or regenerated sorbent where removal of the sulfur occurs. The cleaned fuel gas then exits the top of the reactor. After the sulfur absorption capacity of the sorbent has been reached, the "dirty" fuel gas is then switched into another reactor which contains freshly regenerated sorbent. The sulfided sorbent vessel is then purged with nitrogen and switched over to air to regenerate the sorbent. A third vessel filled with sorbent is usually required for these fixed-bed HGD systems to ensure constant availability of regenerated sorbent (fixed-bed vessels need to be taken off-line when refilling sorbent charges). This concept however, involves some possible operational issues/limitations: each vessel must operate in both reducing and oxidizing gas environments; high temperature valving with positive shutoff to the vessels is required; and a third vessel to ensure regenerated sorbent availability is required. Although high conversion rates are attainable, inherent temperature control limitations were identified for this concept (due to the highly exothermic regeneration reaction) which can make the fixed-bed gas/solid contacting mode undesirable [18]. A diluted air stream (typically $4 \% \mathrm{O}_{2}$ ) is required to manage the heat rise and this results in a low concentration $\mathrm{SO}_{2}$ product stream. This low 
concentration of $\mathrm{SO}_{2}$, along with concentration variations that occur as the bed is regenerated, results in more difficult and costly downstream sulfur recovery.

A variation of the fixed-bed reactor currently under development by General Electric is the moving-bed reactor (Figure 2.4). This concept consists of an integrated reactor with an absorption section situated on top of a regeneration section and separated by a lockhopper. Sulfur-bearing gas from the gasifier is fed to the bottom of the absorber and travels countercurrent to the sorbent which is intermittently dropped to the regenerator below. The cleaned product gas exits the the top of the absorption section of the reactor. Air is fed to the top of the regenerator section and flows co-current with the sorbent. The $\mathrm{SO}_{2}$-bearing product gas from the regenerator exits the bottom of that vessel and is sent to a down-stream sulfur recovery process. A mechanical or pneumatic system transports the regenerated sorbent back to the top of the absorber for continued hot gas desulfurization. The moving-bed system has several advantages over a true fixed-bed system including: dedicated absorption and regeneration vessels, ability to remove fines from the system, and ability to add fresh sorbent on a semi-continuous basis. Still, the moving-bed concept has the disadvantage of relying on high temperature, high pressure valving. The moving-bed concept also utilizes recirculation of cooled regeneration off-gas through the regenerator to control the temperature rise. Although the higher $\mathrm{SO}_{2}$ exit concentrations allow for more favorable downstream sulfur recovery processing, the potential exists in the regenerator for sulfate formation due to the simultaneous presence of $\mathrm{ZnS}, \mathrm{SO}_{2}$, and $\mathrm{O}_{2}$. In addition, this concept results in an extremely large and expensive structure that can 


\section{Fixed Bed Hot Gas Desulfurization Subsystem}

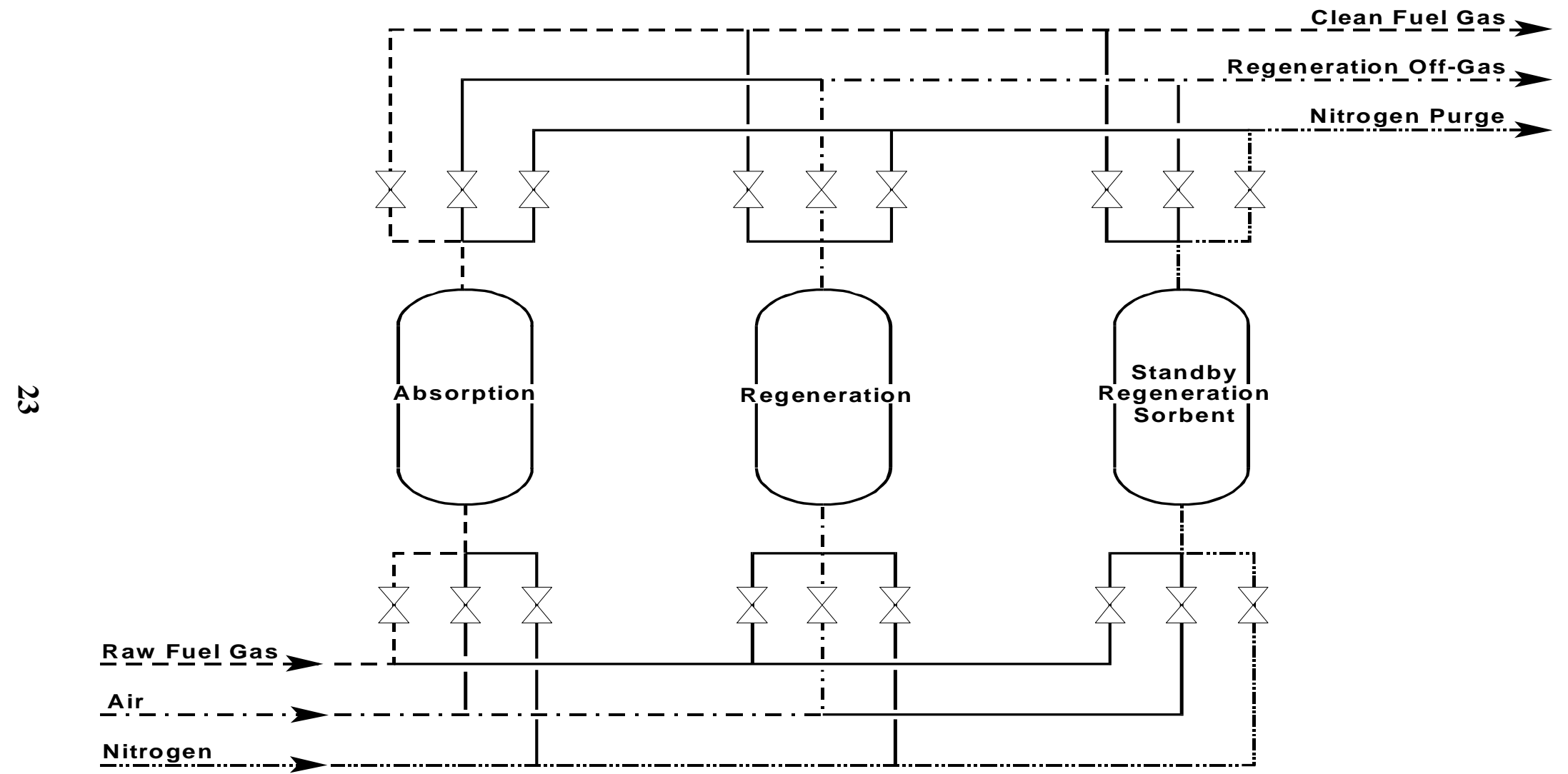

Figure 2.3 Fixed-bed Reactor HGD Subsystem 


\section{GEESI Moving Bed Desulfurizer}

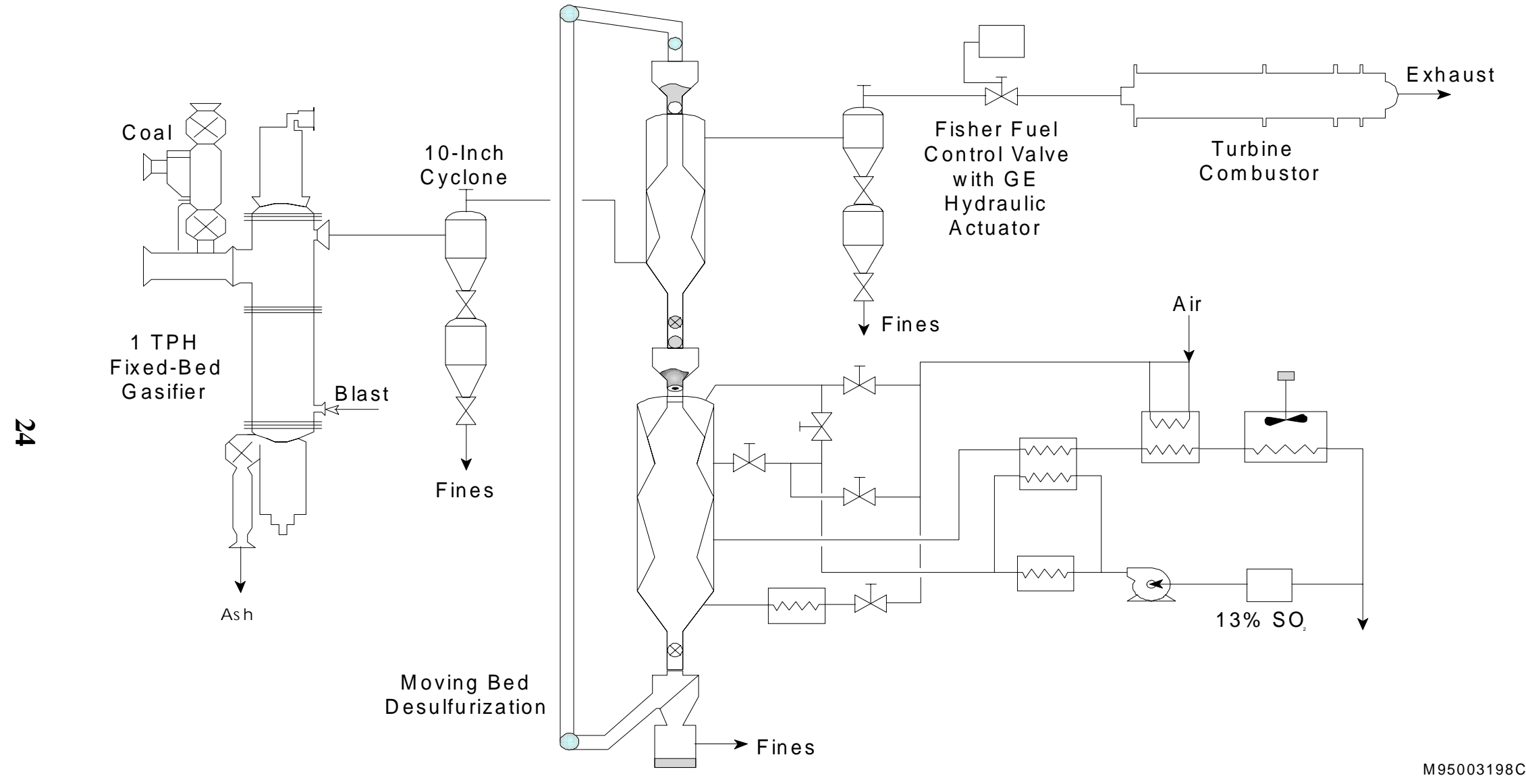

Figure 2.4 Moving-Bed HGD Subsystem 
dwarf many of the other process reactors in an IGCC power plant leading to siting problems and unattractive economics. The petroleum industry followed a similar progression of development and is now dominated by transport reactors for the fluid catalytic cracking (FCC) process.

\subsubsection{Fluid-Bed Reactors}

Fluid-bed reactors differ from fixed or moving-bed reactors in that the bed of solid material is "fluidized" to allow mixing and flow of the solids as opposed to them being held in a static or semi-static position. The principle benefits of fluid-bed reactors relative to fixed-bed reactors are:

1. Uniformity of temperature and gas-phase concentration resulting from the high degree of mixing of the gas and solids.

2. Ability to remove/add heat more efficiently to the reactor through immersed heat exchange tubes or the reactor walls.

3. Ability to add or remove solids continuously.

4. Ability to handle a wide $\mathrm{H}_{2} \mathrm{~S}$ concentration range in the gas feedstock by increasing flow and/or circulation rates (for circulating systems).

5. Lower pressure drop through the bed.

6. Increased heat and mass transfer between the gas and solid phases. 
However, there are various disadvantages that may or may not be of importance when dealing with fluidized-bed reactors:

1. Substantial back mixing of gas and solids can occur which could result in lower product gas conversion.

2. Increased attrition of solid bed material and/or erosion of reactor components.

3. Potential increased gas-bypassing resulting in lower product yields.

4. Increased entrainment of solids that could lead to increased pollution, loss of costly solid reactant, and increased particulate control requirements.

5. Increased uncertainty in scale-up due to the complex hydrodynamic nature of fluidbed reactors.

Still, for certain gas/solid reaction systems, the advantages of fluidized-beds can far outweigh the disadvantages when compared to the fixed-bed counterpart. For HGD subsystems, these advantages or improvements are primarily derived from the well-mixed characteristics of fluidized-beds. For example, when dealing with the highly exothermic regeneration reaction of the metal sulfide, temperature profiles can be "leveled out" and potential hot-spots eliminated. This is the principle advantage gained when the fixed-bed HGD system noted in Figure 2.3 is converted into a batch fluid-bed HGD subsystem. However, the disadvantage of dealing with an extra vessel and dealing with high temperature, high pressure valving still exists. Fluid-beds can also be configured for continuous mode operation. Figure 2.5 represents a continuous two-vessel fluid-bed HGD system. In this concept, sulfur-laden coal- 


\section{Two Vessel Fluid-Bed Absorber/Regenerator Concept}

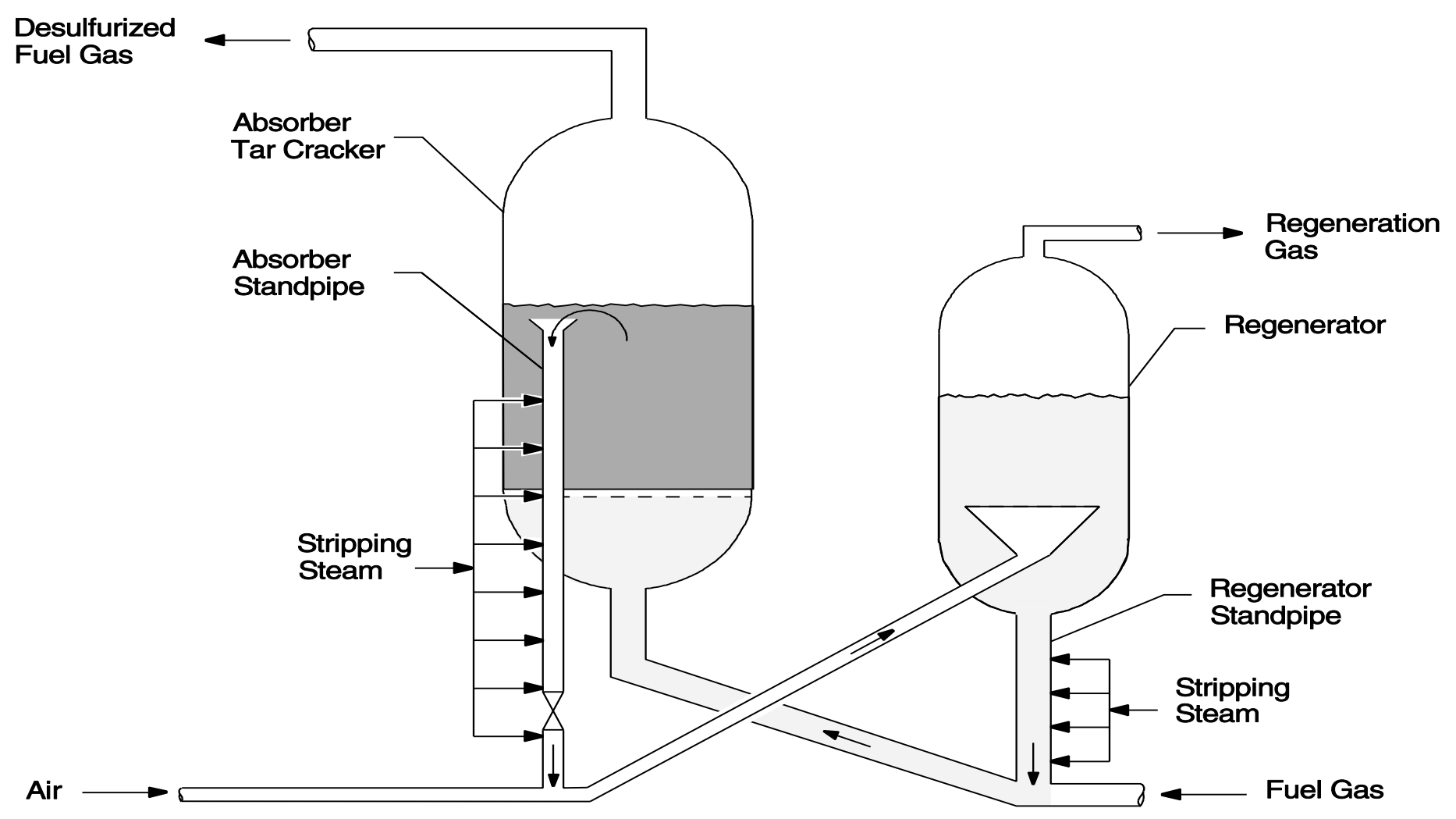

FIGURE 2.5 Two Vessel FBG Concept 
gas from the gasifier is sent to the absorber for cleanup where new or freshly regenerated sorbent is fluidized. As the sorbent in the absorber becomes sulfided, a portion of it is continuously removed through a standpipe where it is steam stripped of any entrained reducing gas. At this point, the sulfided sorbent is transported with air (or other appropriate transport gas) to the regenerator vessel. As the sorbent is regenerated, a portion of it is continuously removed through a standpipe where it is steam stripped of any entrained oxidizing gas. The regenerated sorbent is then transported with fuel gas (or any appropriate transport gas) back to the absorber where the process begins again.

There are additional advantages when going to a continuous system. Gaseous feedstock variations (as can be found in IGCC coal-gasification systems) can be more easily handled due to the wider range of operation of continuous fluid-beds and the ability to change solid circulation rates between the absorber and regenerator. Another advantage of this type of arrangement is the elimination of troublesome high-temperature positive shut-off valves necessary for batch fixed and fluid-bed schemes. And, not the least of which, is the elimination of the third reactor vessel.

Because of these features, emphasis in research and development has now shifted to fluid-bed desulfurization systems. Some prior HGD fluid-bed testing has been conducted and put into practice in Japan [19] and England [20]. These systems employed the use of iron oxide as a desulfurization sorbent. Current U.S. DOE-sponsored programs are focusing on regenerable zinc-based sorbents. 


\subsubsection{Transport Reactors}

While the fluid-bed HGD reactor system concept holds great promise as a viable gas-solid contacting mode, further improvement on that system has recently been identified [21]. By examination of Figure 2.5, it can be seen that the continuous fluid-bed concept requires separate absorption and regeneration vessels. The improvement on that concept utilizes a solids transfer lift (riser) tube from the bottom of the absorber to conduct in-situ regeneration of the sorbent by transporting it with air (Figure 2.6). The obvious benefit of this concept is the elimination of an entire vessel leading to lower system costs. Preliminary experiments were conducted in a down-flow entrained reactor which substantiated the technical feasibility of this concept for either transport absorption or regeneration [21].

Pushing this idea to the furthest extreme, it may be possible to incorporate transport absorption and regeneration into the same HGD subsystem. Figure 2.7 depicts a transport absorption loop (riser reactor with cyclone separator and solids return/recycle standpipe) integrated with a similar transport regeneration loop. In this concept, fresh (or regenerated) sorbent is transported up through the riser with the raw fuel gas and absorbs the $\mathrm{H}_{2} \mathrm{~S}$. The sulfided sorbent is separated from the cleaned fuel gas in a cyclone and returned to the bottom of the absorption riser via a standpipe. However, a fraction of the sulfided sorbent is diverted to the bottom of a regeneration riser where it is transported and regenerated back to its "nearoriginal" metal oxide state with air (or some other oxidizing medium). The regenerated sorbent is separated from the $\mathrm{SO}_{2}$ rich gas and returned to the bottom of the regeneration riser via a standpipe for further regeneration or diverted to the absorption loop to conduct 


\section{Fluid-Bed Absorber With Riser-Tube Regenerator}

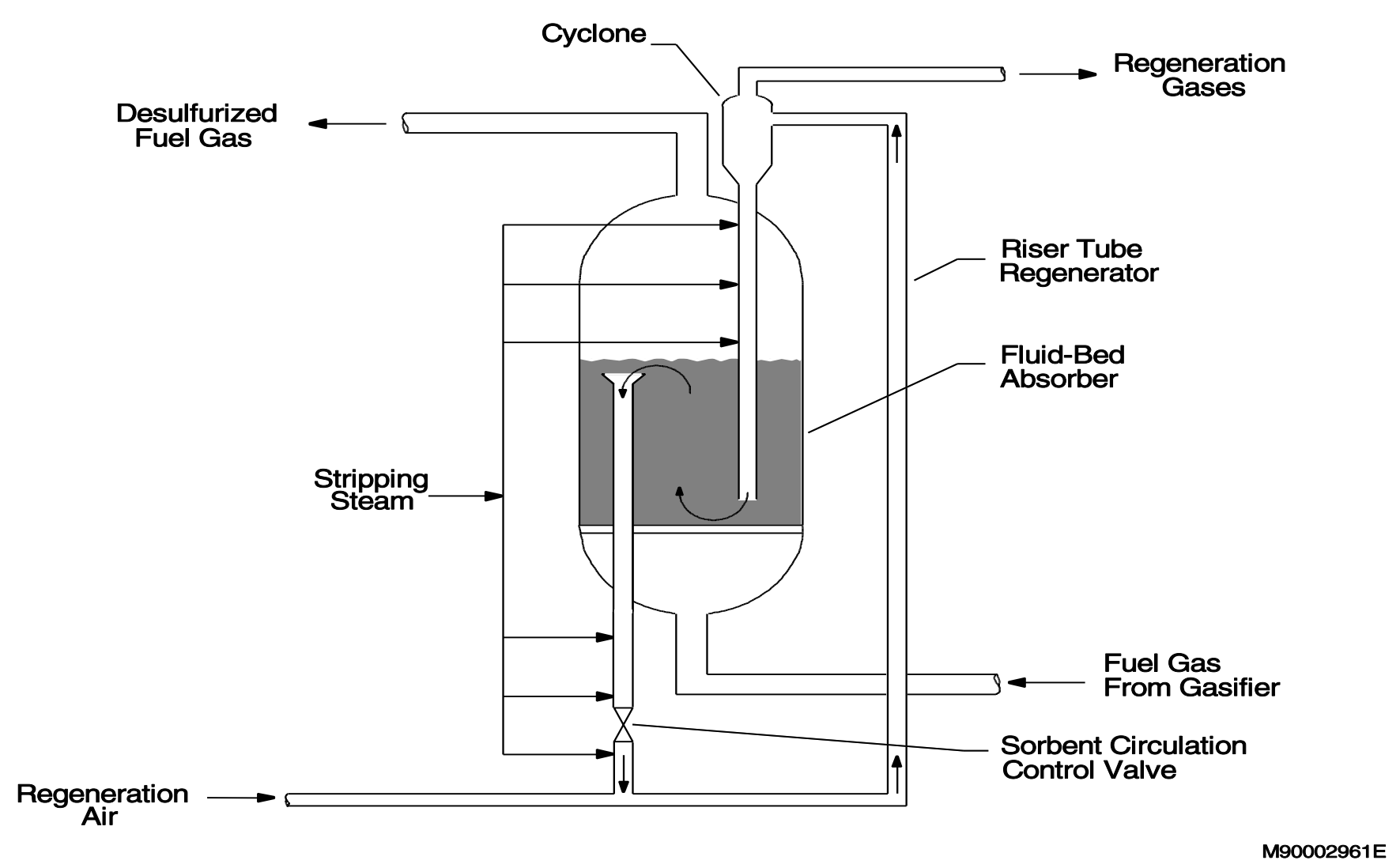

FIGURE 2.6 Single-Vessel Fluid-bed HGD with Riser 


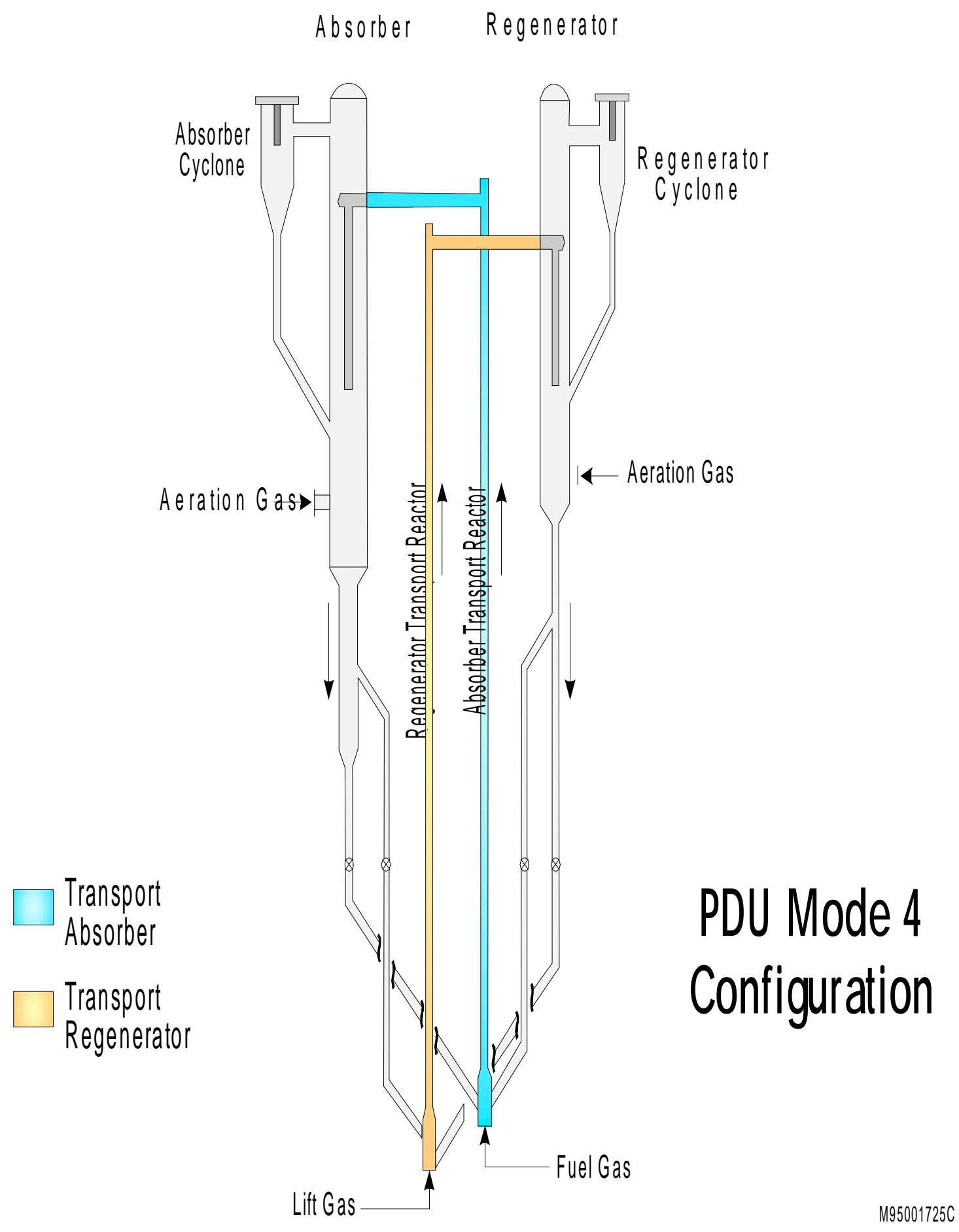

Figure 2.7 Circulating Transport Reactor HGD Process 
continued gas cleanup. Having the ability to vary the recirculation within a loop or vary the circulation between two loops allows great flexibility for the HGD subsystem. For example, after a period of time the sorbent may lose some activity. To account for this, recirculation of sorbent within the absorption (or regeneration) loop is increased. Feedstock or $\mathrm{H}_{2} \mathrm{~S}$ variations can be handled by varying the sorbent circulation rate. This type of flexibility, along with high throughput and smaller vessel sizes (compared with fixed and fluid-bed batch processes) make the transport reactor concept very attractive. However, one of the downsides of these higher velocity systems is the increased attrition of both sorbent and process equipment. Thus, a careful optimization is required when developing these systems. Still, the payoff is attractive and potential for success appears promising.

If one compares IGCC HGD development and the evolution of catalytic crackers in the petroleum industry, there are some apparent similarities. Both deal with gas/solid reaction systems. Both require regeneration of a sorbent or catalyst material to justify the economics of the process. Both involve a significant exothermic reaction. The catalytic cracking industry started with fixed-bed reactors because of their inherent high conversion. When difficulties controlling the reactor temperature profile became too onerous, fluid-bed units were incorporated [22]. Eventually, the process evolved towards transport reactor regeneration because of the size reduction in process vessels due to the higher operating velocities. This was possible because of the "fast" reaction kinetics for the catalytic cracking systems. Preliminary scoping tests indicate the same may be true for HGD systems being developed today. 
A cost study by Rutkowski showed that an IGCC system operating with fluid-bed or transport HGD subsystems were cost competitive with fixed/moving-bed HGD subsystems [23]. The study also showed a trend for additional cost savings with faster fluidizing gas systems. When compared to the transport HGD, an edge for the fluid-bed system was noted because of the large excess air flow requirements of the transport system during regeneration for temperature control. As was stated previously, this causes downstream sulfur recovery systems to be oversized due to the excess air requirement. However, this assumed that a significant fraction of sulfur from the spent sorbent was being removed in the regeneration riser during transport. But, this excess air flow requirement for temperature control can be eliminated by limiting the amount of sulfur removed from the sorbent per pass through the regenerator riser. For example, if one were removing $10 \mathrm{wt} \%$ sulfur per pass through the reactor from the spent sorbent, excess air would be required to limit temperature rise for an adiabatic design (i.e. No heat removal from the system). However, it may be possible to remove some fraction of this amount (say $1 \%$ sulfur) with stoichiometric air without excessive temperature rise. This scenario would require increased sorbent recirculation (multiple passes) within the regeneration riser to accomplish the same overall sulfur removal from the sorbent, but the riser could be smaller and produce a highly concentrated $\mathrm{SO}_{2}$ effluent stream. Because this concentrated $\mathrm{SO}_{2}$ stream from the regenerator is likely to be a requirement for IGCC power systems, the excess air penalty for the transport HGD subsystem is no longer incurred and the cost advantage returns. Of course, solids circulation must be increased and that can lead to higher sorbent attrition and equipment erosion. The effects of all these parameters (reaction kinetics, gas flow, solid circulation rates, attrition, sulfate formation, 
etc.) are not clearly quantified. Further research and development is required and thus, the need for experimental units such as the one being built for this thesis.

Both the Federal Energy Technology Center (FETC) and M.W. Kellogg are exploring the transport HGD process. In addition to the experimental reactor discussed in this thesis, FETC's Morgantown, West Virginia site is currently in the process of constructing a HGD process development unit (PDU) depicted in Figure 2.7 [24][25][26]. A point of interest in this larger transport reactor-based subsystem is the incorporation of a fluid-bed vessel in both the absorption and regeneration loop. Because of the many uncertainties that exist for these processes and reaction systems, FETC built in flexibility to the concept to allow for any combination of transport and fluid-bed configuration for the sulfidation and regeneration reactions. This unit is slated for operation by the year 2000. M.W. Kellogg has built a small, 1-inch diameter, single-loop circulating reactor at their Houston, Texas facility to study the process. Under an existing DOE-sponsored Clean Coal Project with Sierra Power, Kellogg has designed a full-scale transport HGD subsystem with a recirculation absorption loop coupled with a single-pass transport regenerator [27]. That unit, located at the Pinon Pines Plant in Reno, Nevada, is scheduled for startup in the later part of 1999. 


\subsection{Experimental Approach}

In this chapter, the pertinent theory and approach are discussed for the design and construction of the experimental HGD transport reactor that was built for this thesis. There were two principle steps involved; 1.) Identify design requirements, and 2.) Conduct process design.

\subsection{Design Requirements}

The design requirements for the experimental HGD transport reactor constructed during the course of this work were constrained by two primary factors: 1.) IGCC system requirements for commercial HGD units; and 2) Research requirements for the experimental reactor being constructed.

\subsubsection{IGCC System Requirements}

The HGD transport reactor is a subsystem of the IGCC power plant concept (Figure 2.1) and is subject to the overall plant operating requirements as well as the HGD subsystem requirements. For IGCC systems, sulfur removal requirements are defined by the Federal Clean Air Act and other State and local considerations. From the discussion in section 2.1.2, it was shown that these can be rather complicated. For the purpose of this study, the DOE goal of 1/10 NSPS was used. For coal-based power systems, this equated to 0.12 pounds of $\mathrm{SO}_{2}$ emitted per million BTU of fuel input. As was previously stated, the extent of cleanup or duty required of the HGD subsystem is highly dependent upon the sulfur content of the fuel. The relationship between sulfur content and required sulfur removal can be seen in 
Figure 3.1. The analysis was based on a typical high-sulfur Illinois \#6 coal composition with the following characteristics [29]:

\begin{tabular}{|c|c|}
\hline$\underline{\text { Chemical Component }}$ & Weight \% \\
\hline Carbon & 61.2 \\
\hline Hydrogen & 4.7 \\
\hline Oxygen & 8.8 \\
\hline Nitrogen & 1.1 \\
\hline Sulfur & 3.4 \\
\hline Water & 12.0 \\
\hline Ash & 8.8 \\
\hline
\end{tabular}

Energy Content $=11.23 \times 10^{3} \mathrm{Btu} / \mathrm{lb}$ coal

It can be calculated for this coal that 1.78 pounds of $\mathrm{SO}_{2}$ would be generated per million Btu of coal input for every weight percent sulfur in the coal feed assuming that all the sulfur is converted to $\mathrm{SO}_{2}$. Thus, approximately $81 \%$ sulfur removal would be required for a $3.5 \%$ sulfur coal to meet NSPS. This is significantly less than the $98.1 \%$ removal required to meet 1/10 NSPS for the same coal-type. This design effort focused on the latter of these two scenarios. 


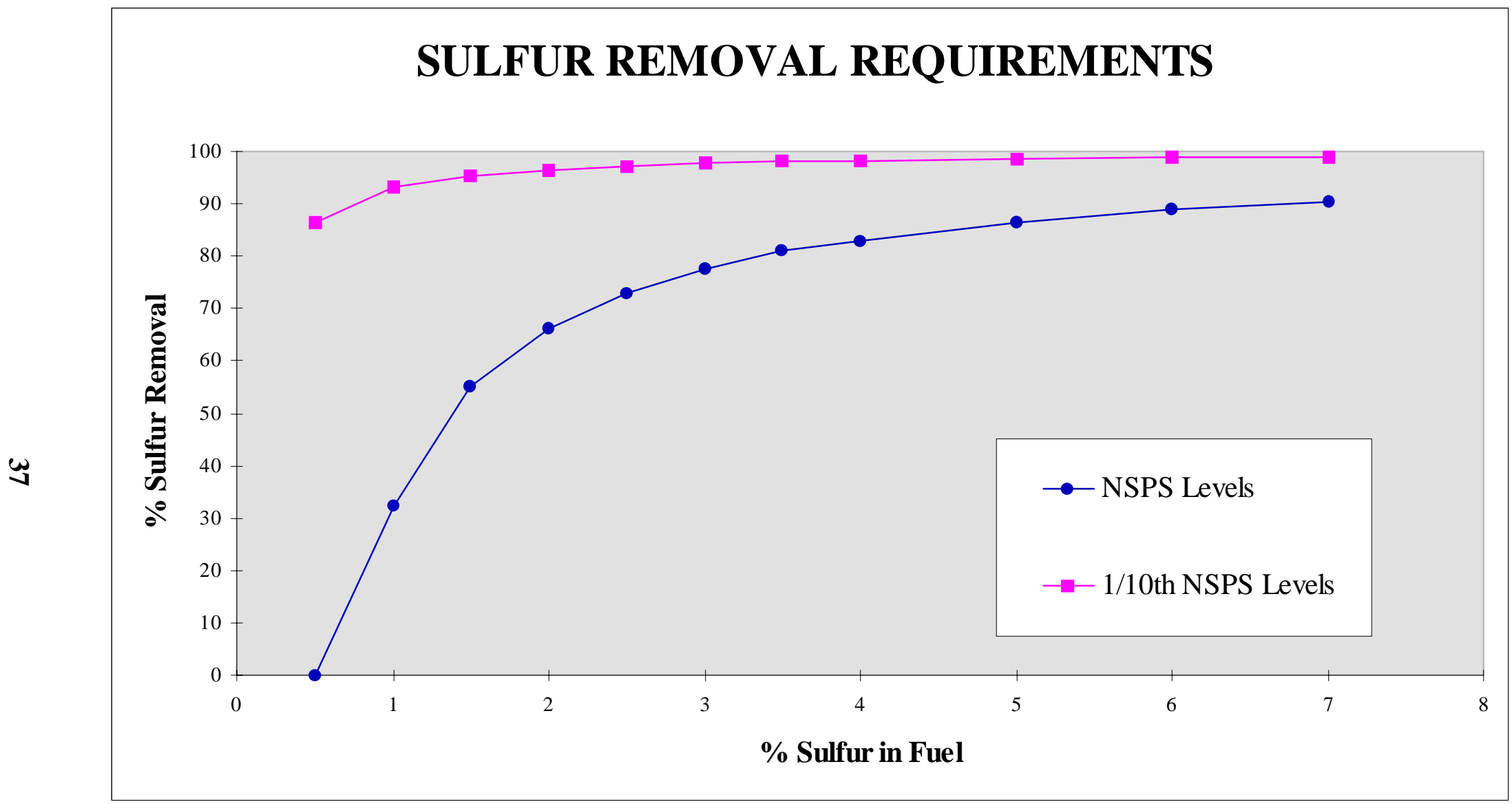

Figure 3.1 NSPS Sulfur Removal Requirements 
The next step was to define the process flows into and out of the HGD subsystem. To do this, a generic air-blown fluid-bed gasifier operating on Illinois \#6 coal with 3.5\% sulfur was chosen for the analysis [28]. (NOTE: The product gas composition obtained from the literature was adjusted to account for operation of the gasifier on air instead of oxygen.) A block flow diagram for the gasifier and HGD subsystem was developed (Figure 3.2). Some simplifying assumptions need to be stated at this point: 1.) All of the sulfur in the coal is converted to $\mathrm{H}_{2} \mathrm{~S}$ in the gasifier; 2.) All of the sulfur exits with the product gas; 3 .) All of the particulates exit with the ash in the bottom of the gasifier; 4.) Stoichiometric air is used in the HGD subsystem to convert the $\mathrm{H}_{2} \mathrm{~S}$ to $\mathrm{SO}_{2}$; and 5.) Reduction of sulfur levels to $1 / 10$ NSPS for a $3.5 \%$ weight sulfur-containing Illinois \#6 coal was chosen. It was stated previously that some schemes involve removing sulfur from the gasifier in the form of calcium sulfate. While this may prove out commercially, the assumption that all of the sulfur in the coal reaches the HGD transport reactor will represent the most severe desulfurization condition and thus was used for this study. Given these assumptions, a mass and mole balance was conducted. Table 3.1 provides the stream summary information for Figure 3.2. The analysis indicates that a desulfurized fuel gas (Stream F) would require $\mathrm{H}_{2} \mathrm{~S}$ concentrations less than 80 ppmv to meet 1/10 NSPS requirements for this particular system. 


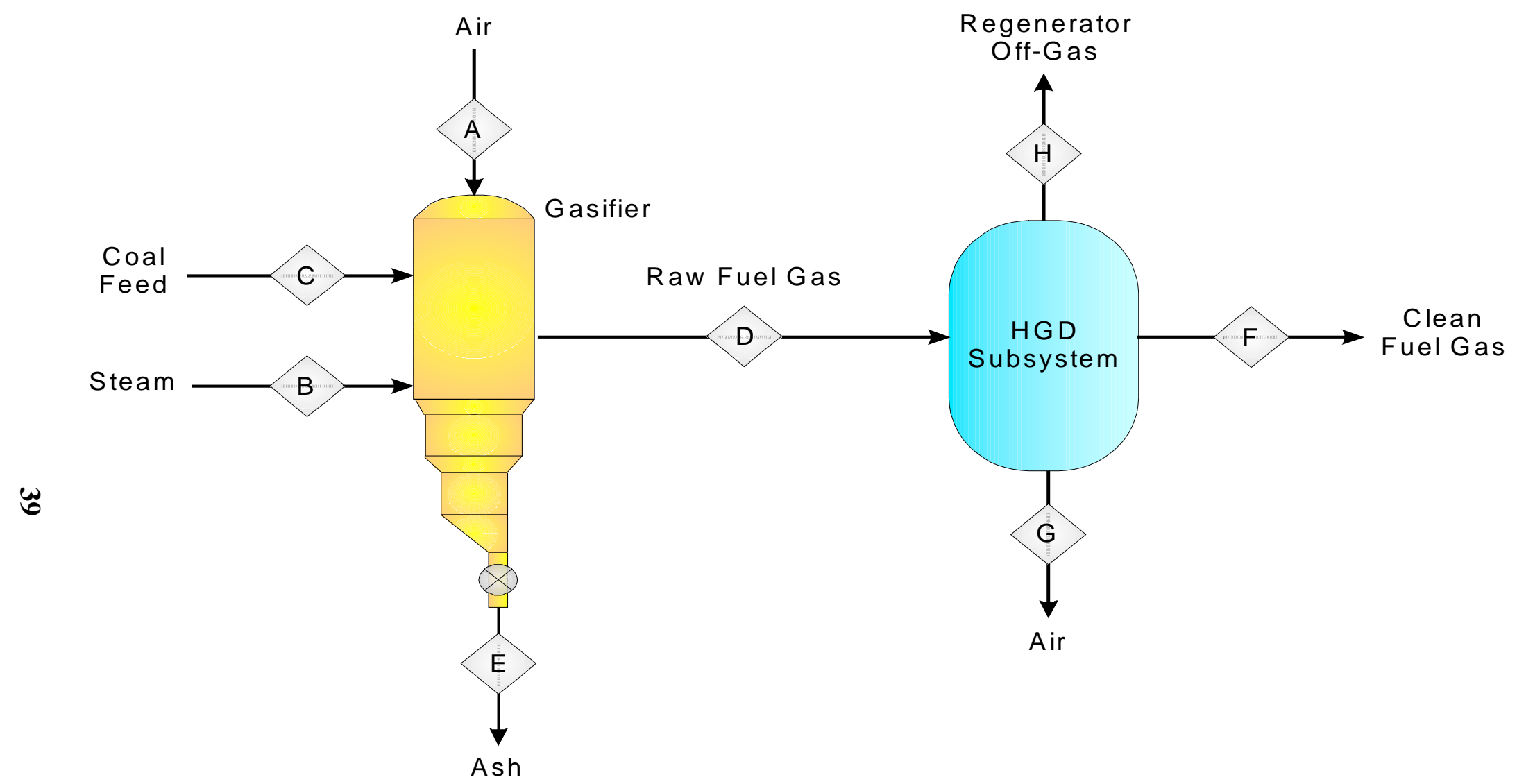

M99000285 C7

Figure 3.2 Gasifier and HGD Block Flow Diagram 


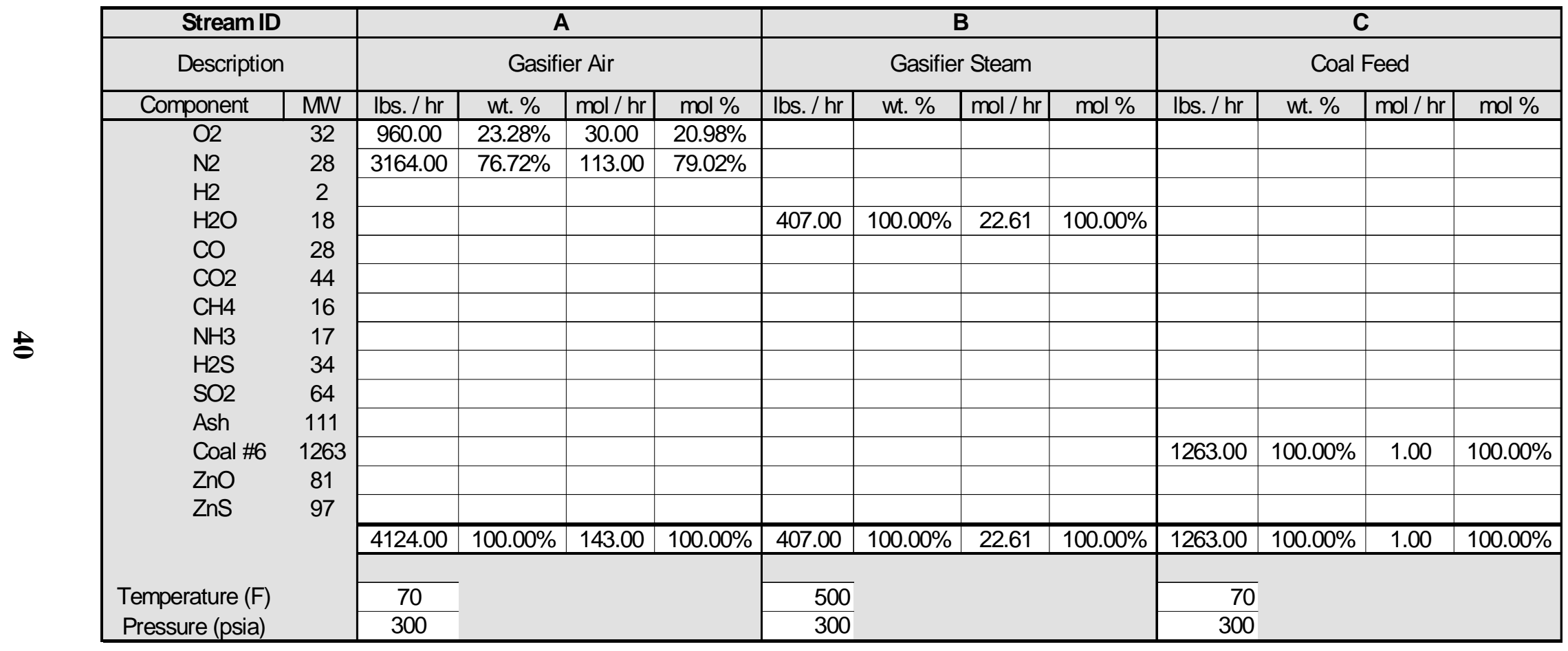

3.1 Stream Summary Table for Gasifier and HGD Block Diagram 


\begin{tabular}{|c|c|c|c|c|c|c|c|c|c|c|c|c|c|}
\hline \multicolumn{2}{|l|}{ Stream ID } & \multicolumn{4}{|c|}{ D } & \multicolumn{4}{|c|}{$E$} & \multicolumn{4}{|c|}{$\mathbf{F}$} \\
\hline \multicolumn{2}{|l|}{ Description } & \multicolumn{4}{|c|}{ Raw Fuel Gas } & \multicolumn{4}{|c|}{ Ash } & \multicolumn{4}{|c|}{ Desulfurized Fuel Gas } \\
\hline Component & MW & Ibs. / hr & wt. \% & $\mathrm{mol} / \mathrm{hr}$ & $\mathrm{mol} \%$ & Ibs. / hr & wt. \% & $\mathrm{mol} / \mathrm{hr}$ & $\mathrm{mol} \%$ & Ibs. $/ \mathrm{hr}$ & wt. \% & $\mathrm{mol} / \mathrm{hr}$ & $\mathrm{mol} \%$ \\
\hline \multicolumn{14}{|l|}{$\mathrm{O} 2$} \\
\hline N2 & 28 & 3178.00 & $55.92 \%$ & 113.50 & $47.76 \%$ & & & & & 3178.00 & $56.13 \%$ & 113.50 & $47.76 \%$ \\
\hline $\mathrm{H} 2$ & 2 & 74.00 & $1.30 \%$ & 37.00 & $15.57 \%$ & & & & & 74.00 & $1.31 \%$ & 37.00 & $15.57 \%$ \\
\hline $\mathrm{H} 2 \mathrm{O}$ & 18 & 385.00 & $6.77 \%$ & 21.39 & $9.00 \%$ & & & & & 408.52 & $7.21 \%$ & 22.70 & $9.55 \%$ \\
\hline $\mathrm{CO}$ & 28 & 1431.00 & $25.18 \%$ & 51.11 & $21.50 \%$ & & & & & 1431.00 & $25.27 \%$ & 51.11 & $21.50 \%$ \\
\hline $\mathrm{CO} 2$ & 44 & 560.00 & $9.85 \%$ & 12.73 & $5.36 \%$ & & & & & 560.00 & $9.89 \%$ & 12.73 & $5.36 \%$ \\
\hline $\mathrm{CH} 4$ & 16 & 6.00 & $0.11 \%$ & 0.38 & $0.16 \%$ & & & & & 6.00 & $0.11 \%$ & 0.38 & $0.16 \%$ \\
\hline $\mathrm{NH} 3$ & 17 & 4.00 & $0.07 \%$ & 0.24 & $0.10 \%$ & & & & & 4.00 & $0.07 \%$ & 0.24 & $0.10 \%$ \\
\hline $\mathrm{H} 2 \mathrm{~S}$ & 34 & 45.00 & $0.79 \%$ & 1.32 & $0.56 \%$ & & & & & 0.68 & $0.01 \%$ & 0.02 & $0.01 \%$ \\
\hline \multirow{6}{*}{$\begin{array}{l}\mathrm{SO} 2 \\
\text { Ash } \\
\text { Coal \#6 } \\
\mathrm{ZnO} \\
\mathrm{ZnS}\end{array}$} & 64 & & & & & & & & & & & & \\
\hline & 111 & & & & & 111.00 & $100.00 \%$ & 1.00 & $100.00 \%$ & & & & \\
\hline & 1263 & & & & & & & & & & & & \\
\hline & 81 & & & & & & & & & & & & \\
\hline & 97 & & & & & & & & & & & & \\
\hline & & 5683.00 & $100.00 \%$ & 237.66 & $100.00 \%$ & 111.00 & $100.00 \%$ & 1.00 & $100.00 \%$ & 5662.20 & $100.00 \%$ & 237.66 & $100.00 \%$ \\
\hline \multicolumn{2}{|l|}{ Temperature (F) } & $\begin{array}{r}1000 \\
300\end{array}$ & & & & $\begin{array}{r}1800 \\
70\end{array}$ & & & & $\begin{array}{r}1025 \\
300\end{array}$ & & & \\
\hline
\end{tabular}

Table 3.1 "Continued" 


\begin{tabular}{|c|c|c|c|c|c|c|c|c|c|c|c|c|c|}
\hline Stream IL & & & & $\overline{\mathbf{t}}$ & & & & & & & $\bar{A}$ & 1 & \\
\hline Descriptio & & & Regene & ation Air & & & Regenerat & on Off-Ga & & & bsorber Sc & orbent Ou & \\
\hline Component & MW & Ibs. / hr & wt. \% & $\mathrm{mol} / \mathrm{hr}$ & $\mathrm{mol} \%$ & Ibs. / hr & wt. \% & $\mathrm{mol} / \mathrm{hr}$ & $\mathrm{mol} \%$ & Ibs. / hr & wt. \% & $\mathrm{mol} / \mathrm{hr}$ & $\mathrm{mol} \%$ \\
\hline $\mathrm{O} 2$ & 32 & 62.40 & $23.30 \%$ & 1.95 & $21.00 \%$ & & & & & & & & \\
\hline N2 & 28 & 205.40 & $76.70 \%$ & 7.34 & $79.00 \%$ & 205.40 & $71.17 \%$ & 7.34 & $84.95 \%$ & & & & \\
\hline $\mathrm{H} 2$ & 2 & & & & & & & & & & & & \\
\hline $\mathrm{H} 2 \mathrm{O}$ & 18 & & & & & & & & & & & & \\
\hline $\mathrm{CO}$ & 28 & & & & & & & & & & & & \\
\hline $\mathrm{CO} 2$ & 44 & & & & & & & & & & & & \\
\hline $\mathrm{CH} 4$ & 16 & & & & & & & & & & & & \\
\hline $\mathrm{NH} 3$ & 17 & & & & & & & & & & & & \\
\hline $\mathrm{H} 2 \mathrm{~S}$ & 34 & & & & & & & & & & & & \\
\hline $\mathrm{SO} 2$ & 64 & & & & & 83.20 & $28.83 \%$ & 1.30 & $15.05 \%$ & & & & \\
\hline Ash & 111 & & & & & & & & & & & & \\
\hline Coal \#6 & 1263 & & & & & & & & & & & & \\
\hline $\mathrm{ZnO}$ & 81 & & & & & & & & & 105.30 & $45.51 \%$ & 1.30 & $50.00 \%$ \\
\hline ZnS & 97 & & & & & & & & & 126.10 & $54.49 \%$ & 1.30 & $50.00 \%$ \\
\hline & & 267.80 & $100.00 \%$ & 9.29 & $100.00 \%$ & 288.60 & $100.00 \%$ & 8.64 & $100.00 \%$ & 231.40 & $100.00 \%$ & 2.60 & $100.00 \%$ \\
\hline Temperature (F) & & 1000 & & & & 1200 & & & & 1000 & & & \\
\hline Pressure (psia) & & 300 & & & & 300 & & & & 300 & & & \\
\hline
\end{tabular}

Table 3.1 "Continued" 


\begin{tabular}{|c|c|c|c|c|c|c|c|c|c|c|c|c|c|}
\hline \multicolumn{2}{|c|}{ Stream ID } & \multicolumn{4}{|c|}{ A2 } & \multicolumn{4}{|c|}{ A3 } & \multicolumn{4}{|c|}{ A4 } \\
\hline \multicolumn{2}{|c|}{ Description } & \multicolumn{4}{|c|}{ Absorber Sorbent Recycle } & \multicolumn{4}{|c|}{$\begin{array}{c}\text { Absorber Sorbent Circulation to } \\
\text { Regenerator } \\
\end{array}$} & \multicolumn{4}{|c|}{ Absorber Sorbent Inlet } \\
\hline Component & MW & lbs. $/ \mathrm{hr}$ & wt. \% & $\mathrm{mol} / \mathrm{hr}$ & $\mathrm{mol} \%$ & Ibs. / hr & wt. \% & $\mathrm{mol} / \mathrm{hr}$ & $\mathrm{mol} \%$ & lbs. $/ \mathrm{hr}$ & wt. \% & $\mathrm{mol} / \mathrm{hr}$ & $\mathrm{mol} \%$ \\
\hline \multicolumn{14}{|l|}{$\mathrm{O} 2$} \\
\hline \multicolumn{14}{|l|}{ N2 } \\
\hline \multicolumn{14}{|l|}{$\mathrm{H} 2$} \\
\hline \multicolumn{14}{|l|}{$\mathrm{H} 2 \mathrm{O}$} \\
\hline \multicolumn{14}{|l|}{$\mathrm{CO}$} \\
\hline \multicolumn{14}{|l|}{$\mathrm{CO} 2$} \\
\hline \multicolumn{14}{|l|}{$\mathrm{CH} 4$} \\
\hline \multicolumn{14}{|l|}{$\mathrm{NH} 3$} \\
\hline \multicolumn{14}{|l|}{$\mathrm{H} 2 \mathrm{~S}$} \\
\hline \multicolumn{14}{|l|}{ SO2 } \\
\hline \multicolumn{14}{|l|}{ Ash } \\
\hline & 1263 & & & & & & & & & & & & \\
\hline \multirow{3}{*}{$\begin{array}{l}\mathrm{ZnO} \\
\mathrm{ZnS}\end{array}$} & 81 & & & & & 105.30 & $45.51 \%$ & 1.30 & $50.00 \%$ & 210.60 & $100.00 \%$ & 2.60 & $100.00 \%$ \\
\hline & 97 & & & & & 126.10 & $54.49 \%$ & 1.30 & $50.00 \%$ & & & & \\
\hline & & & & & & 231.40 & $100.00 \%$ & 2.60 & $100.00 \%$ & 210.60 & $100.00 \%$ & 2.60 & $100.00 \%$ \\
\hline \multicolumn{2}{|l|}{ Temperature (F) } & \multicolumn{4}{|l|}{$\frac{1000}{200}$} & \multicolumn{4}{|l|}{$\begin{array}{r}1000 \\
300\end{array}$} & \multicolumn{4}{|l|}{$\begin{array}{r}1000 \\
300\end{array}$} \\
\hline
\end{tabular}

Table 3.1 "Continued" 


\begin{tabular}{|c|c|c|c|c|c|c|c|c|c|c|c|c|c|c|c|c|c|}
\hline Stream IC & & & $\mathbf{R 1}$ & & & & & $\overline{\mathbf{R 2}}$ & & & $\mathbf{R}$ & & & & $\mathbf{R A}$ & & \\
\hline Descriptio & & & enerator So & orbent & Ditlet & & $\begin{array}{l}\text { egenera } \\
\text { Recir }\end{array}$ & $\begin{array}{l}\text { ator Sorbe } \\
\text { culation }\end{array}$ & & Regene & $\begin{array}{l}\text { rator Sorbe } \\
\text { Absor }\end{array}$ & $\begin{array}{l}\text { ent Ororo } \\
\text { rber }\end{array}$ & ulation to & & yenerator $s$ & Sorbent I & Inlet \\
\hline Component & MW & lbs. / hr & wt. \% & $\mathrm{mol} / \mathrm{h}$ & $\mathrm{mol} \%$ & lbs. / hr & wt. \% & $\mathrm{md} / \mathrm{hr}$ & $\mathrm{mbl} \%$ & lbs. $/ \mathrm{hr}$ & wh. \% & $\mathrm{mol} / \mathrm{h}$ & $\mathrm{mbl} \%$ & lbs. / hr & w. $\%$ & $\mathrm{~mol} / \mathrm{h}$ & $\mathrm{mol} \%$ \\
\hline $\mathrm{O} 2$ & 32 & & & & & & & & & & & & & & & & \\
\hline N2 & 28 & & & & & & & & & & & & & & & & \\
\hline H2 & 2 & & & & & & & & & & & & & & & & \\
\hline $\mathrm{H} 2 \mathrm{O}$ & 18 & & & & & & & & & & & & & & & & \\
\hline $\mathrm{CO}$ & 28 & & & & & & & & & & & & & & & & \\
\hline $\mathrm{CO} 2$ & 44 & & & & & & & & & & & & & & & & \\
\hline $\mathrm{CH} 4$ & 16 & & & & & & & & & & & & & & & & \\
\hline NH3 & 17 & & & & & & & & & & & & & & & & \\
\hline H2S & 34 & & & & & & & & & & & & & & & & \\
\hline $\mathrm{SO} 2$ & 64 & & & & & & & & & & & & & & & & \\
\hline Ash & 111 & & & & & & & & & & & & & & & & \\
\hline Coal \#6 & 1263 & & & & & & & & & & & & & & & & \\
\hline $\mathrm{ZnO}$ & 81 & 210.60 & $100.00 \%$ & 260 & $100.00 \%$ & & & & & 210.60 & $100.00 \%$ & 260 & $100.00 \%$ & 105.30 & $45.51 \%$ & 1.30 & $50.00 \%$ \\
\hline ZnS & 97 & & & & & & & & & & & & & 126.10 & $54.49 \%$ & 1.30 & $50.00 \%$ \\
\hline & & 210.60 & $100.00 \%$ & 260 & $100.00 \%$ & & & & & 210.60 & 1.00 & 260 & $100.00 \%$ & 231.40 & $100.00 \%$ & 260 & $100.00 \%$ \\
\hline Temperature (F) & & 1000 & & & & 1000 & & & & 1000 & & & & 1000 & & & \\
\hline Pressure (psia) & & 300 & & & & 300 & & & & 300 & & & & 300 & & & \\
\hline
\end{tabular}

Table 3.1 "Continued" 
The "generic" HGD subsystem was represented by a single block for the overall chemical reaction:

$$
\mathrm{H}_{2} \mathrm{~S}+3 / 2 \mathrm{O}_{2}=\mathrm{SO}_{2}+\mathrm{H}_{2} \mathrm{O}
$$

In reality, a Transport HGD subsystem (based on regenerable metal oxide sorbent technology) is comprised of two integrated process reactors; 1.) an absorber, and 2.) a regenerator (Figure 3.3). For a zinc oxide based system, the following reactions occur:

In the Absorber:

$$
\mathrm{ZnO}+\mathrm{H}_{2} \mathrm{~S}=\mathrm{ZnS}+\mathrm{H}_{2} \mathrm{O}
$$

In the Regenerator:

$$
\mathrm{ZnS}+3 / 2 \mathrm{O}_{2}=\mathrm{ZnO}+\mathrm{SO}_{2}
$$

A mass and mole balance was conducted for the transport HGD subsystem and is included in Table 3.1. The additional process flows are due to the regenerable sorbent solids that flow between the absorber and the regenerator where:

Stream S1 - Sulfided sorbent exiting the absorber.

Stream S2 - Sulfided sorbent recycled back to the absorber.

Stream S3 - Sulfided sorbent circulated to the regenerator.

Stream S4 - Sulfided and regenerated sorbent (Stream R2) to regenerator. 


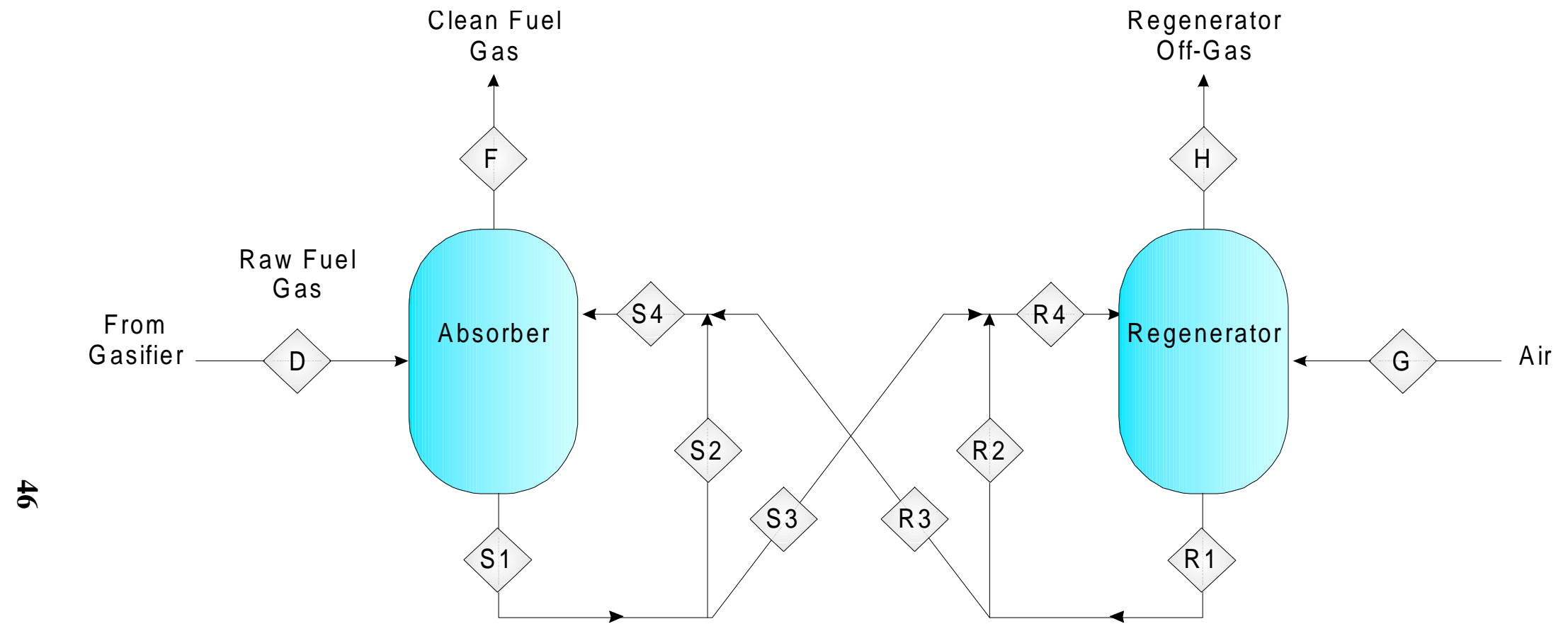

M99000286 C7

Figure 3.3 HGD Subsystem Block Flow Diagram 
Stream R1 - Regenerated sorbent exiting the regenerator.

Stream R2 - Regenerated sorbent recycled back to the regenerator.

Stream R3 - Regenerated sorbent circulated to the absorber.

Stream R4 - Regenerated and sulfided sorbent (Stream S2) to absorber.

From examination of Figure 3.3, it becomes obvious that although the overall gas flows into and out of the process may be similar for most "generic" HGD systems, the circulation of sorbent (Streams S1 through R4) between the absorber and regenerator is rather complex for transport-based reactors. It is this complexity that allows this type of system to more easily handle variation in feed gas $\left(\% \mathrm{H}_{2} \mathrm{~S}\right)$, adjust to changing sorbent/catalyst activity by varying solid circulation rates, and conduct heat management with the solids inventory. This provides for a multitude of scenarios involving the interaction and variation of the sorbent streams. For example, solids recirculation rate throughout the regenerator may need to be increased to control temperature rise in that unit. Now, more mass is moving through the regenerator, less sulfur is absorbed per sorbent particle, and the increased heat capacity of the solids lowers the temperature rise in the reactor. However, one simple balance must remain true: the total sulfur removed by the sorbent in the absorber must be equal to the total sulfur expelled in the regenerator. If not, the sulfur content would build-up on the sorbent until it exceeded the sorbent capacity and the HGD subsystem would fail. It's easy to see that several variations are possible. For the sake of simplicity, the mass balance illustrated no sorbent "recirculations". No attempt was made during the course of this effort to study these variations due to the lack of information and understanding of the reaction kinetics for 
these systems (transport HGD reactors). One of the primary objectives of this thesis was to construct an experimental unit to gain further understanding of reaction chemistry and reactor performance issues. The remainder of this design effort focuses on uncoupled operation of the transport absorber reactor and transport regenerator reactor (i.e. No analysis of circulation between and recirculation within the reactor loops.).

\subsubsection{Research Requirements}

Many aspects of transport HGD are in the exploratory or research phase. HGD sorbent development has been an ongoing supported activity by the DOE since the early 1970's. Sorbents have been developed to allow desulfurization below 50 ppmv $\mathrm{H}_{2} \mathrm{~S}$ in fixed-bed reactors, but none have been commercialized at this point and research continues. Process reactor design has shifted to transport HGD because of the previous mentioned benefits, but very little performance information (i.e. reactor kinetics, operating limits, ...) exists for these systems. Because of the developmental stage of this technology, a well-instrumented and flexible experimental reactor was needed. The following traits were desired for the experimental unit:

A.) Multi-gas capability - To study the effect of component gas concentration on absorption and regeneration.

B.) Precise Independent Flow Control - To allow variable gas/solids ratios in the reactor to aid in determining reactor performance for various sorbents. 
C.) Independent Temperature Control - To study the performance impact of various sorbent, reactant gas, and reactor temperatures.

D.) Multiple Reaction Quench - To allow quenching of the reaction at different locations across the reactor in order to vary the residence time and to aid in characterization of reaction kinetics.

E.) Gas and solids analysis - To allow accurate compositional measurements of reaction products for analysis.

F.) Extensive Instrumentation and Control - To allow for precise control and monitoring of reactor conditions and accurate data interpretation.

G.) High Temperature and High Pressure Operation - To study advanced 600 psia IGCC systems with HGD sorbents up to $1400^{\circ} \mathrm{F}$.

As a result of the aforementioned traits and requirements, a conceptual drawing of an experimental riser reactor was developed (Figure 3.4). This type of unit would allow for simplicity of operation while still maintaining the flexibility needed for studying transport HGD. It was this conceptual system that served as the basis for the process design of the experimental HGD reactor. 


\section{Riser Reactor}

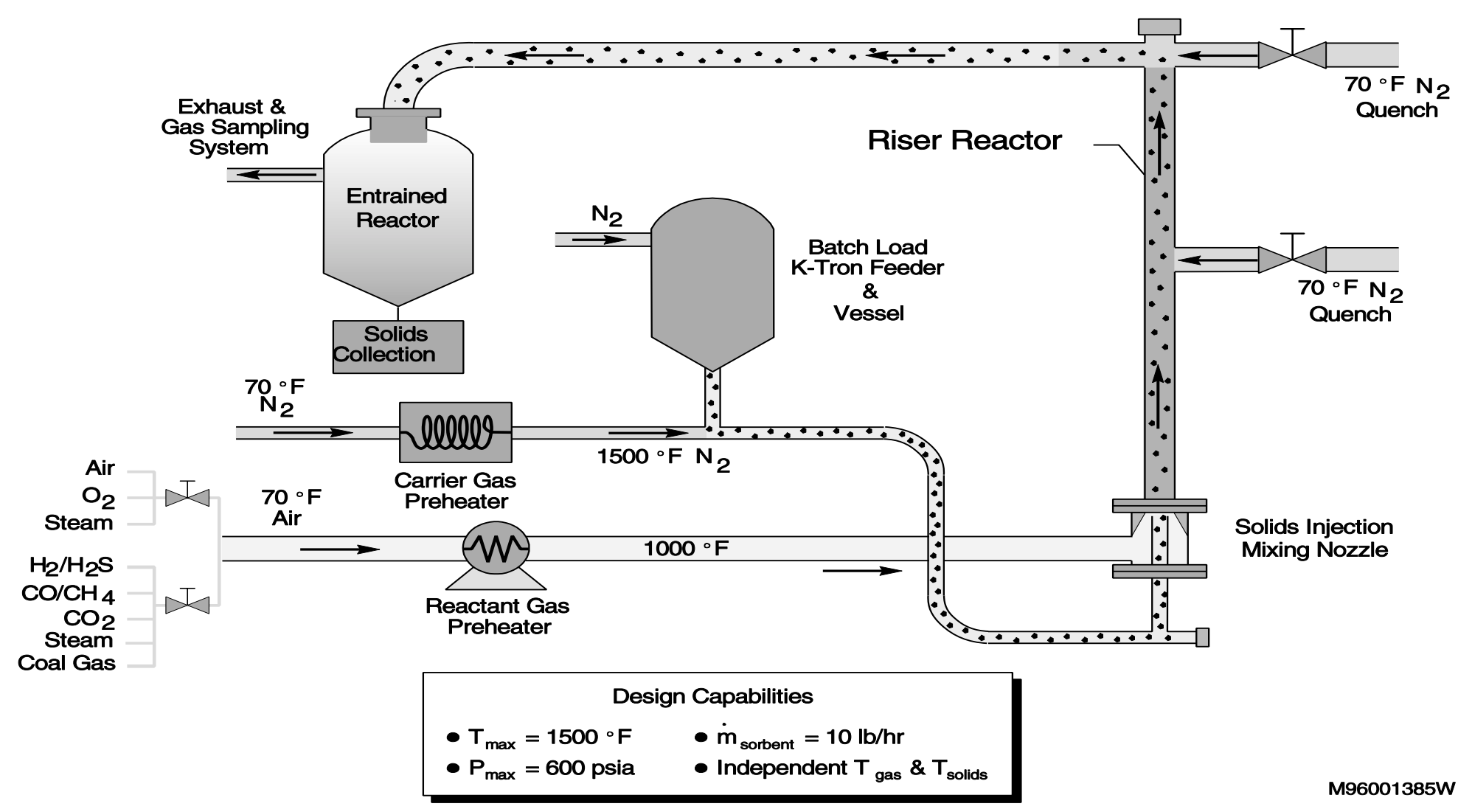

Figure 3.4 Conceptual HGD Riser Reactor 


\subsection{Transport Reactor Process Design}

There are three primary considerations when conducting process design involving transport reactors: 1.) Reactor Hydrodynamics; 2.) Reaction Thermodynamics; and 3.) Reaction Kinetics. The hydrodynamics deals with the dynamics of gas/solid interaction and the physical constraints under which the system must operate to function properly. The thermodynamics defines the heating/cooling requirements of the system based on the stream enthalpy, heats of reaction, and temperature constraints of the reactants or hardware. The kinetics determines to what extent a reaction will proceed in a given reaction time and reactant concentration. Proper evaluation of these three areas allowed for successful process design specification of the experimental transport (riser) reactor.

\subsubsection{Design Basis}

The process design conducted in this study was based on the gas-solid reaction system defined in Section 3.1.1. The desulfurization sorbent selected for evaluation was $\mathrm{ZnO}$ which had the following general properties:

Composition: $100 \% \mathrm{ZnO}$

MW: 81

$\mathrm{dp}=80 \mu \mathrm{m}($ average $)$

s.g. $=1.0($ particle $)$ 
Although the material balance indicated that $50 \%$ of the sorbent was utilized per pass through the absorber and regenerator with no recycle, this was only presented as a hypothetical case. The actual operation of these systems may be quite different due to the many variations of gas/solid ratios that are possible. This mass ratio of gas and solids in the HGD transport subsystem is one of the two primary variables that were explored in the process design effort. Only the inlet and outlet gas concentrations are fixed because they are a known requirement for commercial IGCC systems. The following were the assumed primary boundary conditions for the system:

Absorber:

Inlet Temperature: $1000{ }^{\circ} \mathrm{F}$

Outlet Temperature: $1400^{\circ} \mathrm{F}$ (max.)

Inlet $\mathrm{H}_{2} \mathrm{~S}$ Concentration: 0.56 vol. \% (max.)

Outlet $\mathrm{H}_{2} \mathrm{~S}$ Concentration: 0.01 vol. \% (100 ppmv max.)

\section{Regenerator:}

Inlet Temperature: $1000^{\circ} \mathrm{F}$

Inlet Temperature: $1400{ }^{\circ} \mathrm{F}$

Inlet $\mathrm{O}_{2}$ Concentration: 21 vol. \%

Outlet $\mathrm{O}_{2}$ Concentration: 0 vol. \% (desired) 
As will be seen in section 3.2.2, gas velocity is the other key primary variable for the design and operation of a transport reactor. The required volumetric flow rate of reactant gas increases as a function of the square of the reactor radius to achieve a given gas velocity. One of the objectives of this thesis was to construct a flexible and practical reactor to conduct experimental research. If the flow rate could be maintained at a few hundred standard cubic feet per hour, bottled gas could be utilized. For this reason, the reactor itself was designed with 1/2-inch O.D tubing ( I.D.= 0.334 inches).

\subsubsection{Reactor Hydrodynamics}

Understanding the hydrodynamics of gas and solids flow in a transport reactor is critical to its design and operation. Proper identification of operational limits will ultimately define the lower flow rate (or velocity) boundary under which this gas-solid reactor can function. This lower boundary has commonly been termed choking velocity $\left(\mathrm{U}_{\mathrm{ch}}\right)$. The choking velocity herein refers to "classical choking" or operation at a gas velocity and mass flux that leads to an extremely unsteady flow condition such as slugging [29].

Pneumatic transport of solids can be classified into four categories: 1.) horizontal dilute phase flow; 2.) vertical dilute phase flow; 3.)horizontal dense phase flow; and 4.) vertical dense phase flow [30]. The boundary between dense and dilute systems is not clear. One parameter used to identify this boundary is solids/gas loading. It has been suggested that dense phase transport be defined at or above a solids/gas mass ratio of 15. As will be seen later, transport HGD absorbers (and similar FCC reactors as well) are well within the 
definition of dilute phase transport. However, operation of the regenerator is a more complex issue.

Focusing on the vertical portion of the riser in which the reactions take place, the most important consideration is choosing a velocity at which to transport the solids. Too low of a velocity will cause slug-flow and unstable operation. Too high of a velocity will lead to increased solid attrition, equipment erosion, low residence times/low conversions, and excessive gas requirements. Pressure drop is related to the velocity and is also a sensitive operating variable that is important in the design of transport reactors.

The relationship between pressure drop and velocity is illustrated in Figure 3.5. Line AB is the pressure drop-velocity relationship for a gas flowing alone through the riser. As the velocity increases, frictional resistance between the gas and riser wall builds causing an increase in pressure drop. Figure 3.5 also contains two other curves, CDE and FG, which represent gas-solid transport at two different solid mass flux rates $\left(\mathrm{G}_{1}\right.$ and $\left.\mathrm{G}_{2}\right)$. As can be seen, each curve passes through a minimum. The explanation for the shape of the curve lies in the fact that the pressure drop though the riser primarily consists of two different pressure drop terms: 1.) frictional resistance; and 2.) static solids head. For curve CDE, point C represents a high gas velocity where the frictional pressure drop term dominates. The transported mixture is very dilute in this region. As the conveying velocity is decreased, the gas and solids rise more slowly in the riser. The mixture becomes more dense and the static head 


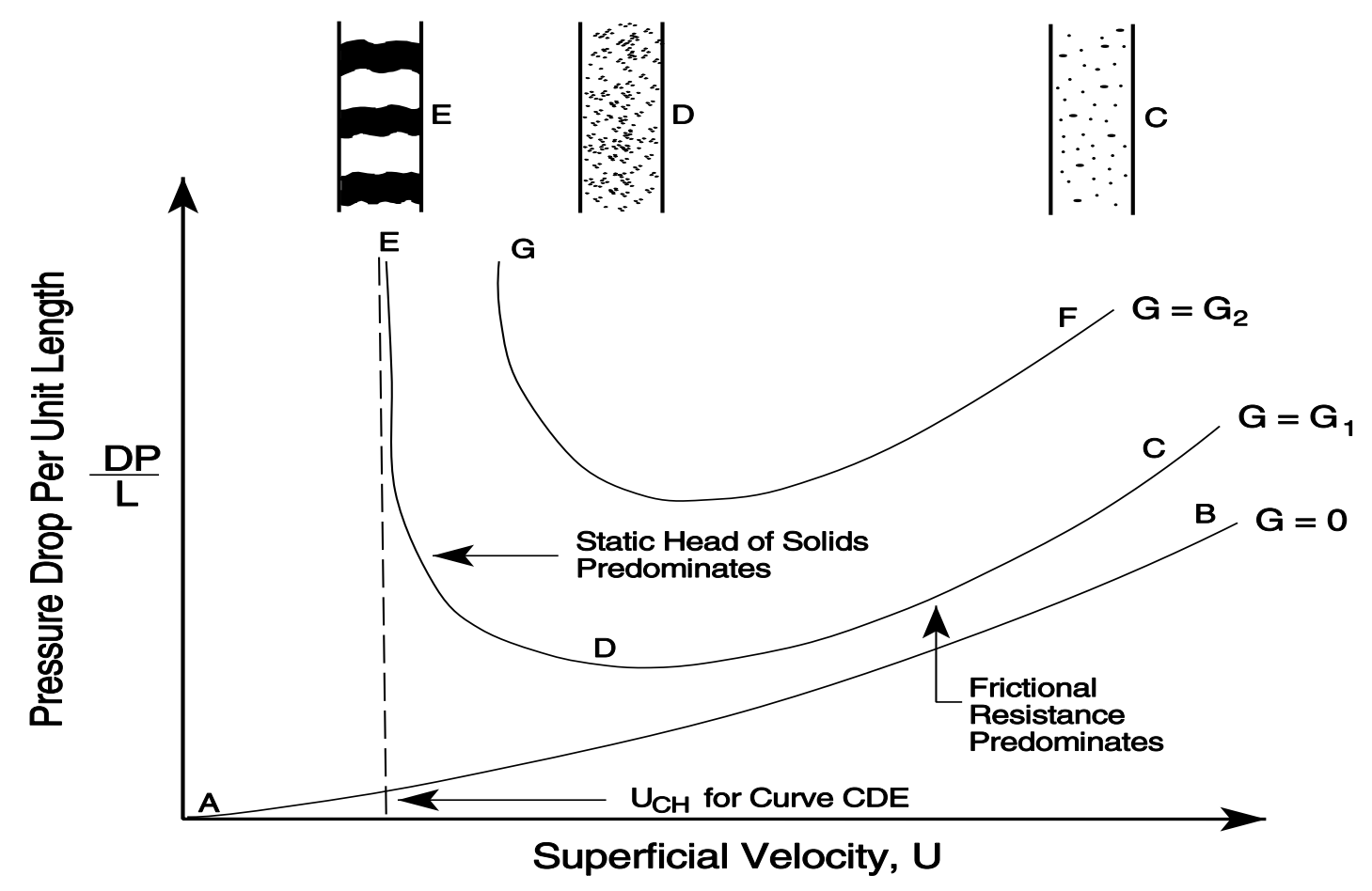

Figure 3.5 Pressure Drop Across a Dilute Pneumatic Conveying Line 
term increases. However, the frictional term still dominates; hence, as the velocity decreases, so does the pressure drop. Eventually, a point is reached with decreasing gas velocity where the frictional term and the static head term are equal (point D). Further decrease in velocity causes a sudden rise in mixture density which results in a dramatically increased pressure drop. At this point, the buoyant force of the gas can no longer support the increased static head forces and the solids collapse and choke the flow. Point E is commonly referred to as the "choking velocity" $\left(\mathrm{U}_{\mathrm{ch}}\right)$. The curve FG represents a dilute gas-solid mixture that is operated at a higher solid mass flux, G2. Therefore, feeding at a higher solid mass flux through the same size converging line or riser will increase the choking velocity. It can be seen that choking can be reached by decreasing the gas velocity at a constant solids flux or increasing the solids flux at a constant gas velocity.

What does this mean from an operational standpoint? At first it would appear that operation slightly above the choking velocity would yield the lowest pressure drop, longest residence time in the reactor, and minimum gas requirement. However, the choking region is very unstable in practice and slight upsets in system pressure could cause the reactor to choke. As this occurs, large fluctuations in pressure can cause structurally damaging vibrations in large systems. The ability of transport reactors to handle wide variations in feed gas compositions may be also be impaired if it were running so close to choking that the solid mass flux could not be increased. So, it appears that the best safe operating point for a particular system would be slightly to the right of point D. There, minimal pressure drop is incurred and the curve is flat enough that system upset tolerances and feed variation 
responses can be maximized. It is important that the most severe realistic condition be chosen for design so that maximum operational flexibility is allowed.

Pressure drop in the riser-section of the reactor was best approximated using the modified Konno-Saito correlation which has been shown to be applicable over a wide range of operating conditions. This correlation requires the assumptions that the terminal velocity is approximately the same as the slip velocity and that the gas voidage is above approximately, 0.95 .

$$
\Delta=\frac{{ }^{2} \rho}{2}+\quad+\frac{2 \rho^{2}}{\sqrt{ }}+\frac{0.057 \rho \theta}{-}+\rho
$$
(3)

(4)

(5)

Where:

$$
\begin{aligned}
& =- \\
& \text { and } \\
& \theta=\frac{}{\rho}
\end{aligned}
$$


As appearing in Equation 3.4, the contributions of the individual pressure drop terms account specifically for:

(1) pressure drop due to gas acceleration,

(2) pressure drop due to particle acceleration,

(3) pressure drop due to gas-to-pipe friction,

(4) pressure drop due to solid-to-pipe friction,

(5) pressure drop due to the static head of the solids,

(6) pressure drop due to the static head of the gas.

Choking velocities $\left(\mathrm{U}_{\mathrm{ch}}\right)$ can also be directly calculated by empirically derived equations. One of the most recent was developed by Bi and Fan [31]:

$$
\bar{l}=21.6\left(\frac{}{\rho}\right)^{0.542} 0.105
$$

where the Archimedes number (Ar) is defined as:

$$
=\rho(\rho-\rho) \frac{3}{\mu^{2}}
$$

It should be pointed out that not every gas/solid mixture will choke. It appears possible that some solids undergo a transition from dilute phase directly to a denser non-choking fluidized 
bed type of transport. Yang (1976) developed the following correlation in defining choking criteria:

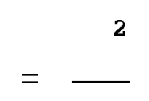

Yang observed that systems where Fr $<35$ would undergo this dilute to dense phase transport without choking.

There are other correlations, but Yang's appears to be most useful because it takes into account the particles terminal velocity and transport line diameter. Leung (1980) compared various correlations and found Yang's to be most consistent with the experimental data [30]. For the sorbent to be tested by the experimental transport riser for this thesis (ID=0.334 in.), a Fr number of 0.14 was calculated.

A spreadsheet program was developed (Appendix 10.1) that was used for predicting operating conditions for gas-solids transport systems by using correlations available in the literature. This spreadsheet was developed to use variables which could easily be altered to meet a specific transport reactor system or to perform parametric studies based on various operating scenarios. It should be mentioned at this point that "industry friendly" units were used throughout this thesis and for the spreadsheet. For example, particle size was one of the few metric units used. This is due to the wide use and standardization of that unit of measure by the catalyst industry. Similarly, within the American system, various mixed unit 
conventions (ex. feet and inches) were used as a matter of common practice and convenience.

For the spreadsheet, required user input variables include: The mass feed rate of solids, $\mathbf{M}_{\mathrm{s}}$, in $\mathrm{lb}_{\mathrm{m}} / \mathrm{hr}$; riser diameter, $\mathrm{D}$, in inches; riser length, $\mathrm{L}$, in $\mathrm{ft}$; operating temperature, $\mathrm{T}$, in ${ }^{\circ} \mathrm{F}$; operating pressure, $\mathrm{P}$, in psig; gas molecular weight, $\mathrm{MW}$, in $\mathrm{lb}_{\mathrm{m}} / \mathrm{lb}_{\mathrm{m}}-\mathrm{mol}$; gas viscosity, $\mu$, in cP; particle diameter, $\mathrm{d}_{\mathrm{p}}$, in $\mu \mathrm{m}$; particle density, $\rho_{\mathrm{s}}$, in $\mathrm{lb}_{\mathrm{m}} / \mathrm{ft}^{3}$; and inlet gas flow rate, $\mathrm{F}_{\mathrm{g}}$, in scfh.

The spreadsheet calculates several quantities based on simple, sometimes empirical, equations which have both implicit and explicit assumptions. All transport technology to date utilizes gases at sub-critical conditions. Therefore, the gas phase was assumed to behave as a perfect gas, obeying the ideal gas law and yielding an equation for gas density of the following form:

$$
\rho=-(\quad)
$$

Quantities such as superficial gas velocity, actual flow rate, and mass of gas per hour were all calculated utilizing the ideal gas law.

The mass flux was calculated by dividing the solids mass feed rate by the inside crosssectional area of the transport riser, yielding the equation: 


$$
=\frac{4}{\Pi^{2}}
$$

Since most commercial transport reactor operate in the region $\operatorname{Re}_{\mathrm{p}}<1,000$, particle terminal velocity was calculated utilizing a simplified empirical equation which was known to be valid in the region between $2<\operatorname{Re}_{\mathrm{p}}<1,000$ [32]:

$$
=\frac{0.135{ }^{1.14} 0.71(\rho-\rho)^{0.71}}{\mu^{0.43} \rho^{0.29}}
$$

Where $\operatorname{Re}_{\mathrm{p}}$ was defined as:

$$
=\frac{\rho}{\mu}
$$

As a check on the choking velocity, the well known correlation by Punwani et al. [33] for choking velocity was also employed:

$$
\frac{2\left(\varepsilon^{-4.7}-1\right)}{\left(\frac{1}{\varepsilon}-\right)^{2}}=8.7210^{-3} \rho^{0.77}
$$

Choking voidages for both the Bi-Fan and the Punwani choking velocity relationships were determined from the relationship: 


$$
\bar{\rho}=\left(\frac{}{\varepsilon}-\right)(1-\varepsilon \quad)
$$

Under typical operating conditions, an average voidage and interstitial gas velocity can then calculated based on the continuity equation:

$$
\varepsilon=1-\bar{\rho}
$$

where

the interstitial gas velocity was defined as:

$$
=\left(\bar{\varepsilon}^{-}\right)
$$

In the literature, particle slip velocity (difference between the gas and particle velocity) was usually assumed to be approximately equal to the particle terminal velocity, for lack of a better correlation [30]:

$$
=
$$

Once the gas voidage had been determined, gas residence time could be calculated by dividing the reactor length by the interstitial gas velocity:

$$
=\underline{\varepsilon}
$$


The solids residence time in the transport reactor was likewise calculated by dividing the reactor length by the solids velocity:

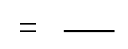

In order to define the hydrodynamic limits around which the experimental riser was designed, the analysis in Section 3.1.1 was reviewed. From examination of Table 3.1, it was seen that the $\mathrm{M}_{\mathrm{g}} / \mathrm{M}_{\mathrm{s}}$ ratio for absorption and regeneration was 24.56 and 1.25 respectively. The regenerator clearly represents the most severe hydrodynamic case since a significantly lower quantity of gas $(1.25 \mathrm{lbs})$ is stoichiometrically available (according to the case presented in section 3.1.1) to transport each pound of sorbent. For a solids flow rate of $1 \mathrm{lb} / \mathrm{hr}\left(\mathrm{G}_{\mathrm{S}}=0.46\right.$ $\mathrm{lb} / \mathrm{ft}^{2}-\mathrm{s}$ ), the predicted superficial choking velocity is $1.83 \mathrm{ft} / \mathrm{s}$. If stoichiometric air flow during regeneration is assumed, the calculated superficial gas velocity is $1.14 \mathrm{ft} / \mathrm{s}$. This is significantly lower than theoretically necessary to avoid choking. This would imply that the air flow rate be increased until the superficial gas velocity was greater that the choking velocity. By doing this however, there would not be enough zinc sulfide to react with the air and breakthrough of oxygen would appear at the outlet of the regenerator. Again, this may or may not be necessary since the Froude number proposed by Yang predicts that this particular system would not choke. This issue was beyond the scope of this thesis, but the experimental reactor that was built is well-suited to explore this area. 
For comparison sake, the absorber superficial gas velocity for the case presented in Section 3.1.1 (based on $1 \mathrm{lb} / \mathrm{hr}$ or $\mathrm{G}_{\mathrm{S}}=0.46 \mathrm{lb} / \mathrm{ft}^{2}-\mathrm{s}$ of sorbent flow) is calculated to be $19 \mathrm{ft} / \mathrm{s}$ which is approximately a factor of 10 greater than the predicted choking velocity and is more than enough to safely transport the sorbent. To better understand the relationship of some of these variables, a sensitivity analysis was preformed. Figure 3.6 examines the predicted relationship between pressure drop along the reactor and superficial gas velocities for various solid fluxes. It is from this figure that the choking velocity can be seen. Figure 3.7 illustrates the relationship between particle diameter and choking velocity for various particle densities.

From the hydrodynamic analysis done for this reaction system, the experimental reactor should be capable of independently flowing up to $10 \mathrm{lb} / \mathrm{hr}$ of sorbent and up to $300 \mathrm{scfh}$ of reactant gas. It is not known whether the reactor would choke at the noted regeneration conditions, but this experimental rig should be well suited to study that issue.

\subsubsection{Reaction Thermodynamics}

Because of the exothermic nature of zinc-based HGD systems, thermodynamic considerations are very important in reactor design and operation. As was noted earlier, sulfidation is not much of a concern because of the low $\mathrm{H}_{2} \mathrm{~S}$ reactant gas concentration and the ability of the remaining fuel gas species to absorb the evolved heat. Regeneration however, is nearly six times as exothermic per mole of sulfur reacted. Coupled with higher reactant concentrations $\left(21 \% \mathrm{O}_{2}\right)$ and lower overall gas to solid mass ratios, it is apparent 


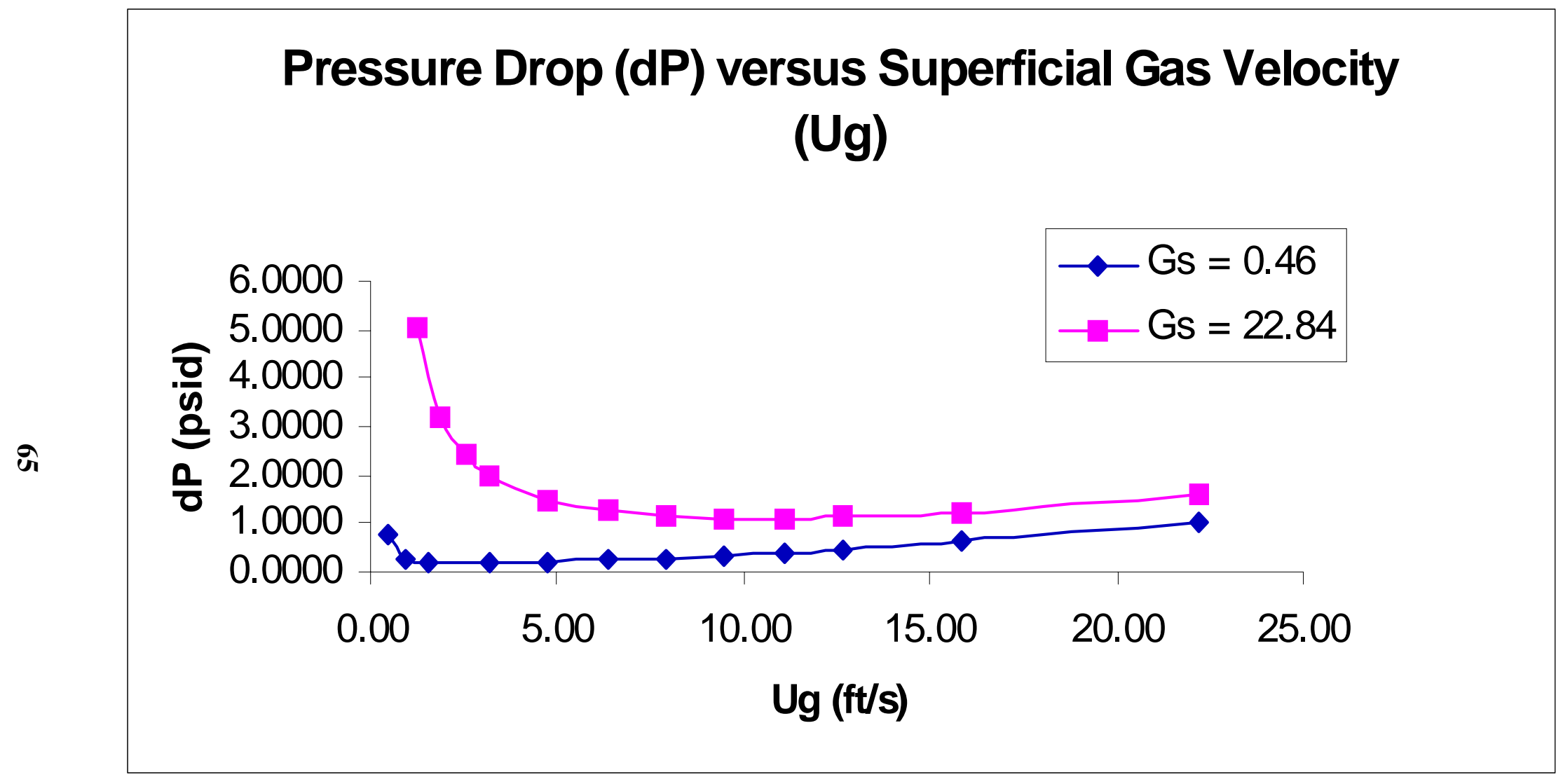

Figure 3.6 Riser Pressure Drop versus Superficial Gas Velocity 


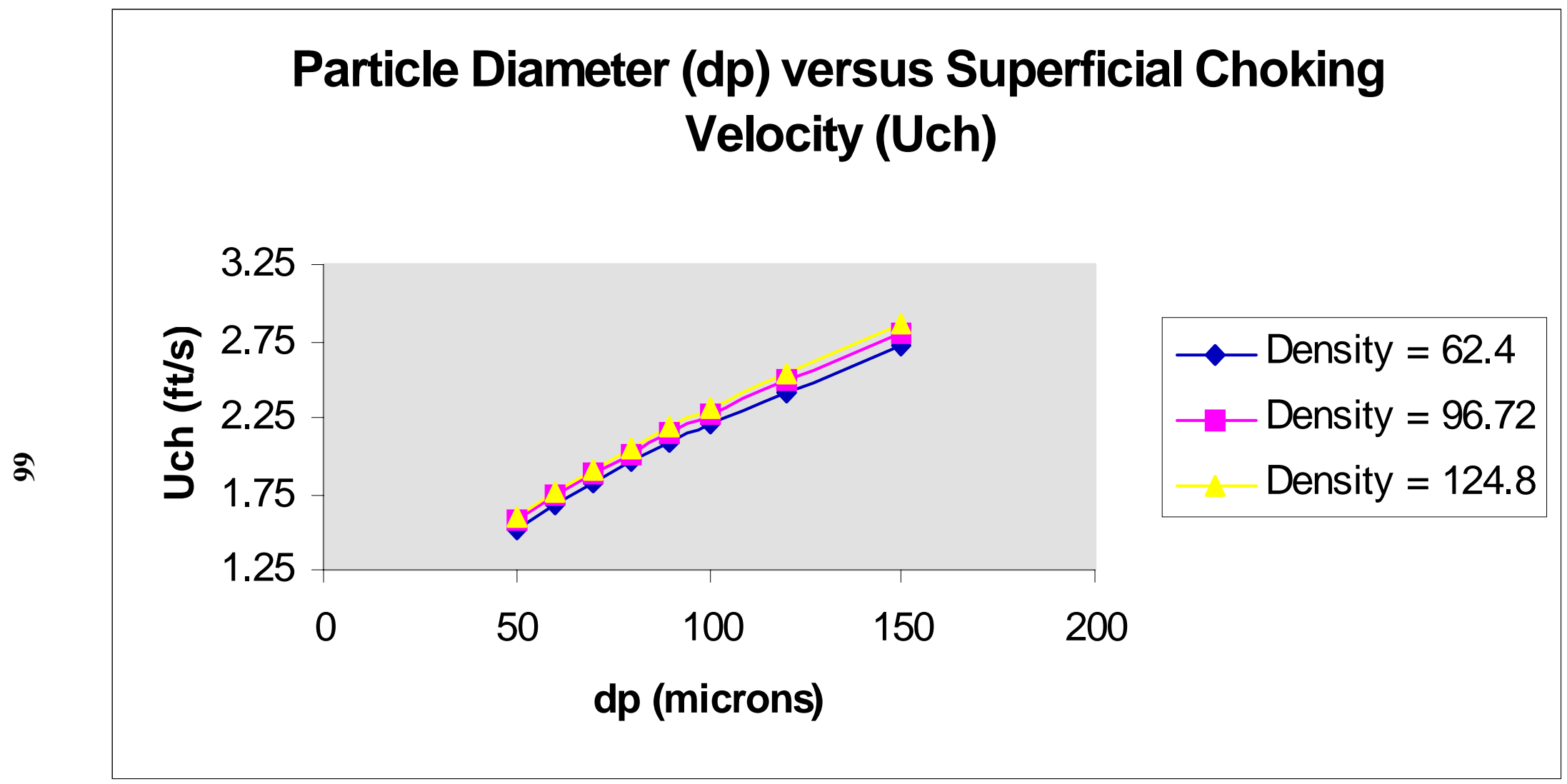

Figure 3.7 Particle Diameter versus Superficial Choking Velocity 
that temperature rise is significantly higher in the regenerator. For the sake of defining a "worse case" scenario, zero heat loss from the reactor was assumed and computer programs were written to calculate adiabatic temperature rise for both sulfidation and regeneration (see Appendix 10.2).

For the case of sulfidation as identified in Section 3.1.1, an adiabatic temperature rise to $1040{ }^{\circ} \mathrm{F}$ was calculated. The stream enthalpy is more than sufficient to absorb the heat of reaction. However, for regeneration, the calculated adiabatic temperature was $2011^{\circ} \mathrm{F}$. The is well above the $1400{ }^{\circ} \mathrm{F}$ temperature limit to avoid sintering of the sorbent. The relationship between zinc sulfide conversion and temperature rise in the regenerator can be seen in Figure 3.8. Because this case represents the stoichiometric air and sorbent mass ratio necessary for regeneration, any increase in gas flow rate to control the temperature would result in breakthrough of oxygen at the reactor outlet. However, decreasing the air flow rate to make oxygen the limiting reactant and utilizing the greater heat capacity may not be feasible because the superficial gas velocity is already below the choking velocity. Since this gas-solid reactor system falls within the "non-choking" region as defined by Yang, there may be some hope in operating this system in a more dense regime. Again, examination of this issue was beyond the scope of this thesis. 


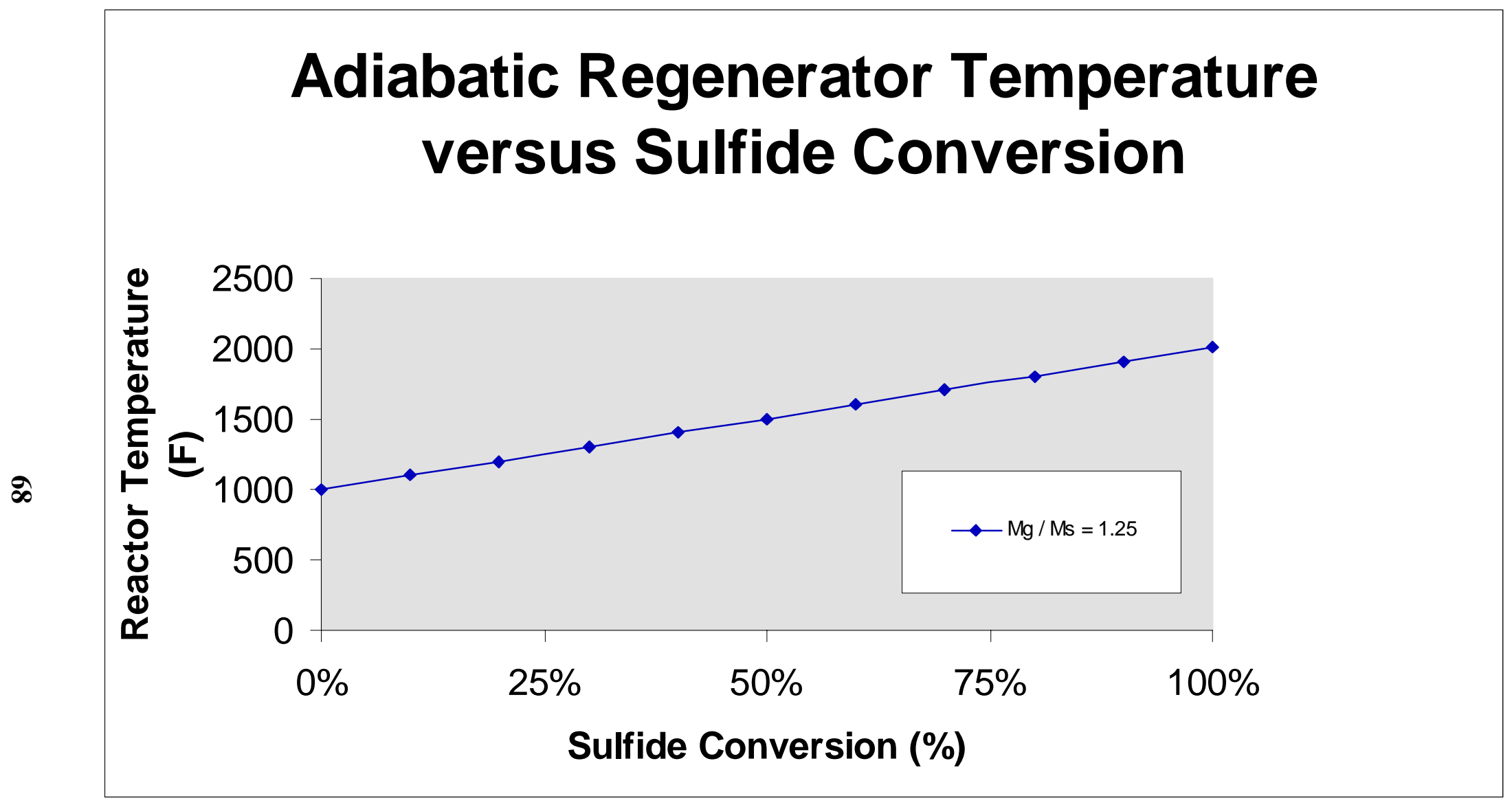

Figure 3.8 Relationship Between Sulfide Conversion and Reactor Temperature 


\subsubsection{Reaction Kinetics}

Several papers have been written on the sulfidation and regeneration kinetics of zinc-based sorbents [34], [35]. Most of these studies were conducted with a thermogravimetric analyzer on pellets or powders to obtain an "intrinsic" rate constant. The steps to reaction are however quite involved and consist of:

1.) Transport of reactant gas through the bulk fluid to the sorbent particle

2.) Diffusion of reactant through an external stagnant film to the particle surface.

3.) Diffusion of reactant through the sorbent pores.

4.) Adsorption of reactant onto pore surface.

5.) Reaction of gas and solid to form products.

6.) De-adsorption of products from the surface.

7) Diffusion of product through the sorbent pores.

8.) Diffusion of product from external surface through external stagnant film.

9.) Transport of product gas from the particle through the bulk fluid.

By proper experimental design, the intrinsic reaction rate (steps 4,5 , and 6) can be reasonably obtained. For "small" particle systems with high surface area to volume ratios, intraparticle resistance (steps 3 and 7) can be minimized or assumed small. The interphase transport (steps 2 and 8) may also be minimal for high gas velocity. However, the interparticle transport (steps 1 and 9) can be very difficult to quantify. Reactor hydrodynamics for transport systems are difficult to define and continue to be developed. 
Because of the complexity and uncertainty involved, kinetic rate information was not directly involved with the design of the experimental riser. The only reported information found in the literature was by Bissett [21] who indicated that "adequate" reaction kinetics were observed for a zinc ferrite sorbent. In principle, the reactor built for this thesis can be highly utilized to aid in development of kinetic models and significantly contribute to the literature for transport HGD.

In summarizing the process design activities undertaken in this chapter, the following key points can be stated:

- Over $98 \%$ sulfur removal is necesary to achieve < $1 / 10 \mathrm{NSPS} \mathrm{SO}_{2}$ emission limits targeted by the DOE. (For the HGD subsystem this translated into a 5600 ppmv inlet concentration and a 100 ppmv outlet for $\mathrm{H}_{2} \mathrm{~S}$ in the fuel gas.)

- Superficial gas velocities above 1 to $3 \mathrm{ft} / \mathrm{s}$ are needed to avoid calculated choking conditions for the gas-solid system evaluated in this thesis (excluding the prediction of Yang's correlation). It is desirable to operate above this point if possible to ensure hydrodynamically stable operation. A gas flowrate in the range of 200 to $300 \mathrm{scfh}(12.67$ to $19 \mathrm{ft} / \mathrm{s})$ was planned for the experimental 1/2-inch reactor built for this thesis. 
- $\quad \mathrm{A} \mathrm{M}_{\mathrm{g}} / \mathrm{M}_{\mathrm{s}}$ ratio of 24.56 was calculated for the absorber (assuming $50 \%$ utilization of the sorbent) to achieve desired outlet gas concentrations for sulfur absorption. This condition appears hydrodynamically stable and would not result in excessive temperature rise.

- $\quad \mathrm{A} \mathrm{M}_{\mathrm{g}} / \mathrm{M}_{\mathrm{s}}$ ratio of 1.25 was calculated for the regenerator (assuming complete regeneration of the sorbent) to achieve complete conversion of the $\mathrm{O}_{2}$ fed to the regenerator into $\mathrm{SO}_{2}$ in the outlet. This condition appears to be below the calculated hydrodynamically stable velocity $(1.83 \mathrm{ft} / \mathrm{s})$ needed and would result in an excessive temperature rise. On increase in gas flowrate to "cool" the reactor would result in unwanted $\mathrm{O}_{2}$ in the regenerator outlet. For an adiabatic reactor, the only other choice for operation would be to increase the solids feed rate to help "soak-up" the excess heat from reaction. This would appear to represent a more severe choking condition. However the Yang correlation $(\mathrm{Fr}<35)$ suggests that choking may not be a problem in the system defined for this thesis. This is a topic for future investigation and was beyond the scope of this thesis. 


\subsection{Results}

This chapter reviews the reactor design results based on the preceding design activities. Also, actual results from a preliminary test conducted with the experimental reactor are discussed.

\subsection{Design Results}

Based on the preceding design activities, a process flow diagram (PFD) was developed for a single-pass transport riser reactor (Figure 4.1) that was then built. In this system, reactant gases from gas cylinders flow through individual high-pressure Teledyne-Hastings mass flow controllers to supply a variety of desired gas compositions. Each of the flow controllers were ranged for 0-100 scfh to insure that required total gas flows up to $300 \mathrm{scfh}$ could be achieved. $\mathrm{H}_{2} \mathrm{~S}$ is typically mixed with a carrier gas such as hydrogen or nitrogen and introduced into the system as a binary gas mixture. This reactor also includes actual coal-gas from a near-by gasifier making it the only known HGD transport reactor in the world with this capability. The reactant gases mix and flow through a Lindberg furnace where they are preheated to inlet reactor temperatures (typically $1000^{\circ} \mathrm{F}$ for this application). All hot incoming gas lines are trace-heated with Chromolox rod heaters to maintain temperature. Sorbent is independently fed to the reactor by a Ktron loss-in-weight screw feeder contained in a nitrogen-pressurized vessel. Hot nitrogen carrier gas (Stream 11) is used to entrain and preheat the sorbent to the desired initial reaction temperature. The reactant gas and sorbent flow into a fluidized diverging nozzle to ensure uniform mixing at the bottom of the reactor. As the gas and solids react through the vertical portion of the riser, five independently 


\section{Riser-Reactor Process Flow Diagram}

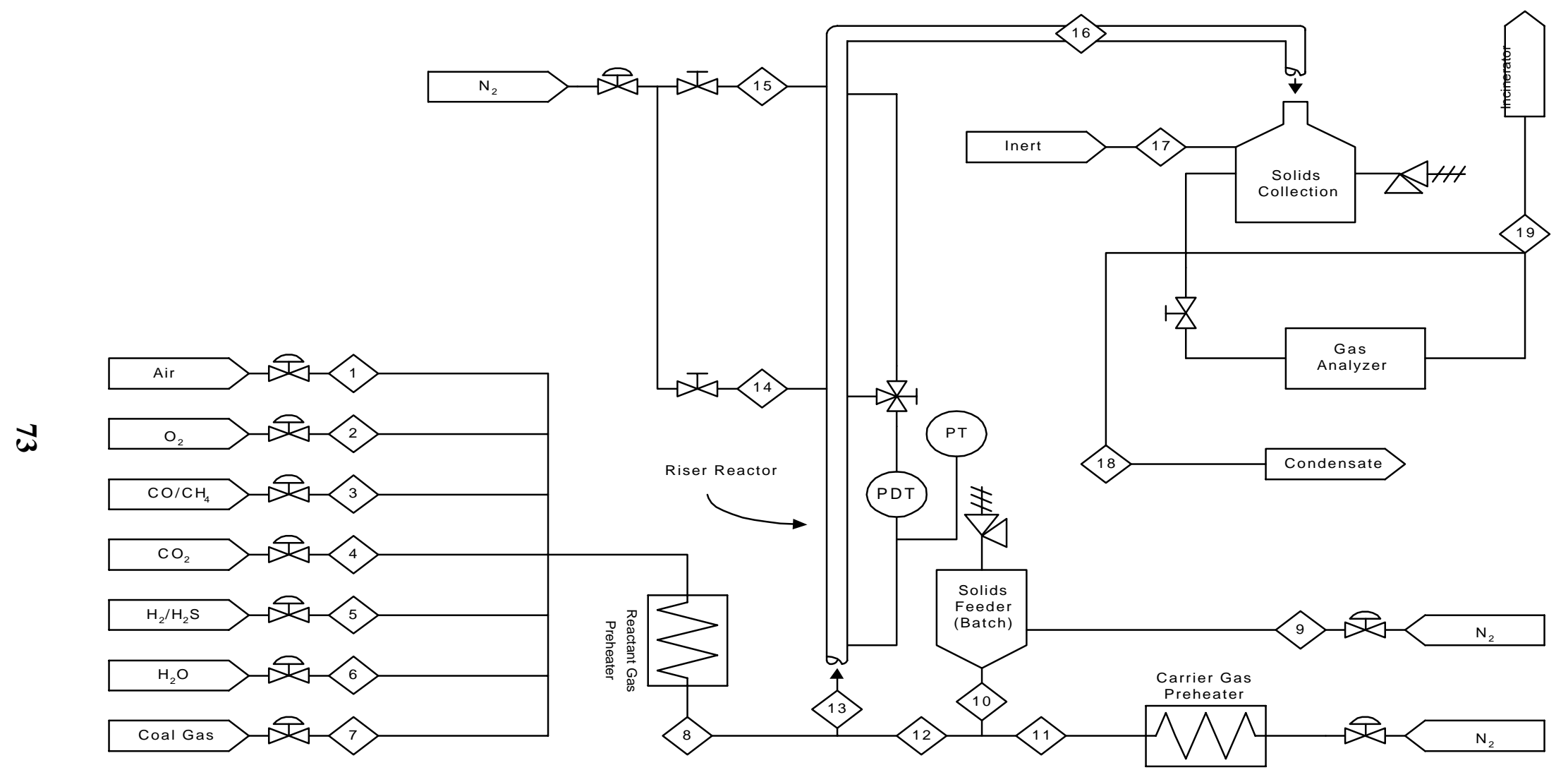


controlled zones of Thermcraft clamshell heaters maintain desired temperature profiles along the reactor. Thermocouples are placed in the middle of each zone on the outside of the tube wall to control heater outputs. Experimental process thermocouples are also located every 5 feet and inserted into the edge of the gas stream to monitor internal process temperatures. Pressure drop across the riser is measured at the mid-point and end of the reactor. Likewise, a cold nitrogen quench is located at those two points as well to study kinetic residence time effects and reactor hydrodynamics. A $90^{\circ}$ blind tee is utilized to turn the quenched gas-solid mixture and is directed to a disengaging zone where the solids are separated from the product gas. The gas is cooled to condense any water in the system (This is done to protect downstream analytical equipment). A slipstream of the conditioned gas is then sent to a Perkin-Elmer quadrapole mass spectrometer to analyze the gas species concentrations. Bottled gas-grab samples are also periodically taken as a quality control measure and analyzed with gas chromatographs. Solids analysis is routinely conducted at the end of each run to assess sulfur content, particle size, and particle size distribution.

\subsection{Test Results}

After the experimental reactor was constructed, shakedown testing of all system components was conducted. The reactor was successfully pressurized to 600 psi to check for leaks. Reactor heaters achieved $1500{ }^{\circ} \mathrm{F}$ temperatures and maximum flow rates (100 scfh) for individual gases were demonstrated. Difficulty was experienced in trying to operate the sorbent particle screw-feeder located inside the pressure vessel. As particles fell from the screws into a collection funnel, suspected bridging across the throat occurred and the sorbent 
overflowed the funnel and spilled onto the floor of the pressure vessel. The fix for the situation involved installing a pressure tap that measured the pressure drop between the feeder vessel and the inlet of the riser. It was found that if a positive nitrogen pressurization flow of $20 \mathrm{scfh}$ and a 2 psi pressure differential were maintained, the sorbent could be successfully fed through the internal funnel and out the feeder vessel. Solid feedrates up to $20 \mathrm{lb} / \mathrm{hr}$ were successfully tested, thus exceeding the desired $10 \mathrm{lb} / \mathrm{hr}$ design value. All process variables were independently controlled via a local controller and through remote setpoint via a central commercial process control program called Paragon TNT. Data acquisition was also accomplished by Paragon. All instrumentation, control, and analytical equipment functioned as designed.

During the course of this thesis, an opportunity to obtain real coal-gas from an adjacent fluid-bed gasifier became available. A cooperative research and development agreement (CRADA) was developed between the candidate and an industrial catalyst company, Intercat, to test their experimental HGD sorbent. Below are the operating conditions for the sulfidation test:

Inlet Temperature: $1000{ }^{\circ} \mathrm{F}$

Pressure: 300 psi

Average Gas Composition: $22 \% \mathrm{CO}, 6 \% \mathrm{CO}_{2}, 16 \% \mathrm{H}_{2}, 12 \% \mathrm{H}_{2} \mathrm{O}, 1 \% \mathrm{CH}_{4}$, $42.9 \% \mathrm{~N}_{2}$, and $0.1 \% \mathrm{H}_{2} \mathrm{~S}$

Flow Rate: Coal Gas $=200 \mathrm{scfh}$, Sorbent $=0.1-1 \mathrm{lb} / \mathrm{hr}$ 
Due to the limited time to access coal-gas, the riser was run in a very dilute manner (gas voidage $=0.9996)$ to minimize the chance of plugging the reactor. Even at this very dilute condition, the reactor and sorbent were routinely able to reduce the $\mathrm{H}_{2} \mathrm{~S}$ concentration from an average of 1500 ppmv ( $0.15 \%$ volume) to below 250 ppmv. This is more than enough to meet NSPS requirements. It was felt that increasing the mass ratio of solids to gas would have easily achieved the $1 / 10$ NSPS DOE targets. Figure 4.2 is a graph of $\mathrm{H}_{2} \mathrm{~S}$ concentration versus time from one of the transport desulfurization runs. The solid line was a plot of the outlet $\mathrm{H}_{2} \mathrm{~S}$ concentration as measured by the mass spectrometer. It can be seen that before the sorbent flow was initiated, the outlet concentration was approximately 1000 ppmv. As sorbent flowrate was initiated and increased to $1 \mathrm{lb} / \mathrm{hr}, \mathrm{H}_{2} \mathrm{~S}$ concentration dropped below 300 ppmv. This condition was maintained throughout the test until the solids feed was gradually reduced to zero. Gas grab samples that were analyzed by a gas chromatagraph were also taken on the inlet and outlet to verify concentrations. This was determined to be a very successful test and is a strong indication that HGD utilizing a transport reactor is achievable. To date, this is the only known test of a transport HGD reactor on actual coal-gas in the world. 


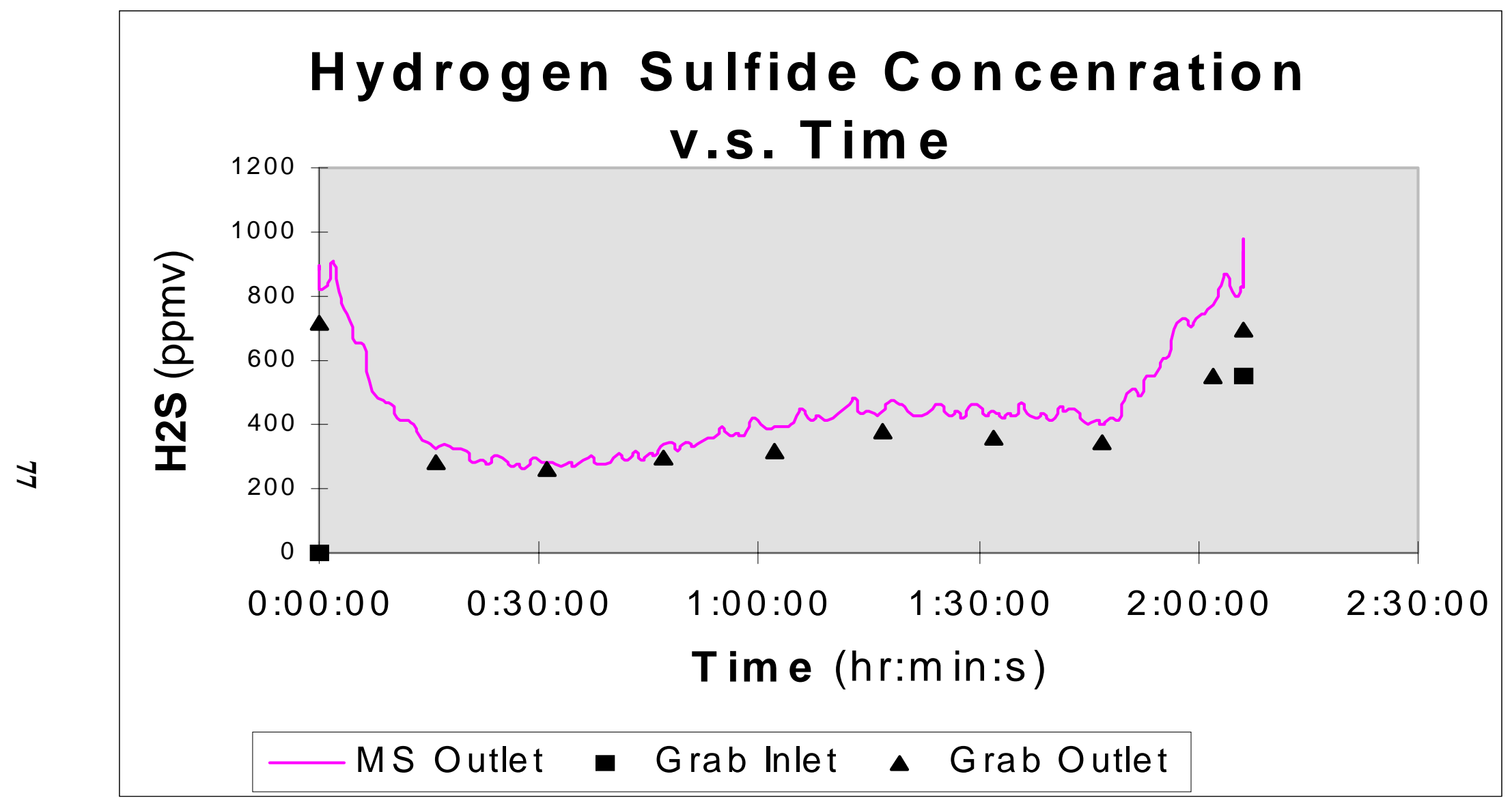

Figure 4.2 Transport HGD Performance Curve on Real Coal-gas 


\subsection{Conclusions}

From the successful design, construction, and test activities undertaken during the course of this thesis, it appears that the use of a transport reactor for hot gas desulfurization is feasible. The analysis of IGCC desulfurization requirements, along with the process design results indicate that transport reactor technology is viable. The experimental reactor constructed for this thesis met all design requirements, underwent successful shakedown, and successfully conducted the only known transport desulfurization in the world. This is a strong indication that this is an achievable technology option for HGD. However, nothing conclusive can be said concerning regeneration due to a lack of understanding and data regarding solids transport at gas flow rates under the choking velocity. The experimental reactor has the capability to address this issue in the future and add to the existing literature and body of knowledge. 


\subsection{Recommendations}

There are several recommendations that can be made as a result of this thesis:

1.) Regeneration needs to carefully examined. The excess stoichiometric air flow theoretically needed to hydrodynamically transport the sorbent would result in unwanted excess oxygen in the product off-gas. This would dilute the $\mathrm{SO}_{2}$ in that stream, making downstream sulfur recovery more difficult and costly. Yang's correlation (Section 3.2.2) suggests that choking would not be encountered within the operating conditions of this type of system. Thus, a higher fraction of solids may be utilized to absorb the heat generated by reaction. Operation under these conditions can easily be performed by this apparatus and the predictions confirmed.

2.) Additional sulfidation and regeneration tests need to be conducted to better define and understand the practical operating limits of transport reactors including load-following characteristics. Testing is also necessary to provide performance requirements and development direction to catalyst manufacturers that would be providing sorbent for this of process. The experimental reactor built for this thesis is well suited for this purpose.

3.) A series of statistically designed tests on various size transport reactors is needed to obtain accurate hydrodynamic and kinetic expressions that can be used to develop accurate transport reactor performance models. This apparatus can aid in developing that data. 


\subsection{ABBREVIATIONS}

$\begin{array}{ll}\text { BACT } & \text { Best Available Control Technology } \\ \text { CAA } & \text { Clean Air Act } \\ \text { CAAA } & \text { Clean Air Act Amendment } \\ \text { DOE } & \text { Department of Energy } \\ \text { DSRP } & \text { Direct Sulfur Recovery Process } \\ \text { EPA } & \text { Environmental Protection Agency } \\ \text { FCC } & \text { Fluid Catalytic Cracking } \\ \text { FETC } & \text { Federal Energy Technology Center } \\ \text { HGD } & \text { Hot Gas Desulfurization } \\ \text { IGCC } & \text { Integrated Gasification Combined Cycle } \\ \text { LAER } & \text { Lowest Achievable Emission Rate } \\ \text { NAAQS } & \text { National Ambient Air Quality Standard } \\ \text { NSPS } & \text { New Source Performance Standards } \\ \text { PC } & \text { Pulverized Coal } \\ \text { PSD } & \text { Prevention of Significant Deteriorization } \\ \text { RTI } & \text { Research Triangle Institute } \\ \text { SIP } & \text { State Implementation Plan }\end{array}$




\subsection{NOMENCLATURE}

\begin{tabular}{|c|c|}
\hline $\mathrm{Ar}$ & Archimedes Number \\
\hline D & Vessel inside diameter, inches \\
\hline$d_{p}$ & Particle diameter, $\mu \mathrm{m}$ \\
\hline $\mathrm{F}_{\mathrm{g}}$ & Gas flow rate, scfh \\
\hline$f_{g}^{\circ}$ & Gas-Wall Friction Factor \\
\hline $\mathrm{F}_{\mathrm{R}}$ & Froude Number \\
\hline g & Gravitational constant, $9.81 \mathrm{~m} / \mathrm{s}^{2}$ \\
\hline $\mathrm{G}_{\mathrm{RT}}$ & Gas residence time, $\mathrm{s}$ \\
\hline $\mathrm{G}_{\mathrm{s}}$ & Mass flux, $\mathrm{lb}_{\mathrm{m}} /(\mathrm{ft} \bullet \mathrm{s})$ \\
\hline $\mathrm{L}$ & Vessel height, ft \\
\hline MW & Molecular weight, $\mathrm{lb}_{\mathrm{m}} / \mathrm{lb}_{\mathrm{m}}-\mathrm{mol}$ \\
\hline$M_{g}$ & Mass flow rate of gas, $\mathrm{lb}_{\mathrm{m}} / \mathrm{hr}$ \\
\hline$M_{s}$ & Mass flow rate of solids, $\mathrm{lb}_{\mathrm{m}} / \mathrm{hr}$ \\
\hline$\Delta \mathrm{P}_{\mathrm{R}}$ & Pressure Drop Through Riser, psig \\
\hline $\mathrm{P}$ & Pressure, psig \\
\hline $\mathrm{R}$ & Ideal gas constant, $10.73 \mathrm{psia} \bullet \mathrm{ft}^{3} / \mathrm{lb}_{\mathrm{m}} \bullet^{\circ} \mathrm{R}$ \\
\hline$S_{R T}$ & Solids residence time, $\mathrm{s}$ \\
\hline $\mathrm{T}$ & System temperature, ${ }^{\circ} \mathrm{F}$ \\
\hline $\mathrm{U}$ & Superficial gas velocity, $\mathrm{ft} / \mathrm{s}$ \\
\hline $\mathrm{U}_{\mathrm{ch}}$ & Choking gas velocity, ft/s \\
\hline $\mathrm{U} / \epsilon$ & Interstitial gas velocity, $\mathrm{ft} / \mathrm{s}$ \\
\hline $\mathrm{v}_{\mathrm{s}}$ & Particle velocity, $\mathrm{ft} / \mathrm{s}$ \\
\hline$v_{t}$ & Particle terminal velocity, ft/s \\
\hline $\mathrm{V}_{\mathrm{g}}$ & Interstitial Gas Velocity, $\mathrm{ft} / \mathrm{s}$ \\
\hline$\theta$ & Loading Factor \\
\hline$\rho_{\mathrm{g}}$ & Gas density, $\mathrm{lb}_{\mathrm{m}} / \mathrm{ft}^{3}$ \\
\hline $\begin{array}{l}\rho_{\mathrm{s}} \\
\mu\end{array}$ & Particle density, $1 b_{\mathrm{m}} / \mathrm{ft}^{3}$ \\
\hline$\varepsilon$ & $\begin{array}{l}\text { Gas viscosity, cP } \\
\text { Gas-phase yoid fraction }\end{array}$ \\
\hline$\varepsilon_{\mathrm{ch}}$ & Gas-phase void fraction at choking con \\
\hline
\end{tabular}




\subsection{LITERATURE CITED}

1. Energy Information Administration, “Annual Energy Outlook 1994", Office of Integrated Analysis and Forecasting, DOE/EIA-0383(96), January 1994

2. Morgantown Energy Technology Center, "Clean Coal Technologies - Research, Development, and Demonstration Program”, US Department of Energy, Morgantown Energy Technology Center, Morgantown WV, 1994.

3. U.S. Department of Energy, "National Energy Strategy", Office of Scientific and Technical Information, Oak Ridge TN, First Edition 1991/1992.

4. Schorr, M.M., “A 1992 Update on Legislation and Regulation Affecting Power Generation”, TMI Handbook, 1992, p. 59.

5. Berstein, M., et al, "The Environment and Economics", Energy Policy, 1994, p. 748.

6. U.S. Energy Information Administration, “Acid Rain compliance Strategies for the CAAA of 1990", March 1994, p. 11.

7. U.S. Energy Information Administration, “Acid Rain compliance Strategies for the CAAA of 1990", March 1994, p. 12.

8. Baily, K.A., et al, "Allowance Trading: Market Operations and Regulatory Response", Argonne National Lab, September 1992.

9. U.S. Department of Energy, "Clean Coal Technologies Research, Development, and Demonstration - Program Plan”, DOE/FE-0284, November 1993.

10. Synthetic Fuels Associates, "Coal Gasification Systems: A Guide To Status, Applications, And Economics", Electric Power Research Institute (EPRI), EPRI AP-3109, 1993

11. Morgantown Energy Technology Center, "IGCC Integrated Gasification Combined Cycle", U.S. Department of Energy, Morgantown Energy Technology Center, Morgantown WV, 1994.

12. Notestein, J.E., "Commercial Gasifier for IGCC Applications Study Report”, U.S. Department of Energy, Morgantown Energy Technology Center, DOE/METC91/6118, June 1990. 
13. Cicero, D.C., et al, "Hot-Gas Cleanup for Coal-Based Gas Turbines", p. 70-75, Mechanical Engineer, September 1994.

14 Rutkowski, M.D., et al, "Sensitivity Effects of Fluidized Bed Hot Gas Desulfurization on IGCC Cost of Electricity", Final Report - Task 9, DOE/METC Contract Number DE AC01-88FE61660, April 1992.

15 Gupta, R.H., et al, “A Process for the Direct Recovery of Sulfur”, Proceedings of the Advanced Coal-Fired Power Systems Review Meeting”, July 1996.

16 Harrison, D.P., "Control of Gaseous Contaminants in IGCC Processes - An Overview", p. 1047-1052, Proceedings of the 12th Annual Pittsburgh Coal Conference, ed. S.H. Chiang, 1995.

17 Siriwardane, R, V, and Woodruff, S., "FTIR Characterization of the Interaction of Oxygen with Zinc Sulfide”, pg. 699-702, I\&EC Research, Vol. 34, No. 2, 1995.

18 Bissett, L.A., and L.D. Strickland, "Aspects of Fixed-Bed Gasification/Fixed-Bed Zinc Ferrite Integration", p. 55-62, Proceedings of the Ninth Annual Gasification and Gas Stream Cleanup Systems Contractors Review Meeting, eds. R.A. Johnson, and T.P. Dorchak, DOE/METC -89/6107, Vol. 1, NTIS/DE890011706 1989.

19. Sugitani, T., et al, "Fundamental Studies of Present Status of IHI Hot Gas Desulfurization Process." p. 915-919, 1987 International Conference on Coal Science, ed. J. a. Moulijn, Elsevier Science, 1987.

20. Bureau, A.C., and M.J.F. Olden, "The Operation of the Frodingham Desulphurising Plant at Exeter.", The Chemical Engineer, p. 55-62, 1967.

21. Bissett, L.A., "Zinc Ferrite Regeneration Studies in an Entrained Reactor", p. 165-179, Proceedings of the Tenth Annual Gasification and Gas Stream Cleanup Systems Contractors Review Meeting, eds. V.P. Kothari and J.L. Beeson, DOE/METC -90/6115, Vol. 2, August 1990.

22. Avidan, A.A., Owen, Hartley, "Innovative Improvements Highlight FCC's Past and Present Future", p. 23-58, Oil and Gas Journal, January 8, 1990.

23. Rutkowski, M.D., H.T. Chen, and M.G. Klett, "Sensitivity Analysis of Hot-Gas Desulfurization on IGCC Cost of Electricity". Proceedings of the 12 Annual Gasification and Gas Stream Cleanup Systems Contractors Review Meeting, pp 
263-279, DOE/METC-92/6128. Vol. 1, NTIS/DE93000228. Springfield, VA: National Technical Information Service. September 1992.

24. Bissett, L. A., J.M. Rockey, and S.C. Walczak, "Preliminary Conceptualization of METC's Fluid-Bed Hot-Gas Desulfurization PDU". Proceedings of the Eleventh Annual Gasification and Gas Stream Cleanup Systems Contractors Review Meeting, pp 556-565, DOE/METC-916123, Vol. 2. NTIS/DE92001102. Springfield, VA.: National Technical Information Service. August 1991.

25. Bissett, L. A., "Fluid-Bed Hot-Gas Desulfurization PDU". Proceedings of the Coal-Fired Power Systems 93 -- Advances in IGCC and PFBC Review Meeting, pp 302-306, DOE/METC-6131, NTIS/DE93000289. Springfield, VA.: National Technical Information Service. June 1993.

26. Bissett, L. A., "METC Fluid-Bed Hot-Gas Desulfurization PDU". Proceedings of the Coal-Fired Power Systems 93 -- Advances in IGCC and PFBC Review Meeting, pp 256-262, Vol. 2, DOE/METC-94/1008, NTIS/DE94012252. Springfield, VA.: National Technical Information Service. June 1994.

27. Moorehead, E.L., Henningsen, G.B., "Hot Gas Desulfurization Using Transport Reactors", Proceedings of the Advanced Coal-Fired Power Systems Review Meeting", July 1996.

28. Simbeck,D.R. et al, "Coal Gasification Systems: A Guide to Status, Applications, and Economics”, p. 2-46, Electric Power Research Institute, EPRI Final Report \#AP-3109, June 1983

29. Bi, H.T., Grace, J.R., \& Zhu, J-X, "Types of Choking in Vertical Pneumatic Systems", pp 1077-1092, International Journal of Multiphase Flow, vol. 19, Pergamon 1993.

30. Knowlton, T. M. "Solids Transfer in Fluidized Systems," Gas Fluidization Technology. Geldart Editor. John Wiley and Sons. p. 345 (1986).

31. Bi, H. T., and Fan, L. S. "Regime Transactions in Gas-Solids Circulating Fluidized Beds." 1991 AIChE Annual Meeting, Los Angeles, CA, paper 101e.

32. Coal Conversion Systems Technical Data Handbook, Contract No. AC0181FE05157, Report No. DOE/FE/05157-2, August 1982.

33. Punwani, D. V., Modi, M. V., and Tarman, P. B. 1976 International Bulk Solids Handling and Processing Conference, Chicago, IL. 
34. Flytzani-Stephanopoulos, M., Gavalas, G. R., Jothimurugesan, K., Lew, S., Sharma, P.K., Basajewicz, M.J., and Patrick, V. "Detailed Studies of Novel Regenerable Sorbents for High-Temperature Coal Gas Desulfurization," U.S. Department of Energy Final Report No. DE-DC21-85MC22193, October 1987.

35. Harrison, D.P., "Control of Gaseous Contaminants in IGCC Processes - An Overview", p. 1047-1052, Proceedings of the 12th Annual Pittsburgh Coal Conference, ed. S.H. Chiang, 1995. 
APPENDIX 10.1

Excel Spreadsheat for Hydrodynamic Calculations 
SYSTEM VARIABLES-INPUT

\begin{tabular}{|c|c|c|c|c|c|c|c|c|c|}
\hline CASE \# & $\begin{array}{l}\text { MASS SOLID } \\
M_{s}\left(L_{m} / H R\right)\end{array}$ & $\begin{array}{l}\text { RISER DIA } \\
\text { I.D. (IN) }\end{array}$ & $\begin{array}{c}\text { RISER LENGTH } \\
\text { L (FT) }\end{array}$ & $\begin{array}{l}\text { TEMP } \\
\mathrm{T}\left({ }^{\circ} \mathrm{F}\right)\end{array}$ & $\begin{array}{l}\text { PRESS } \\
\text { P (PSIG) }\end{array}$ & $\begin{array}{c}\text { GAS M.W. } \\
\left.\text { MW (LB }{ }_{m} / L B_{m}-M O L\right)\end{array}$ & $\begin{array}{c}\text { GAS VISCOSITY } \\
u(\mathrm{cP})\end{array}$ & $\begin{array}{l}\text { GAS DENSITY } \\
p_{\mathrm{g}}\left(\mathrm{LB}_{\mathrm{m}} / \mathrm{FT}^{3}\right)\end{array}$ & $\begin{array}{c}\text { PARTICLE DIA } \\
\mathrm{d}_{\mathrm{p}}(u \mathrm{~m})\end{array}$ \\
\hline 1 & 1 & 0.334 & 28 & 1000 & 300 & 24.32 & 3.17E-02 & 0.489 & 80 \\
\hline 2 & 2 & 0.334 & 28 & 1000 & 300 & 24.32 & 3.17E-02 & 0.489 & 80 \\
\hline 3 & 3 & 0.334 & 28 & 1000 & 300 & 24.32 & 3.17E-02 & 0.489 & 80 \\
\hline 4 & 4 & 0.334 & 28 & 1000 & 300 & 24.32 & 3.17E-02 & 0.489 & 80 \\
\hline 5 & 5 & 0.334 & 28 & 1000 & 300 & 24.32 & 3.17E-02 & 0.489 & 80 \\
\hline 6 & 6 & 0.334 & 28 & 1000 & 300 & 24.32 & 3.17E-02 & 0.489 & 80 \\
\hline 7 & 7 & 0.334 & 28 & 1000 & 300 & 24.32 & 3.17E-02 & 0.489 & 80 \\
\hline 8 & 8 & 0.334 & 28 & 1000 & 300 & 24.32 & 3.17E-02 & 0.489 & 80 \\
\hline 9 & 9 & 0.334 & 28 & 1000 & 300 & 24.32 & 3.17E-02 & 0.489 & 80 \\
\hline 10 & 10 & 0.334 & 28 & 1000 & 300 & 24.32 & 3.17E-02 & 0.489 & 80 \\
\hline 11 & 10 & 0.334 & 28 & 1000 & 300 & 24.32 & 3.17E-02 & 0.489 & 80 \\
\hline 12 & 10 & 0.334 & 28 & 1000 & 300 & 24.32 & 3.17E-02 & 0.489 & 80 \\
\hline 13 & 10 & 0.334 & 28 & 1000 & 300 & 24.32 & 3.17E-02 & 0.489 & 80 \\
\hline 14 & 10 & 0.334 & 28 & 1000 & 300 & 24.32 & 3.17E-02 & 0.489 & 80 \\
\hline 15 & 10 & 0.334 & 28 & 1000 & 300 & 24.32 & 3.17E-02 & 0.489 & 80 \\
\hline 16 & 10 & 0.334 & 28 & 1000 & 300 & 24.32 & 3.17E-02 & 0.489 & 80 \\
\hline 17 & 10 & 0.334 & 28 & 1000 & 300 & 24.32 & 3.17E-02 & 0.489 & 80 \\
\hline 18 & 10 & 0.334 & 28 & 1000 & 300 & 24.32 & 3.17E-02 & 0.489 & 80 \\
\hline 19 & 10 & 0.334 & 28 & 1000 & 300 & 24.32 & 3.17E-02 & 0.489 & 80 \\
\hline 20 & 10 & 0.334 & 28 & 1000 & 300 & 24.32 & 3.17E-02 & 0.489 & 80 \\
\hline 21 & 10 & 0.334 & 28 & 1000 & 300 & 24.32 & 3.17E-02 & 0.489 & 80 \\
\hline 22 & 10 & 0.334 & 28 & 1000 & 300 & 24.32 & 3.17E-02 & 0.489 & 80 \\
\hline 23 & 10 & 0.334 & 28 & 1000 & 300 & 24.32 & 3.17E-02 & 0.489 & 80 \\
\hline 24 & 10 & 0.334 & 28 & 1000 & 300 & 24.32 & 3.17E-02 & 0.489 & 80 \\
\hline 25 & 10 & 0.334 & 28 & 1000 & 300 & 24.32 & 3.17E-02 & 0.489 & 80 \\
\hline
\end{tabular}




\section{CALCULATED VARIABLES-THEORETICAL}

\begin{tabular}{|c|c|c|c|c|c|c|}
\hline CASE \# & $\begin{array}{l}\text { PARTICLE DEN } \\
p_{\mathrm{s}}\left(\mathrm{LB}_{\mathrm{m}} / \mathrm{FT}^{3}\right)\end{array}$ & $\begin{array}{c}\text { MASS FLUX } \\
\mathrm{G}_{\mathbf{s}}\left(\mathrm{LB}_{\mathrm{m}} / \mathrm{FT}^{2}-\mathrm{S}\right)\end{array}$ & $\begin{array}{l}\text { TERM VEL } \\
V_{t}(F T / S)\end{array}$ & $\begin{array}{c}\text { CHOKING VEL (BI-FAN) } \\
\mathrm{U}_{\mathrm{ch}}(\mathrm{FT} / \mathrm{S})\end{array}$ & $\begin{array}{l}\text { CHOKING FLOW RATE (BI-FAN) } \\
\qquad F_{c h}(\mathrm{SCFH})\end{array}$ & $\begin{array}{c}\text { CHOKING VEL (PUNWANI) } \\
\mathrm{U}_{\mathrm{ch}}(\mathrm{FT} / \mathrm{S})\end{array}$ \\
\hline 1 & 62.4 & 0.46 & 0.34 & 1.95 & 31 & 2.39 \\
\hline 2 & 62.4 & 0.91 & 0.34 & 2.49 & 39 & 2.39 \\
\hline 3 & 62.4 & 1.37 & 0.34 & 2.88 & 45 & 2.39 \\
\hline 4 & 62.4 & 1.83 & 0.34 & 3.18 & 50 & 2.39 \\
\hline 5 & 62.4 & 2.28 & 0.34 & 3.44 & 54 & 2.39 \\
\hline 6 & 62.4 & 2.74 & 0.34 & 3.67 & 58 & 2.39 \\
\hline 7 & 62.4 & 3.20 & 0.34 & 3.87 & 61 & 2.39 \\
\hline 8 & 62.4 & 3.65 & 0.34 & 4.06 & 64 & 2.39 \\
\hline 9 & 62.4 & 4.11 & 0.34 & 4.23 & 67 & 2.39 \\
\hline 10 & 62.4 & 4.57 & 0.34 & 4.39 & 69 & 2.39 \\
\hline 11 & 62.4 & 4.57 & 0.34 & 4.39 & 69 & 2.39 \\
\hline 12 & 62.4 & 4.57 & 0.34 & 4.39 & 69 & 2.39 \\
\hline 13 & 62.4 & 4.57 & 0.34 & 4.39 & 69 & 2.39 \\
\hline 14 & 62.4 & 4.57 & 0.34 & 4.39 & 69 & 2.39 \\
\hline 15 & 62.4 & 4.57 & 0.34 & 4.39 & 69 & 2.39 \\
\hline 16 & 62.4 & 4.57 & 0.34 & 4.39 & 69 & 2.39 \\
\hline 17 & 62.4 & 4.57 & 0.34 & 4.39 & 69 & 2.39 \\
\hline 18 & 62.4 & 4.57 & 0.34 & 4.39 & 69 & 2.39 \\
\hline 19 & 62.4 & 4.57 & 0.34 & 4.39 & 69 & 2.39 \\
\hline 20 & 62.4 & 4.57 & 0.34 & 4.39 & 69 & 2.39 \\
\hline 21 & 62.4 & 4.57 & 0.34 & 4.39 & 69 & 2.39 \\
\hline 22 & 62.4 & 4.57 & 0.34 & 4.39 & 69 & 2.39 \\
\hline 23 & 62.4 & 4.57 & 0.34 & 4.39 & 69 & 2.39 \\
\hline 24 & 62.4 & 4.57 & 0.34 & 4.39 & 69 & 2.39 \\
\hline 25 & 62.4 & 4.57 & 0.34 & 4.39 & 69 & 2.39 \\
\hline
\end{tabular}


CALCULATED VARIABLES-THEORETICAL

\begin{tabular}{|c|c|c|c|c|c|c|c|}
\hline CASE \# & $\begin{array}{l}\text { CHOKING FLOW RATE (PUNWANI) } \\
\qquad F_{\mathrm{ch}}(\mathrm{SCFH})\end{array}$ & $\begin{array}{c}\text { INTERSTITIAL VEL } \\
\mathbf{V}_{\mathrm{g}}(\mathrm{FT} / \mathrm{S})\end{array}$ & $\begin{array}{l}\text { GUESSED } \\
\text { VOIDAGE }\end{array}$ & $\begin{array}{l}\text { CHOKING VOIDAGE } \\
E_{\mathrm{ch}}(\%)\end{array}$ & $\begin{array}{l}\text { GUESSED } \\
\text { VOIDAGE }\end{array}$ & $\begin{array}{c}\text { GAS VOIDAGE } \\
\text { E (\%) }\end{array}$ & $\begin{array}{l}\text { SUP GAS VEL } \\
\text { U (FT/S) }\end{array}$ \\
\hline$\overline{1}$ & 38 & 1.27 & 0.9969 & 0.9955 & 0.9997 & 0.9942 & 1.27 \\
\hline 2 & 38 & 12.68 & 0.9891 & 0.9933 & 0.9560 & 0.9989 & 12.67 \\
\hline 3 & 38 & 12.69 & 0.9891 & 0.9914 & 0.9560 & 0.9983 & 12.67 \\
\hline 4 & 38 & 12.70 & 0.9891 & 0.9898 & 0.9560 & 0.9978 & 12.67 \\
\hline 5 & 38 & 12.70 & 0.9891 & 0.9883 & 0.9560 & 0.9972 & 12.67 \\
\hline 6 & 38 & 12.71 & 0.9891 & 0.9869 & 0.9560 & 0.9967 & 12.67 \\
\hline 7 & 38 & 12.72 & 0.9891 & 0.9857 & 0.9560 & 0.9961 & 12.67 \\
\hline 8 & 38 & 12.72 & 0.9891 & 0.9844 & 0.9560 & 0.9956 & 12.67 \\
\hline 9 & 38 & 12.73 & 0.9891 & 0.9832 & 0.9560 & 0.9950 & 12.67 \\
\hline 10 & 38 & 12.74 & 0.9891 & 0.9821 & 0.9560 & 0.9945 & 12.67 \\
\hline 11 & 38 & 12.74 & 0.9891 & 0.9821 & 0.9560 & 0.9945 & 12.67 \\
\hline 12 & 38 & 12.74 & 0.9891 & 0.9821 & 0.9560 & 0.9945 & 12.67 \\
\hline 13 & 38 & 12.74 & 0.9891 & 0.9821 & 0.9560 & 0.9945 & 12.67 \\
\hline 14 & 38 & 12.74 & 0.9891 & 0.9821 & 0.9560 & 0.9945 & 12.67 \\
\hline 15 & 38 & 12.74 & 0.9891 & 0.9821 & 0.9560 & 0.9945 & 12.67 \\
\hline 16 & 38 & 12.74 & 0.9891 & 0.9821 & 0.9560 & 0.9945 & 12.67 \\
\hline 17 & 38 & 12.74 & 0.9891 & 0.9821 & 0.9560 & 0.9945 & 12.67 \\
\hline 18 & 38 & 12.74 & 0.9891 & 0.9821 & 0.9560 & 0.9945 & 12.67 \\
\hline 19 & 38 & 12.74 & 0.9891 & 0.9821 & 0.9560 & 0.9945 & 12.67 \\
\hline 20 & 38 & 12.74 & 0.9891 & 0.9821 & 0.9560 & 0.9945 & 12.67 \\
\hline 21 & 38 & 12.74 & 0.9891 & 0.9821 & 0.9560 & 0.9945 & 12.67 \\
\hline 22 & 38 & 12.74 & 0.9891 & 0.9821 & 0.9560 & 0.9945 & 12.67 \\
\hline 23 & 38 & 12.74 & 0.9891 & 0.9821 & 0.9560 & 0.9945 & 12.67 \\
\hline 24 & 38 & 12.74 & 0.9891 & 0.9821 & 0.9560 & 0.9945 & 12.67 \\
\hline 25 & 38 & 12.74 & 0.9891 & 0.9821 & 0.9560 & 0.9945 & 12.67 \\
\hline
\end{tabular}




\section{CALCULATED VARIABLES-THEORETICAL}

\begin{tabular}{|c|c|c|c|c|c|c|c|}
\hline CASE \# & $\begin{array}{c}\text { CHOKING FLOW RATE (PUNWANI) } \\
F_{\mathrm{ch}}(\mathrm{SCFH})\end{array}$ & $\begin{array}{l}\text { INTERSTITIAL VEL } \\
\mathrm{V}_{\mathrm{g}}(\mathrm{FT} / \mathrm{S})\end{array}$ & $\begin{array}{l}\text { GUESSED } \\
\text { VOIDAGE }\end{array}$ & $\begin{array}{c}\text { CHOKING VOIDAGE } \\
E_{\mathrm{ch}}(\%)\end{array}$ & $\begin{array}{l}\text { GUESSED } \\
\text { VOIDAGE }\end{array}$ & $\begin{array}{c}\text { GAS VOIDAGE } \\
E(\%)\end{array}$ & $\begin{array}{l}\text { SUP GAS VEL } \\
\text { U (FT/S) }\end{array}$ \\
\hline 1 & 38 & 1.27 & 0.9969 & 0.9955 & 0.9997 & 0.9942 & 1.27 \\
\hline 2 & 38 & 12.68 & 0.9891 & 0.9933 & 0.9560 & 0.9989 & 12.67 \\
\hline 3 & 38 & 12.69 & 0.9891 & 0.9914 & 0.9560 & 0.9983 & 12.67 \\
\hline 4 & 38 & 12.70 & 0.9891 & 0.9898 & 0.9560 & 0.9978 & 12.67 \\
\hline 5 & 38 & 12.70 & 0.9891 & 0.9883 & 0.9560 & 0.9972 & 12.67 \\
\hline 6 & 38 & 12.71 & 0.9891 & 0.9869 & 0.9560 & 0.9967 & 12.67 \\
\hline 7 & 38 & 12.72 & 0.9891 & 0.9857 & 0.9560 & 0.9961 & 12.67 \\
\hline 8 & 38 & 12.72 & 0.9891 & 0.9844 & 0.9560 & 0.9956 & 12.67 \\
\hline 9 & 38 & 12.73 & 0.9891 & 0.9832 & 0.9560 & 0.9950 & 12.67 \\
\hline 10 & 38 & 12.74 & 0.9891 & 0.9821 & 0.9560 & 0.9945 & 12.67 \\
\hline 11 & 38 & 12.74 & 0.9891 & 0.9821 & 0.9560 & 0.9945 & 12.67 \\
\hline 12 & 38 & 12.74 & 0.9891 & 0.9821 & 0.9560 & 0.9945 & 12.67 \\
\hline 13 & 38 & 12.74 & 0.9891 & 0.9821 & 0.9560 & 0.9945 & 12.67 \\
\hline 14 & 38 & 12.74 & 0.9891 & 0.9821 & 0.9560 & 0.9945 & 12.67 \\
\hline 15 & 38 & 12.74 & 0.9891 & 0.9821 & 0.9560 & 0.9945 & 12.67 \\
\hline 16 & 38 & 12.74 & 0.9891 & 0.9821 & 0.9560 & 0.9945 & 12.67 \\
\hline 17 & 38 & 12.74 & 0.9891 & 0.9821 & 0.9560 & 0.9945 & 12.67 \\
\hline 18 & 38 & 12.74 & 0.9891 & 0.9821 & 0.9560 & 0.9945 & 12.67 \\
\hline 19 & 38 & 12.74 & 0.9891 & 0.9821 & 0.9560 & 0.9945 & 12.67 \\
\hline 20 & 38 & 12.74 & 0.9891 & 0.9821 & 0.9560 & 0.9945 & 12.67 \\
\hline 21 & 38 & 12.74 & 0.9891 & 0.9821 & 0.9560 & 0.9945 & 12.67 \\
\hline 22 & 38 & 12.74 & 0.9891 & 0.9821 & 0.9560 & 0.9945 & 12.67 \\
\hline 23 & 38 & 12.74 & 0.9891 & 0.9821 & 0.9560 & 0.9945 & 12.67 \\
\hline 24 & 38 & 12.74 & 0.9891 & 0.9821 & 0.9560 & 0.9945 & 12.67 \\
\hline 25 & 38 & 12.74 & 0.9891 & 0.9821 & 0.9560 & 0.9945 & 12.67 \\
\hline
\end{tabular}




\section{OPERATING VARIABLES-ACTUAL}

\begin{tabular}{|c|c|c|c|c|c|c|c|c|}
\hline CASE \# & $\begin{array}{c}\text { FLOWRATE-STD } \\
\text { F }_{\mathrm{g}}(\mathrm{SCFH})\end{array}$ & $\begin{array}{c}\text { FLOWRATE-ACT } \\
F_{\mathrm{a}} \text { (CFM) }\end{array}$ & $\begin{array}{l}\text { MASS GAS } \\
M_{g}\left(\text { LB }_{m} / \mathrm{HR}\right)\end{array}$ & $\begin{array}{c}\text { GAS/SOLIDS } \\
M_{g} / M_{s}\end{array}$ & $\begin{array}{l}\text { SLIP VEL } \\
\mathrm{V}_{\text {slip }}(\mathrm{FT} / \mathrm{S})\end{array}$ & $\begin{array}{c}\text { SOLIDS VEL } \\
V_{s}(F T / S)\end{array}$ & $\begin{array}{c}\text { GAS RES TIME } \\
\text { G }_{R T}(\mathrm{~S})\end{array}$ & $\begin{array}{c}\text { SOLIDS RES TIME } \\
S_{\mathrm{RT}_{\mathrm{T}}(\mathrm{S})}\end{array}$ \\
\hline 1 & 20 & 0.05 & 1.36 & 1.36 & 0.34 & 0.92 & 21.98 & 30.36 \\
\hline 2 & 200 & 0.46 & 13.55 & 6.78 & 0.34 & 12.32 & 2.21 & 2.27 \\
\hline 3 & 200 & 0.46 & 13.55 & 4.52 & 0.34 & 12.32 & 2.21 & 2.27 \\
\hline 4 & 200 & 0.46 & 13.55 & 3.39 & 0.34 & 12.32 & 2.21 & 2.27 \\
\hline 5 & 200 & 0.46 & 13.55 & 2.71 & 0.34 & 12.32 & 2.20 & 2.27 \\
\hline 6 & 200 & 0.46 & 13.55 & 2.26 & 0.34 & 12.32 & 2.20 & 2.27 \\
\hline 7 & 200 & 0.46 & 13.55 & 1.94 & 0.34 & 12.32 & 2.20 & 2.27 \\
\hline 8 & 200 & 0.46 & 13.55 & 1.69 & 0.34 & 12.32 & 2.20 & 2.27 \\
\hline 9 & 200 & 0.46 & 13.55 & 1.51 & 0.34 & 12.32 & 2.20 & 2.27 \\
\hline 10 & 200 & 0.46 & 13.55 & 1.36 & 0.34 & 12.32 & 2.20 & 2.27 \\
\hline 11 & 200 & 0.46 & 13.55 & 1.36 & 0.34 & 12.32 & 2.20 & 2.27 \\
\hline 12 & 200 & 0.46 & 13.55 & 1.36 & 0.34 & 12.32 & 2.20 & 2.27 \\
\hline 13 & 200 & 0.46 & 13.55 & 1.36 & 0.34 & 12.32 & 2.20 & 2.27 \\
\hline 14 & 200 & 0.46 & 13.55 & 1.36 & 0.34 & 12.32 & 2.20 & 2.27 \\
\hline 15 & 200 & 0.46 & 13.55 & 1.36 & 0.34 & 12.32 & 2.20 & 2.27 \\
\hline 16 & 200 & 0.46 & 13.55 & 1.36 & 0.34 & 12.32 & 2.20 & 2.27 \\
\hline 17 & 200 & 0.46 & 13.55 & 1.36 & 0.34 & 12.32 & 2.20 & 2.27 \\
\hline 18 & 200 & 0.46 & 13.55 & 1.36 & 0.34 & 12.32 & 2.20 & 2.27 \\
\hline 19 & 200 & 0.46 & 13.55 & 1.36 & 0.34 & 12.32 & 2.20 & 2.27 \\
\hline 20 & 200 & 0.46 & 13.55 & 1.36 & 0.34 & 12.32 & 2.20 & 2.27 \\
\hline 21 & 200 & 0.46 & 13.55 & 1.36 & 0.34 & 12.32 & 2.20 & 2.27 \\
\hline 22 & 200 & 0.46 & 13.55 & 1.36 & 0.34 & 12.32 & 2.20 & 2.27 \\
\hline 23 & 200 & 0.46 & 13.55 & 1.36 & 0.34 & 12.32 & 2.20 & 2.27 \\
\hline 24 & 200 & 0.46 & 13.55 & 1.36 & 0.34 & 12.32 & 2.20 & 2.27 \\
\hline 25 & 200 & 0.46 & 13.55 & 1.36 & 0.34 & 12.32 & 2.20 & 2.27 \\
\hline
\end{tabular}




\section{CALCULATED VARIABLES}

\begin{tabular}{|c|c|c|c|c|c|}
\hline CASE \# & $\begin{array}{c}\text { MIN FLUIDIZATION VEL } \\
U_{\mathrm{mf}}(\mathrm{FT} / \mathrm{S})\end{array}$ & $\begin{array}{l}\text { REYNOLDS \# } \\
\operatorname{RE}_{\mathrm{t}}\end{array}$ & $\begin{array}{c}\text { GAS-WALL FRICTION } \\
\text { F }_{\mathrm{g}}\end{array}$ & $\begin{array}{l}\text { PRESS. DROP } \\
\text { (PSID) }\end{array}$ & $\begin{array}{l}\text { UNIT LENGTH dP } \\
\text { (PSID / L) }\end{array}$ \\
\hline 1 & 0.0039004 & 808.08 & 0.016073 & 0.2023 & 0.0072 \\
\hline 2 & 0.0039004 & 8080.79 & 0.008423 & 0.4179 & 0.0149 \\
\hline 3 & 0.0039004 & 8080.79 & 0.008423 & 0.4316 & 0.0154 \\
\hline 4 & 0.0039004 & 8080.79 & 0.008423 & 0.4454 & 0.0159 \\
\hline 5 & 0.0039004 & 8080.79 & 0.008423 & 0.4592 & 0.0164 \\
\hline 6 & 0.0039004 & 8080.79 & 0.008423 & 0.4730 & 0.0169 \\
\hline 7 & 0.0039004 & 8080.79 & 0.008423 & 0.4867 & 0.0174 \\
\hline 8 & 0.0039004 & 8080.79 & 0.008423 & 0.5005 & 0.0179 \\
\hline 9 & 0.0039004 & 8080.79 & 0.008423 & 0.5143 & 0.0184 \\
\hline 10 & 0.0039004 & 8080.79 & 0.008423 & 0.5280 & 0.0189 \\
\hline 11 & 0.0039004 & 8080.79 & 0.008423 & 0.5280 & 0.0189 \\
\hline 12 & 0.0039004 & 8080.79 & 0.008423 & 0.5280 & 0.0189 \\
\hline 13 & 0.0039004 & 8080.79 & 0.008423 & 0.5280 & 0.0189 \\
\hline 14 & 0.0039004 & 8080.79 & 0.008423 & 0.5280 & 0.0189 \\
\hline 15 & 0.0039004 & 8080.79 & 0.008423 & 0.5280 & 0.0189 \\
\hline 16 & 0.0039004 & 8080.79 & 0.008423 & 0.5280 & 0.0189 \\
\hline 17 & 0.0039004 & 8080.79 & 0.008423 & 0.5280 & 0.0189 \\
\hline 18 & 0.0039004 & 8080.79 & 0.008423 & 0.5280 & 0.0189 \\
\hline 19 & 0.0039004 & 8080.79 & 0.008423 & 0.5280 & 0.0189 \\
\hline 20 & 0.0039004 & 8080.79 & 0.008423 & 0.5280 & 0.0189 \\
\hline 21 & 0.0039004 & 8080.79 & 0.008423 & 0.5280 & 0.0189 \\
\hline 22 & 0.0039004 & 8080.79 & 0.008423 & 0.5280 & 0.0189 \\
\hline 23 & 0.0039004 & 8080.79 & 0.008423 & 0.5280 & 0.0189 \\
\hline 24 & 0.0039004 & 8080.79 & 0.008423 & 0.5280 & 0.0189 \\
\hline 25 & 0.0039004 & 8080.79 & 0.008423 & 0.5280 & 0.0189 \\
\hline
\end{tabular}


APPENDIX 10.2

Computer Programs for Thermodynamic Calculations 


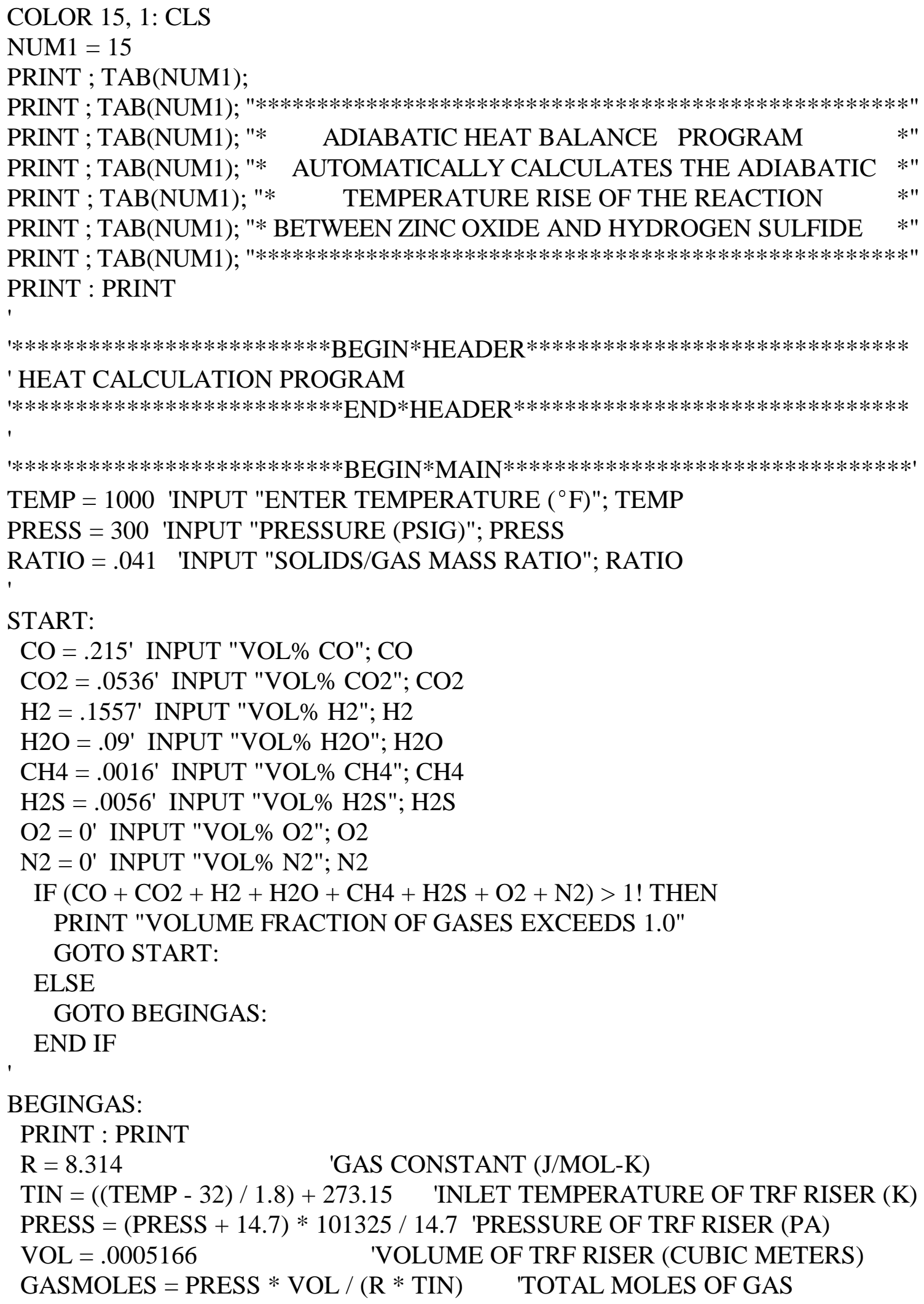




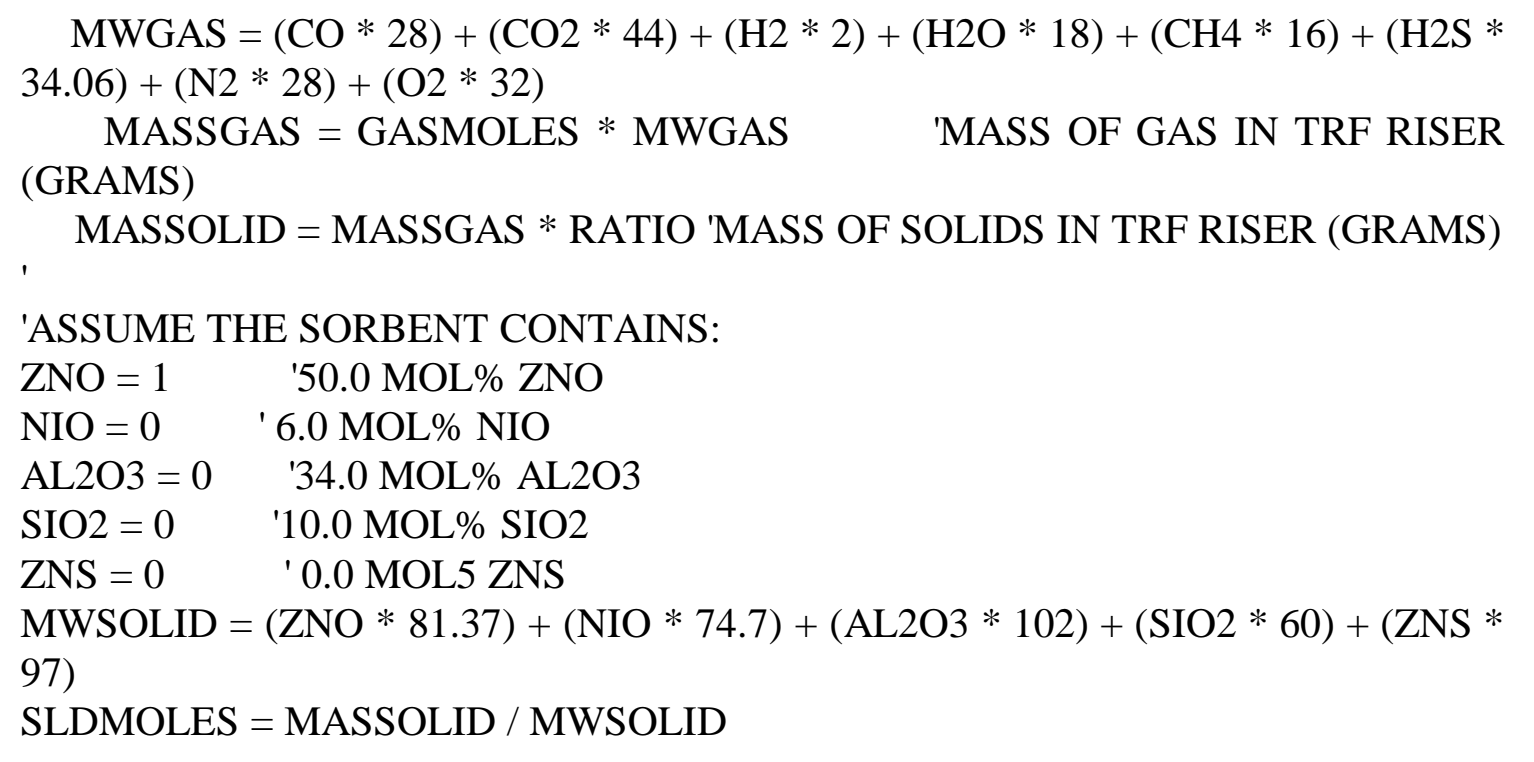


'PRINT "AL2O3"; AL2O3MOLES

'PRINT "SIO2"; SIO2MOLES

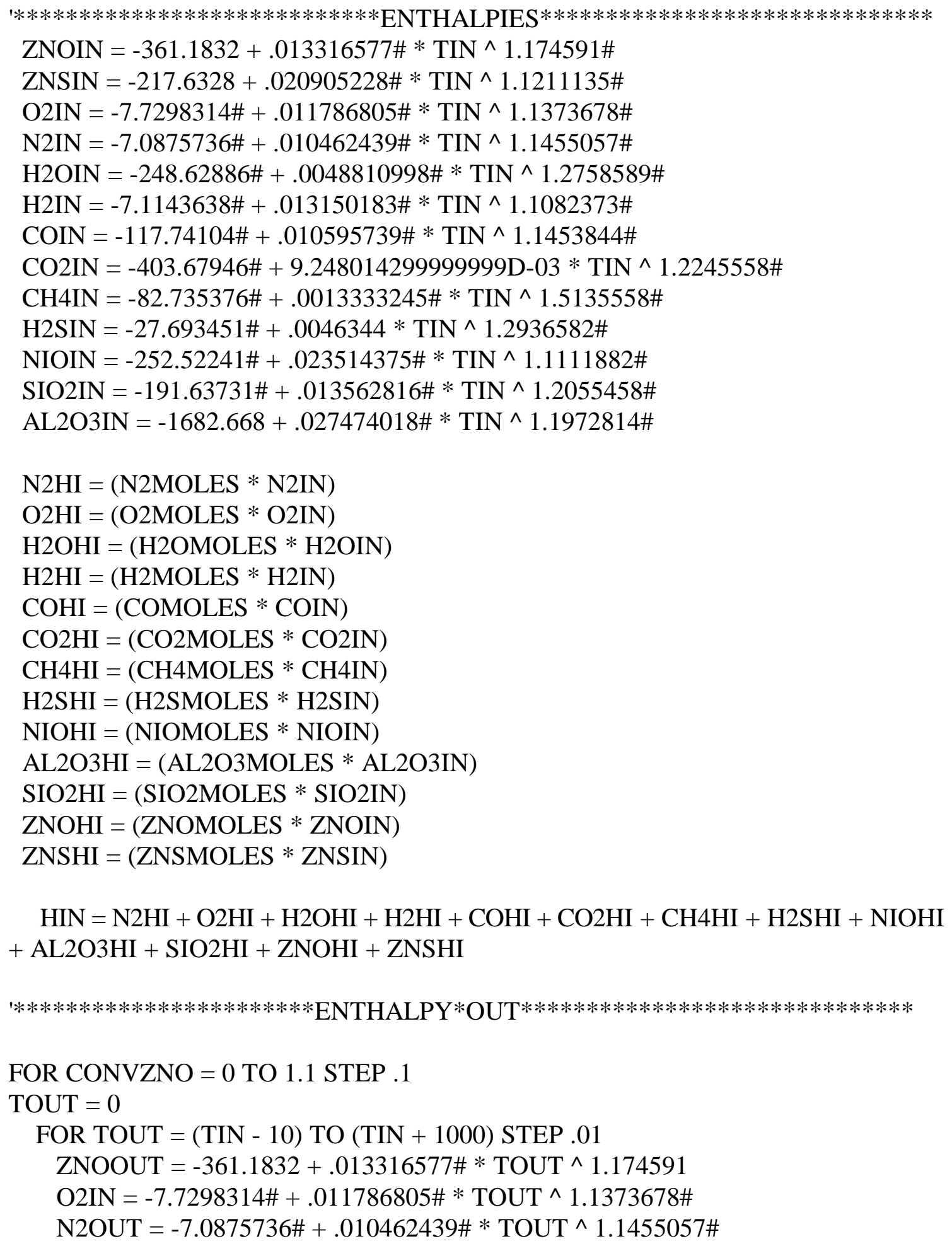




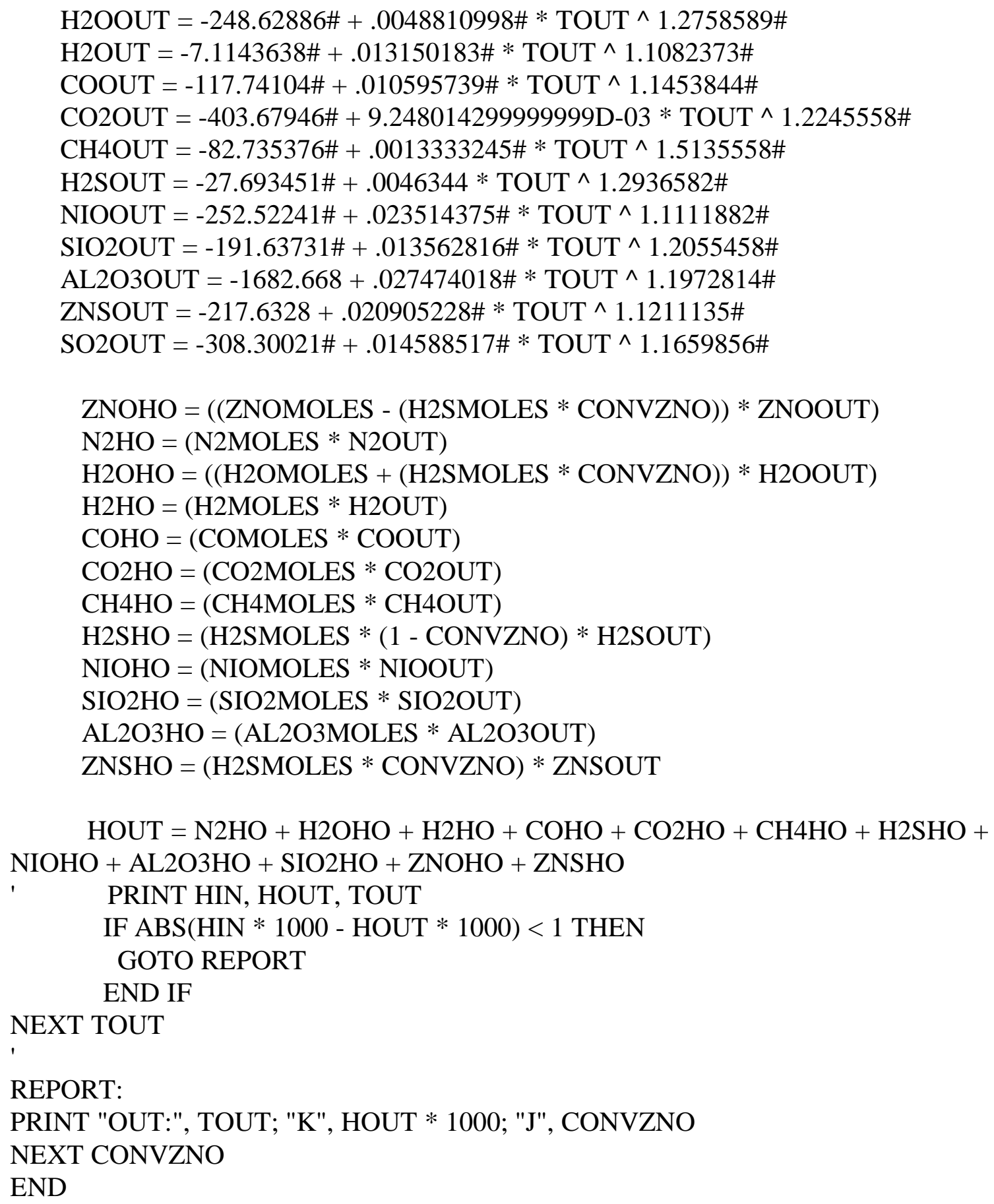




\begin{abstract}
RINT ; TAB(NUM1); "********************************************************" PRINT ; TAB(NUM1); "* ADIABATIC HEAT BALANCE PROGRAM * * PRINT ; TAB(NUM1); "* PRINT ; TAB(NUM1); "* PRINT ; TAB(NUM1); "* AUTOMATICALLY CALCULATES THE ADIABATIC *" TEMPERATURE RISE OF THE REACTION * * BETWEEN ZINC SULFIDE AND AIR * * PRINT ; TAB(NUM1); "* COLLINS FERRY ROAD, MORGANTOWN, WV $26505 *$ " PRINT ; TAB(NUM1); "******************************************************" PRINT : PRINT
\end{abstract}

,

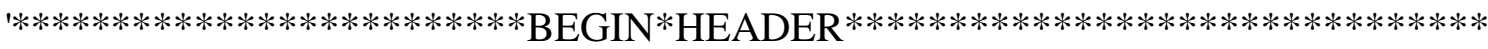
' PROGRAM HEAT CALCULATES

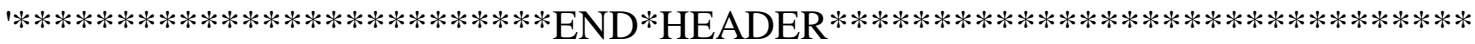

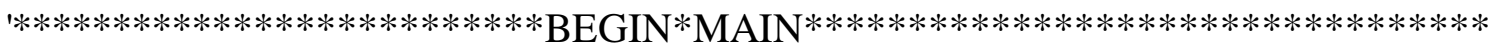
TEMP $=1000$ 'INPUT "ENTER TEMPERATURE $\left({ }^{\circ} \mathrm{F}\right) "$; TEMP

PRESS = 300 'INPUT "PRESSURE (PSIG)"; PRESS

RATIO $=.47$ 'INPUT "SOLIDS/GAS MASS RATIO"; RATIO ,

START:

$\mathrm{H} 2 \mathrm{O}=0$ ' INPUT "VOL\% H2O"; H2O

$\mathrm{O} 2=.21$ ' INPUT "VOL\% O2"; O2

$\mathrm{N} 2=.79^{\prime}$ INPUT "VOL\% N2"; N2

$\mathrm{IF}(\mathrm{H} 2 \mathrm{O}+\mathrm{O} 2+\mathrm{N} 2)>1.1 \mathrm{THEN}$

PRINT "VOLUME FRACTION OF GASES EXCEEDS 1.0"

GOTO START:

ELSE

GOTO BEGINGAS:

END IF

BEGINGAS:

PRINT : PRINT

$\mathrm{R}=8.314 \quad$ 'GAS CONSTANT (J/MOL-K)

TIN $=(($ TEMP -32$) / 1.8)+273.15$ 'INLET TEMPERATURE OF TRF RISER $(\mathrm{K})$ PRESS $=($ PRESS + 14.7) $* 101325 / 14.7$ 'PRESSURE OF TRF RISER $($ PA) VOL $=.0005166 \quad$ 'VOLUME OF TRF RISER (CUBIC METERS)

GASMOLES $=$ PRESS $*$ VOL $/(\mathrm{R} *$ TIN) TOTAL MOLES OF GAS MWGAS $=(\mathrm{H} 2 \mathrm{O} * 18)+(\mathrm{N} 2 * 28)+(\mathrm{O} 2 * 32)$

MASSGAS $=$ GASMOLES $*$ MWGAS (GRAMS)

MASSOLID $=$ MASSGAS $*$ RATIO

'MASS OF GAS IN TRF RISER (GRAMS)

'ASSUME THE SORBENT CONTAINS:

'MASS OF SOLIDS IN TRF RISER 


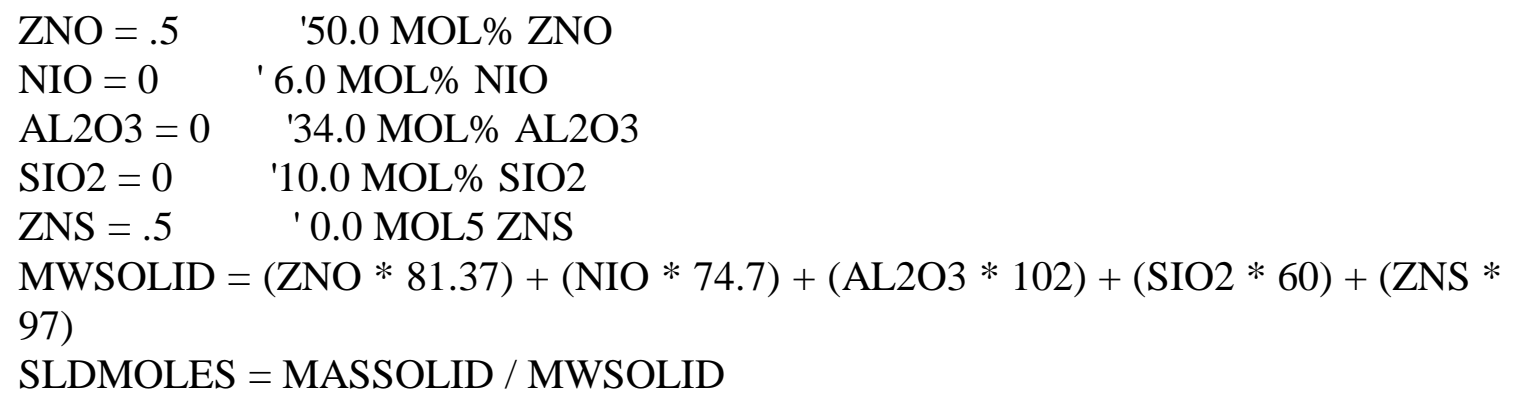




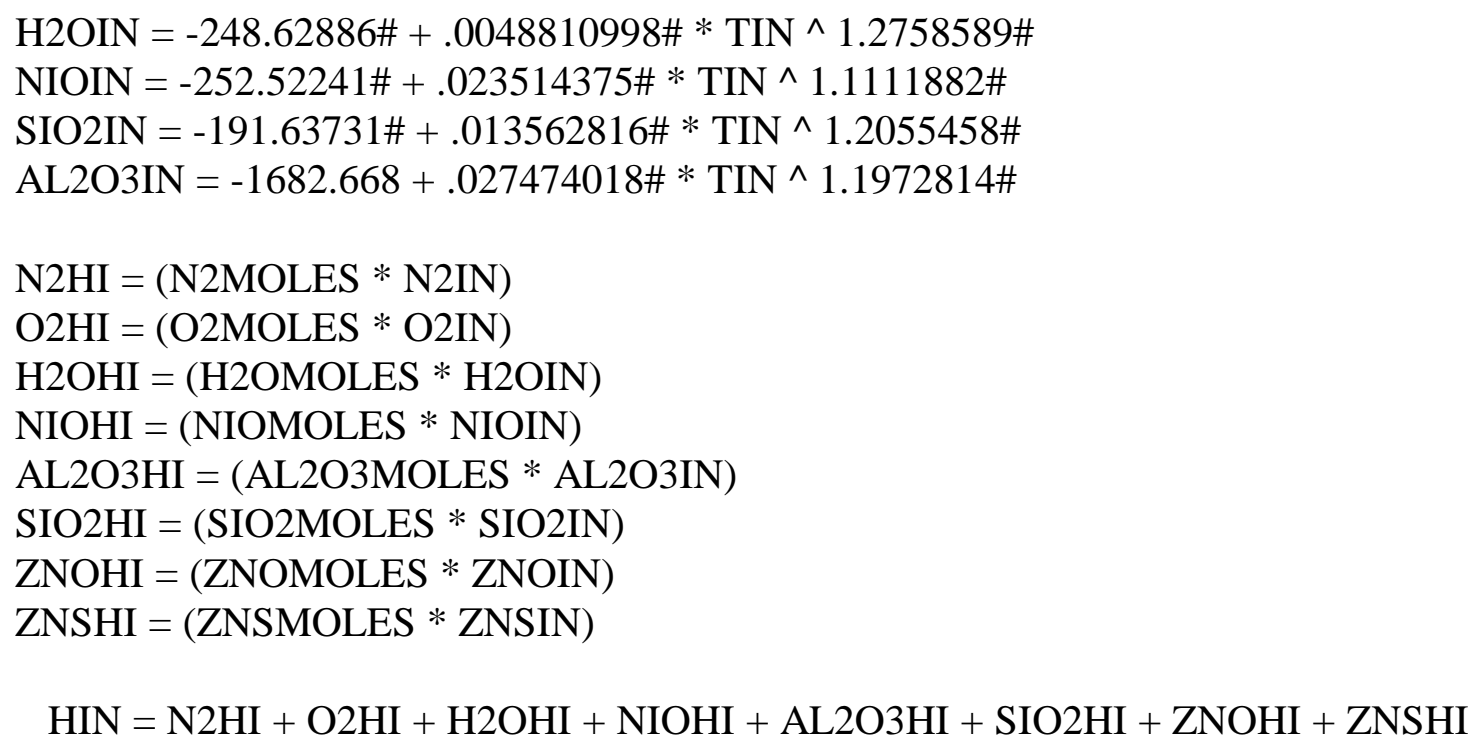

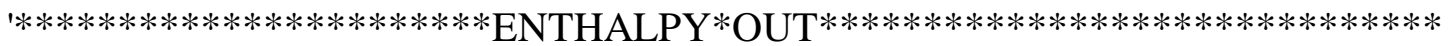

FOR CONVZNS $=0$ TO 1.1 STEP .1

TOUT $=0$

FOR TOUT $=($ TIN -10$)$ TO $($ TIN +1000$)$ STEP .01

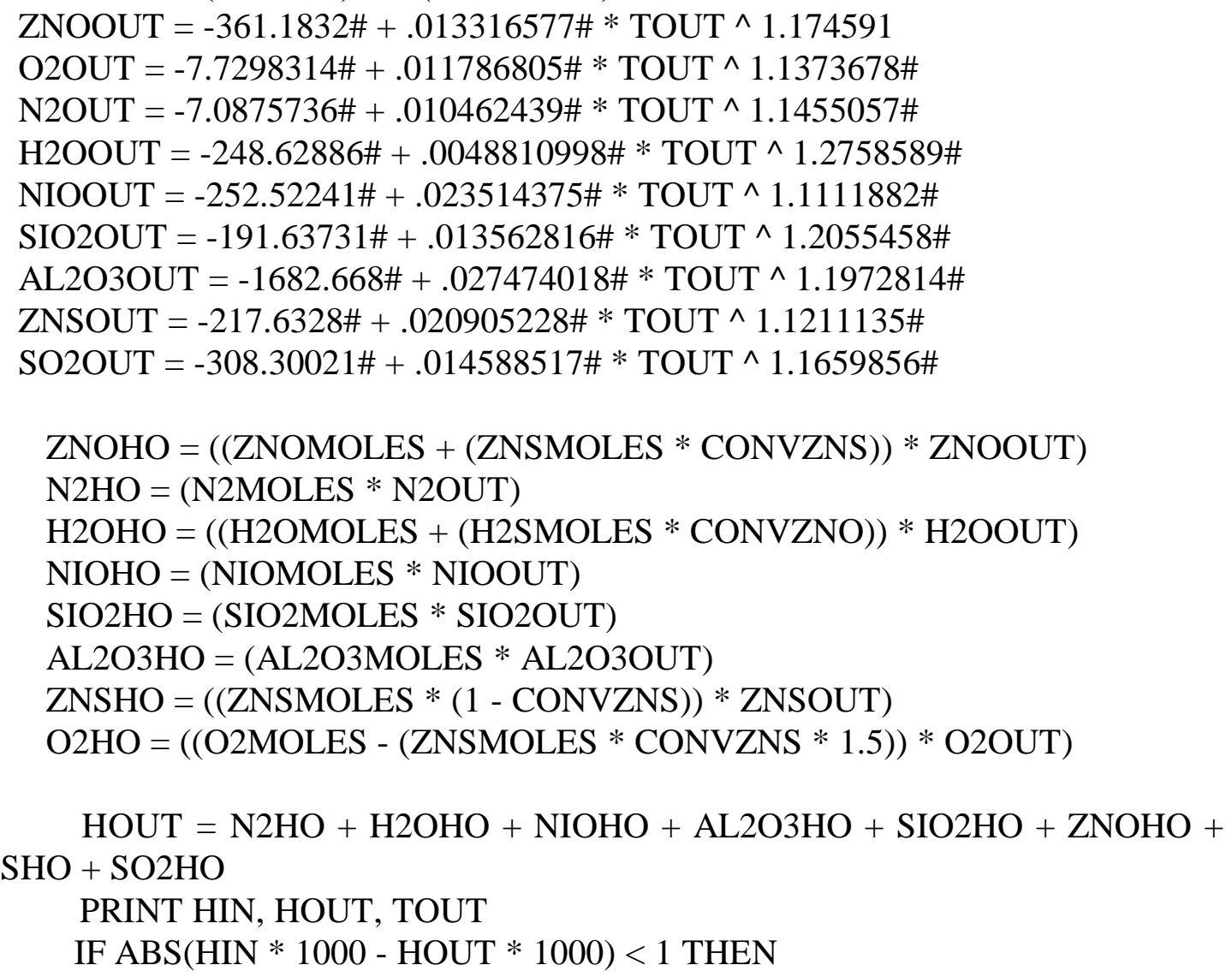




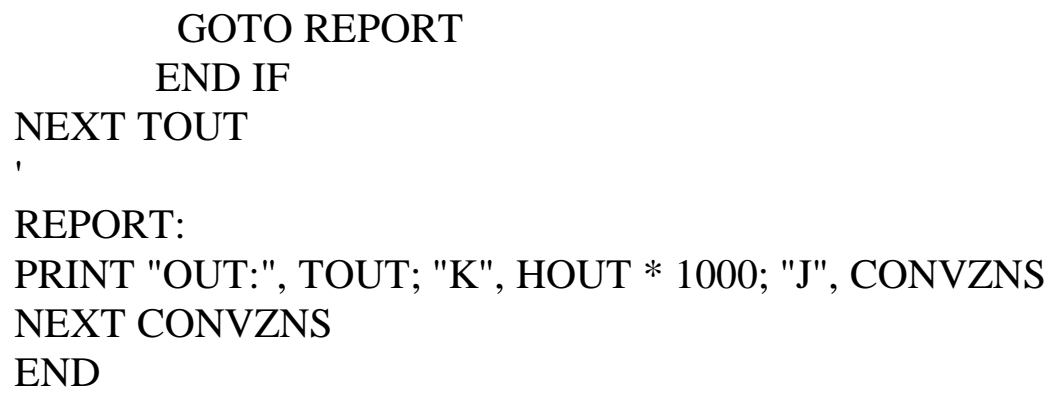

END 